\title{
Perspectivas de movilidad y preferencias por la redistribución en América Latina
}

\author{
Evelin Lasarga ${ }^{1}$ \\ Director: Martín Leites, Co-director: Leonardo Gasparini \\ Tesis Maestría en Economía - Universidad Nacional de la Plata
}

\begin{abstract}
Resumen
El presente trabajo tiene como objetivo aportar evidencia acerca de la hipótesis POUM (prospects of upward mobility) en América Latina. La misma postula que las preferencias por la redistribución disminuyen con las perspectivas de movilidad ascendente de los individuos, dado que ante una posible mejora económica serían perjudicados por la redistribución. Se analiza el caso de Latinoamérica para el período 2009-2018, que ha registrado cambios en la desigualdad y la movilidad intrageneracional en parte, debido a un despliegue de políticas redistributivas en la década pasada. Para ello se utilizan datos de Latinobarómetro y la metodología Probit-Adapted OLS. Los resultados obtenidos muestran el cumplimiento de la hipótesis POUM, a diferencia de lo que obtienen los estudios realizados para períodos anteriores, en otro contexto de desigualdad y movilidad en Latinoamérica. Además, se obtienen resultados sugerentes acerca de la influencia de la movilidad intergeneracional, la religiosidad, la ideología y la calidad insitucional sobre las preferencias por la redistribución. Cabe destacar que estos resultados varían según el país de que se trate.

Palabras clave: preferencias, redistribución, perspectivas, movilidad
\end{abstract}

Agradecimientos: A mi director, Phd. Martın Leites y co-director Phd. Leonardo Gasparini por sus invaluables aportes. Al profesor PhD. Guillermo Cruces por su ayuda en la eleccion de la tem atica a estudiar.

\footnotetext{
1evelasarga@gmail.com
} 


\section{Índice}

1. Introducción $\quad 3$

2. Marco Teórico $\quad 6$

$\begin{array}{ll}\text { 3. Literatura empírica } & 10\end{array}$

4. Hipótesis $\quad 12$

5. Estrategia empírica $\quad 13$

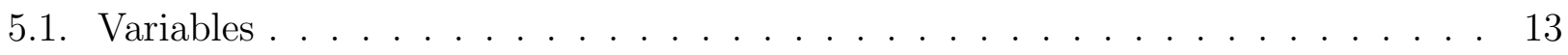

5.2. Metodología . . . . . . . . . . . . . . . . . 15

5.3. Fuente de Datos . . . . . . . . . . . . . . . . . . . . . . 18

$\begin{array}{lr}\text { 6. Resultados } & \mathbf{2 0}\end{array}$

6.1. Estadísticas descriptivas . . . . . . . . . . . . . . . 20

6.2. Estimaciones econométricas . . . . . . . . . . . . . . . . . 32

6.3. Robustez . . . . . . . . . . . . . . . . . . . . . 38

$\begin{array}{ll}\text { 7. Conclusiones } & 40\end{array}$

8. Referencias $\quad 42$

9. Anexo 45 


\section{Introducción}

América Latina es una de las regiones más desiguales del mundo, por lo que el estudio de los factores determinantes de la distribución de recursos resulta de gran relevancia. Si bien desde los años 2000 se ha dado una importante caída de la desigualdad en promedio en América Latina, luego del 2010 se observa un enlentecimiento de dicha tendencia (Cruces et al, 2016). La caída de la desigualdad lograda en los distintos países de América Latina en el período mencionado, fue acompañada por un crecimiento económico sostenido y por políticas públicas orientadas a la redistribución del ingreso tanto por diseños impositivos progresivos como transferencias, lo que en un contexto de alta desigualdad como el de Latinoamérica fue determinante. Sin embargo, luego de estos procesos tuvo lugar un viraje político de los gobiernos en sentido contrario con respecto a la redistribución. Por otro lado, la movilidad social intergeneracional está creciendo en promedio en Latinoamérica, lo cual parece impulsado por una movilidad ascendente de los niños de familias de bajo nivel educativo, al tiempo que hay una fuerte inmovilidad en la cola alta de la distribución, si bien hay diferencias significativas entre países (Gasparini et al, 2018). De todas formas, los niveles de movilidad intergeneracional continúan siendo bajos para los estándares internacionales (Daude y Robano, 2015) y la mejora de la desigualdad puede relativizarse por resultados que muestran que la proporción de ingresos de los percentiles más altos se ha mantenido estable (Solimano, 2016, Burdín et al, 2019). De esta forma, América Latina se destaca en un mundo de desigualdad de ingresos en aumento y movilidad social decreciente o estancada. Todo esto tiene repercusiones en múltiples dimensiones, en particular, en las que se centra el presente trabajo: las perspectivas de movilidad y en las preferencias por la redistribución.

Distintos estudios hacen referencia a que la movilidad social intrageneracional ha aumentado en América Latina entre los años noventa y el presente, donde aquellos países que presentaron mayores caídas de la desigualdad, son aquellos que experimentaron mayores aumentos en la movilidad social intrageneracional, en concordancia con la literatura teórica (Ferreira et al, 2013). Un factor de relevancia para ello fueron las reformas impositivas y los programas de transferencias orientados a la reducción de la pobreza.

La posibilidad de implementar políticas públicas redistributivas por parte de los gobiernos depende en gran parte del apoyo de la población. De esta forma, es fundamental el estudio de los factores que inciden en la demanda de redistribución del ingreso, y así, en la eficiencia en la asignación de recursos. Es esperable que los cambios ya mencionados en las últimas décadas en América Latina, hayan tenido un impacto negativo en las preferencias por la redistribución, dado que una gran cantidad de personas mejoró su situación económica y ya no demanda redistribución. Si consideramos que el apoyo a las políticas redistributivas fomenta la ejecución de políticas públicas que permitan mejorar la movilidad social y el bienestar de toda 
la sociedad, es pertinente estudiar cómo se determinan las preferencias por la redistribución. Así, la hipótesis POUM -por las siglas en inglés de prospects of upward mobility- postula que ante altas perspectivas de movilidad, individuos no demasiado aversos al riesgo disminuirán sus preferencias por la redistribución, ya que esperan estar mejor posicionados en el futuro y no desean ser perjudicados por los impuestos. Esto podría provocar una trampa de movilidad en la que las políticas redistributivas, al generar mayor movilidad, ocasionen una pérdida de apoyo a dichas políticas y así, que estas no continúen y se desencadene una reducción de la movilidad. Este proceso podría explicar en parte la coyuntura de la desigualdad en América Latina, con el mencionado enlentecimiento de la caída en la misma.

La hipótesis POUM, representa uno de los argumentos acerca de porqué en democracias donde una mayoría relativamente pobre tiene el poder político, no se producen expropiaciones y redistribución a gran escala como suba de impuestos o de transferencias. Incluso las personas con ingresos menores al promedio no apoyarían ese tipo de políticas por las perspectivas de movilidad ascendente, dado que ellos o sus descendientes pueden moverse en forma ascendente en la distribución del ingreso y por tanto ser dañados por esas políticas (Benabou y Ok, 2001).

La literatura previa sugiere que es difícil probar empíricamente dicha hipótesis ya que las preferencias dependen de muchos otros factores tales como la aversión al riesgo, que afecta las preferencias en el sentido de que independientemente de la movilidad experimentada, la aversión al riesgo aumenta las preferencias por la redistribución ya que la misma aseguraría cierto nivel de ingreso en coyunturas adversas. Por su parte, el altruismo también actúa en favor de la redistribución ya que los individuos altruistas anteponen el bienestar social a su interés personal. Además, algunos individuos pueden presentar aversión a la desigualdad, debido a que consideran que la desigualdad es indeseable por sus efectos negativos en la sociedad como la delicuencia, la fragmentación social, etc. Otro factor de personalidad que incide en las preferencias es el grado de optimismo o pesimismo del individuo, ya que un individuo con mayor optimismo respecto a su situación económica, tendrá más confianza en el futuro y menores preferencias por la redistribución que uno pesimista. Además de los factores de personalidad, hay factores institucionales que afectan las preferencias por la redistribución. Por ejemplo, el nivel de corrupción y la calidad de la democracia del país de que se trate, ya que individuos que en condiciones normales tendrían mayor preferencia por la redistribución, la disminuyen por desconfianza en cómo se realizará esa redistribución por parte del estado (Hauk et al, 2017). Por último, ciclos económicos, aspectos culturales del país, tradición familiar, e historial individual de movilidad, también tienen su incidencia sobre las preferencias por la redistribución.

Además, en las sociedades en las que se considera que el desempeño económico de los individuos depende del esfuerzo y el mérito personal, existe una menor demanda de redistribución 
del ingreso, en tanto que en las que consideran que el ingreso y la riqueza de los individuos depende de la suerte y factores arbitrarios como la herencia, hay mayor demanda por redistribución (Alesina y Angeletos, 2005). Desde las distintas nociones de justicia que enmarca el enfoque de la igualdad de oportunidades parece ser aceptado que en una sociedad justa debe ser posible la movilidad intergeneracional de ingresos, es decir que un individuo debe ser capaz de moverse dentro de las distintas clases sociales independientemente de donde parta. La misma es moralmente deseable dado que mayores niveles de movilidad en el sentido de menor dependencia entre orígenes y destinos se asocia con mayor igualdad de oportunidades y retribución al esfuerzo, que es un principio ampliamente aceptado a diferencia de la igualdad de resultados (Jäntti y Jenkins, 2015). De todas formas, cabe mencionar que el enfoque de la igualdad de oportunidades, donde el resultado económico debe ser consecuencia del esfuerzo y no de las circunstancias (Roemer y Trannoy, 2016) no considera factores tales como la influencia de los grupos de referencia, la transmisión de habilidades productivas que son más o menos valoradas en el mercado, contactos, etc. que influyen en la movilidad y en la justicia de los resultados. En cuanto a la movilidad intrageneracional, además de las razones morales es deseable por razones instrumentales, ya que permite la reducción de la desigualdad en el largo plazo, pero dado que la variable de interés, sea el ingreso, la riqueza, el consumo, etc. se mide en un punto del tiempo parece reflejar diferencias en las habilidades y esfuerzos, las cuales son consideradas justas salvo para autores como Roemer (2004) que consideran que los talentos innatos son genéticamente heredados y por lo tanto, arbitrarios. Asimismo, no es necesariamente deseable si la movilidad representa shocks transitorios, ya que es sinónimo de inestabilidad e inseguridad económica sobre todo para individuos aversos al riesgo.

Debido a la importancia de las modificaciones ya mencionadas en la movilidad y la desigualdad en la región, el presente trabajo se propone como objetivo principal estudiar la hipótesis POUM para el caso de América Latina con la encuesta Latinobarómetro, en el período 2009-2018 (última encuesta disponible). Si bien no se presenta evidencia causal, se utiliza la metodología Probit-adapted OLS (POLS) de manera de aproximarse a los determinantes de las preferencias por la redistribución mediante correlaciones cross-country. Para la mayoría de los países bajo estudio no se han hecho investigaciones acerca de la hipótesis POUM para la década actual, por lo que es esperable obtener cambios tanto en las preferencias por la redistribución como en las perspectivas de movilidad con respecto a trabajos anteriores. Más allá de esto, se pretende analizar el cumplimiento de la relación planteada en la hipótesis entre esas variables. Además, se presentan estimaciones comparables para 18 países de la región, lo cual permite análisis comparativos. Otra contribución de este trabajo consiste además en explorar la influencia de variables no incluidas en los modelos analizados en estudios anteriores tales como la religiosidad, la percepción de la corrupción o el funcionamiento de la democracia en el país considerado. Estas dimensiones resultan de gran relevancia en América Latina ya que 
el continente se ha caracterizado por niveles importantes de religiosidad y de corrupción. De acuerdo con la literatura empírica, el compromiso religioso tiene un efecto sustitución en las preferencias por la redistribución, de manera que a mayor compromiso menores preferencias por la redistribución. Por su parte, la corrupción tiene un efecto ambiguo: por un lado, deteriora la confianza en el gobierno disminuyendo la demanda de redistribución y por otro, la redistribución actúa como compensación por la pérdida relativa generada por la corrupción.

El presente documento se estructura de la siguiente manera: la segunda sección presenta el marco teórico, en la tercera sección se presentan los antecedentes en la temática, luego la hipótesis principal y las secundarias. En el quinto apartado se expone la estrategia empírica, con subsecciones para la discusión acerca de las variables, la metodología y la fuente de datos. En el siguiente apartado se presentan los resultados descriptivos y econométricos y por último las conclusiones finales.

\section{Marco Teórico}

Las políticas redistributivas y su demanda han sido ampliamente discutidas en la literatura económica. Si bien el presente trabajo se centra en la hipótesis POUM, no fue sino hasta el trabajo de Benabou y Ok (2001) que se formalizó dicha idea, luego de múltiples desarrollos teóricos sobre el tema. Uno de los primeros trabajos en que se relacionó el comportamiento redistributivo de los agentes con la percepción de movilidad corresponde a Hirschman y Rothschild (1973), quienes postulan que los individuos con altos ingresos, que esperan quedar en desventaja debido a la movilidad social, serán favorables a la redistribución, destacando la importancia de la movilidad percibida. Así, presentan el llamado efecto túnel, que implica que una persona puede sentir una satisfacción por el enriquecimiento de otra cuando en un contexto de incertidumbre, la observación de la situación de otro individuo consta de un contenido informativo tan importante que domina la comparación y envidia, llevando a cierta tolerancia a la desigualdad, ya que el enriquecimiento de otros puede ser indicador del futuro enriquecimiento propio. A nivel teórico, un primer avance fue realizado por Meltzer y Richard (1981), quienes elaboran un modelo de equilibrio general estático donde se supone un gobierno que solo recauda impuestos y los redistribuye e información completa para los votantes, y concluyen que el votante de ingresos medios, es el decisivo en la determinación de la participación en los impuestos.

Benabou y Ok (2001) formalizan teóricamente estas ideas en la hipótesis de las perspectivas de movilidad ascendente, en inglés prospects of upward mobility (POUM). Esta hipótesis indica que los individuos que proyectan una posición social futura mejor que la actual y por tanto creen que la redistribución no será conveniente y disminuirá su apoyo a las mismas. Esta hipótesis se basa en los supuestos de que las perspectivas y las políticas redistributivas presentes 
se mantendrán en el futuro, que el ingreso futuro es función cóncava del ingreso presente y que los individuos no son del todo aversos al riesgo.

El modelo presentado por estos autores adopta un esquema redistributivo estándar basado en una imposición proporcional con transferencias de suma fija, sin pérdidas de bienestar a raíz de la redistribución (también extienden el análisis a los casos de imposición regresiva y progresiva y los resultados se mantienen). De esta forma, los individuos deben elegir una tasa impositiva $\tau_{t}$ que maximice el ingreso futuro esperado, donde el ingreso acumulado en cada período t está dado por la siguiente ecuación:

$\left.\hat{y}_{t}=y_{t}+\tau_{t}\left(\bar{y}_{t}-y_{t}\right) t\right)$

donde $\hat{y}_{t}$ representa el ingreso neto de impuestos y $\bar{y}_{t}$ el ingreso promedio de la población. Si se asume que el ingreso no crece en el tiempo y que no hay aversión a la desigualdad, el óptimo para los que tienen ingresos mayores al promedio es la redistribución nula $\tau_{t}=0$ y para los que tienen ingresos menores al promedio es la redistribución total $\tau_{t}=100$. Si se asume que el ingreso es estocástico, de deben tener en cuenta otros elementos tales como el horizonte temporal, el grado de aversión al riesgo y la distribución del ingreso futura. Si se asumen individuos neutrales al riesgo y funciones de transición deterministas, Benabou y Ok (2001) llegan a los siguientes resultados:

1) mientras más cóncava sea la función de transición, menor será la proporción de la población con ingresos actuales menores al promedio que apoye la redistribución.

2) mientras mayor sea el período de validez de la tasa impositiva elegida, menor será la proporción de la población con ingresos actuales menores al promedio que apoye la redistribución.

En base al modelo de Benabou y Ok (2001), Alesina y Angeletos (2005) proponen un modelo simplificado de dos períodos, sistema impositivo no lineal donde los individuos son o pagadores de impuestos o beneficiarios dependiendo de un umbral de ingresos determinado, donde las expectativas de ingreso futuro son una función creciente del ingreso actual, los individuos tienen cierta aversión al riesgo, y la estructura impositiva no se ajusta permanentemente sino que depende del ciclo electoral, una vez votada no puede ser ajustada permanentemente. Así, individuos racionales intentarán maximizar el ingreso neto intertemporal, que depende, por un lado, del ingreso antes de impuestos $\left.\left(y_{g}^{i 1}\right)\right)$ así como también de un descuento por pago de impuestos $\left(\Psi^{i 1}\right)$ o un beneficio $\left(v^{i 1}\right)$ en el primer período y por otro lado, de las expectativas de ingreso antes de impuestos futuro $\left(E\left(y_{g}^{i 2}\right)\right)$, y de las expectativas de descuento por pago de impuestos futuro $\left(E\left(\Psi^{i 2}\right)\right.$ o de las expectativas de beneficio $\left(E\left(v^{i 2}\right)\right)$ en el segundo período. 
El individuo optará por cierto sistema de impuestos y beneficios redistributivo si espera obtener mayor utilidad de este sistema en ambos períodos. Dado que el futuro genera incertidumbre, los individuos minimizan la probabilidad de ser pagadores de impuestos. Operando, los autores llegan a la siguiente ecuación:

$p^{i}<\left[\Psi^{i 1}-v^{i 1}+E\left(\Psi^{i 2}\right)\right] /\left[E\left(v^{i 2}\right)+E\left(\Psi^{i 2}\right]\right.$

de donde se obtiene que los individuos se oponen a la redistribución si actualmente son pobres y esperan un aumento suficiente en el ingreso. Tomando en cuenta ambos períodos serán perdedores netos del sistema redistributivo.

Por su parte, Piketty (1995) explica el apoyo a la redistribución vinculándolo con la movilidad social intergeneracional y las creencias del individuo acerca de la importancia de la suerte y el esfuerzo sobre el ingreso de una persona. Este modelo concluye que las creencias sobre las políticas redistributivas no son arbitrarias, ya que los agentes están expuestos a diferente información. En contraste con la hipótesis POUM, donde las expectativas sobre el futuro son el factor de más relevancia para explicar las preferencias de los individuos, Piketty (1995) toma la idea del efecto túnel de Hirschman y Rothschild (1973) y formula un modelo de aprendizaje racional. Este modelo muestra que las distintas preferencias por la redistribución dependen de diferencias en las experiencias pasadas, donde los individuos que han experimentado movilidad ascendente creen que el esfuerzo personal es recompensado y demandan menos redistribución. Este modelo justifica la inclusión de la movilidad intergeneracional en el presente análisis.

Corneo y Gruner (2002) postulan la existencia de tres efectos en cuanto al apoyo a las políticas de redistribución, por un lado el efecto homo economicus, donde para apoyar determinada política esta debe maximizar el ingreso personal, por otro lado el efecto public values donde se prefiere la política que más beneficie a la sociedad en su conjunto y por último el efecto social rivalry donde las preferencias dependen de intereses personales en relación a la posición relativa del individuo en la sociedad.

Por último, cabe destacar el trabajo de Benabou y Tirole (2006), quienes elaboran un modelo en el que las creencias optimistas acerca del hecho de que todos obtienen su justo premio por su esfuerzo tienen un valor funcional, ya que ayudan al individuo a motivarse a si mismo hacia el esfuerzo, la inversión en educación, la perseverancia ante la adversidad, entre otras. Este valor funcional, sin embargo, depende de los incentivos que ofrecen las instituciones que los individuos enfrentan, es mayor en las sociedades con baja redistribución que en aquellas en las que los impuestos marginales son altos y el sistema de seguridad es generoso. Dado que los logros políticos dependen de las creencias de los individuos, se pueden encontrar dos tipos 
de resultados. Por un lado, el equilibrio "Americano", que se caracteriza por una dominancia de la creencia en un mundo justo (y resistencia a la evidencia en sentido contrario), baja redistribución, alto nivel de esfuerzo y estigma social a la pobreza. Por otro lado, el equilibrio "Europeo", caracterizado por un pesimismo realista de las mayorías, un estado de bienestar más extenso, menor esfuerzo y mayor justificación de la pobreza en la suerte y las circunstancias.

La literatura ha explorado otros canales que explican las preferencias por la redistribución. Uno de ellos responde a la existencia de percepciones sesgadas e información limitada. Las preferencias por la redistribucion dependen del acceso a la información y la habilidad para procesarla. Sin embargo, la información suele ser limitada y la inferencia errónea de dicha información a toda la población puede resultar en percepciones sesgadas. La información sobre la distribución del ingreso puede ser costosa de adquirir o las ventajas de adquirirla no ser evidentes, al tiempo que los individuos pueden fallar en considerar toda la información disponible o usarla de forma incorrecta (Simon, 1972) a través de estrategias heurísticas erróneas estudiadas por la economía comportamental y cognitiva (Kahneman et al., 1982). Otro de los canales presentes en la literatura acerca de los determinantes de las preferencias por la redistribución tiene relación con las percepciones acerca de la calidad institucional, particularmente de la corrupción. La misma puede distorsionar la demanda y la oferta de redistribución a través de varios mecanismos: por un lado, prácticas de compra de votos y baja confianza en el gobierno, y por otro, presiones de grupos de interés (Goda y Sanchez, 2018). Alternativamente, otros autores plantean que gobiernos de gran tamaño aumentan las posibilidades de corrupción, y a su vez la corrupción aumenta la demanda de redistribución para corregir la desigualdad e injusticia generadas por la corrupción (Alesina y Angeletos, 2005). Además, la cultura y la estructura de la familia también influyen en las preferencias por la redistribución (Alesina y Giuliano, 2018). En particular, la religiosidad de una sociedad puede jugar un rol importante en la formación de las preferencias. Dada la evidencia para algunas democracias industriales avanzadas, es sabido que las medidas de religiosidad son mejores predictores de las preferencias por la redistribución que el ingreso o proxies de clase (Dalton, 2006). Tal es el caso planteado por Scheve y Stasavage (2006) que argumentan que la religión y la redistribución son mecanismos sustitutos que aseguran a los individuos contra los eventos adversos de la vida. Como resultado, los individuos más religiosos preferirán menor redistribución que los no religiosos. Por otra parte, puede ocurrir que los individuos religiosos prefieran gobiernos pequeños con poca capacidad redistributiva ya que ven al gobierno como una amenaza y una competencia en la educación y las actividades de caridad (Lee and Roemer, 2005). El primero de estos tres canales mencionados no será abordado en el presente análisis ya que no se cuenta con datos para ello, pero si lo serán los dos restantes como variables de control. 


\section{Literatura empírica}

La hipótesis POUM ha sido ampliamente estudiada, contando con más trabajos realizados para países de Europa o Norteamérica que para América Latina. Esto se debe en parte a la disponibilidad de datos, ya que las fuentes de datos para los países latinoamericanos son escasas y la mayoría de los trabajos, al igual que el presente, utilizan datos de Latinobarómetro. Como se muestra a continuación, la hipótesis POUM encuentra mayor respaldo en los países no latinoamericanos, lo cual puede deberse a múltiples factores.

Comenzando con algunos antecedentes para el caso de los países no Latinoamericanos, Ravallion and Lokshin (2000) obtienen para el caso de Rusia que la demanda de redistribución disminuye no solo con el status socio-económico presente, sino también con las expectativas de futuras mejoras en el bienestar. Por su parte, Alesina y La Ferrara (2002) han estudiado los determinantes de las preferencias por redistribución condicionadas a las perspectivas de movilidad del ingreso. Obtienen que las minorías, las mujeres y los jóvenes apoyan la redistribución, así como también hay un efecto positivo de las variables proxies para aversión al riesgo y el altruismo. A su vez obtienen un impacto negativo en la demanda de redistribución del ingreso presente y de las perspectivas de movilidad ascendente, tanto con medidas subjetivas como objetivas. Otro antecedente de investigación corresponde a Checchi Filippin (2004), donde se realiza un estudio experimental en el que se controla mediante el diseño experimental y la información recabada por elementos de difícil medición como la aversión al riesgo y a la desigualdad, obteniendo que se cumple la hipótesis bajo distintas especificaciones del modelo e incluso controlando por efectos fijos individuales.

Más recientemente, Rainer y Siedler (2007) analizan las preferencias por redistribución en relación a las perspectivas ocupacionales, donde las perspectivas de movilidad ocupacional ascendente disminuyen la demanda por redistribución, en tanto que una movilidad ocupacional descendente la aumentan. Otro antecedente corresponde a Alesina y Giuliano (2009) en el que analizan los determinantes de las preferencias por la redistribución, y encuentran que los mismos son las características personales como edad, género, clase social, pero también por historia personal, cultura, experiencias históricas, religión, ideología política, volatilidad macroeconómica y percepciones de justicia. Pfarr (2012) a través de un experimento de elección discreta para Alemania, obtiene como resultado una fuerte preferencia por la redistribución que excede al efecto del ingreso presente. Se contradice la hipótesis POUM, siendo este resultado más acorde al modelo de aprendizaje de Piketty (1995), por lo que los factores económicos solo explican parte de las preferencias de los individuos, concluyendo que la economía del comportamiento puede explicar este resultado.

Otro trabajo corresponde a Engelhardt y Wagener (2014) realizado para varios países de la 
OCDE entre los años 1987 y 2009, en el que hallan que la hipótesis POUM se cumple para medidas subjetivas pero no para medidas objetivas, lo que tiene grandes implicancias en las políticas públicas. Cojocaru (2014) investiga empíricamente esta hipótesis para un gran número de países mediante la Life in Transition Survey, que aporta datos de calidad sobre las expectativas de movilidad futura y el grado de aversión al riesgo de los respondentes. Según este trabajo, la hipótesis se constata para los casos de baja aversión al riesgo en países miembros de la Unión Europea, pero no para el resto de los países. Por su parte, Lee (2016) realiza un estudio para Corea del Sur en base a encuestas sociales donde encuentra como resultado que los individuos con perspectivas de ingresos pesimistas y una percepción negativa de la igualdad de oportunidades, demandan mayor redistribución en tanto que factores como el ingreso corriente y la ideología política no tienen efecto para Corea del Sur. Finalmente, Alesina et al (2018) investigan a través de encuestas para Estados Unidos y varios países europeos y datos experimentales, como las creencias acerca de la movilidad intergeneracional afectan las preferencias por la redistribución. El tratamiento consiste en mostrar información pesimista sobre la movilidad y se observa que aumenta el apoyo a la redistribución, aunque con una fuerte polarización política.

En cuanto a los antecedentes para el caso de América Latina se destaca el trabajo de Gaviria (2007). Sus principales hallazgos, utilizando datos de Latinobarómetro para los años 1996, 2000 y 2001, muestran que en América Latina hay fuertes preferencias por la redistribución en el período considerado, si bien varía entre clases sociales, siendo las diferencias entre ricos y pobres mayores que en otras regiones del mundo. Aquellos individuos con visiones pesimistas sobre la justicia social y la igualdad de oportunidades tienden a apoyar la redistribución y estar en desacuerdo con la economía de mercado y las privatizaciones.

Otro antecedente a destacar es el trabajo de Daude y Melguizo (2010) que a través de datos de Latinobarómetro de 2007 y 2008, no obtienen evidencia que respalde la hipótesis POUM. Además, el trabajo de Silva y Figueiredo (2013) utilizando la misma base de datos para el año 2007, rechazan la hipótesis POUM para la región latinoamericana, en tanto que destacan la importancia de la movilidad pasada, el interés personal y las percepciones de justicia e igualdad de oportunidades.

Por último, para el caso de Bolivia, Ecuador y Venezuela, Melo et al (2016) se basan en datos de la encuesta Latinobarómetro para 2013 y obtienen como resultado que la percepción de movilidad ascendente afecta negativamente el apoyo a políticas redistributivas.

En cuanto a los antecedentes acerca de la calidad de las instituciones, un trabajo a destacar corresponde a Hauk et al (2017) quienes estudian la relación entre las creencias de las personas 
acerca de la calidad de las instituciones, medidas a través de las percepciones de corrupción, y las preferencias por la redistribución en América Latina. El análisis se basa en un modelo teórico que introduce impuestos en el modelo de equilibrio general de corrupción no colusiva de Foellmi y Oechslin's (2007). En este modelo, las percepciones de corrupción influencian a las preferencias por la redistribución a través de dos canales. Por un lado, debilita la confianza en el gobierno, lo que reduce el apoyo a la redistribución, y por otro, a mayor corrupción disminuye la riqueza personal relativa a la riqueza promedio de los individuos con riqueza por debajo del promedio, llevando a una mayor demanda de redistribución. Así, el efecto de las percepciones de corrupción sobre la redistribución depende de qué efecto sea el dominante. Estos autores obtienen como resultado que la percepción de corrupción en el sector público en América Latina incrementa el apoyo a la redistribución.

\section{Hipótesis}

El presente trabajo busca probar empíricamente la hipótesis POUM, que postula que las preferencias por la redistribución decrecen cuando mayores son las expectativas de movilidad ascendente de los individuos. Se analiza el caso de Latinoamérica para el período 2009-2018 con datos de Latinobarómetro. De acuerdo con los antecedentes presentados y con los datos recientes sobre movilidad y preferencias, cabe esperar que las perspectivas de movilidad ascendente tengan una incidencia positiva en las preferencias por redistribución.

Para responder a esta pregunta, se incluyen controles en el modelo a desarrollar que implican además el planteamiento de algunas hipótesis secundarias:

- En línea con el modelo de Piketty (1995), los individuos que experimentaron movilidad intergeneracional ascendente (descendente), tienen menor (mayor) preferencia por la redistribución, ya que la experiencia pasada influye en las expectativas futuras.

- Los individuos cuyas percepciones acerca de la calidad de las instituciones son bajas (altas), tienen menor (mayor) preferencia por la redistribución, ya que no confían en el estado como redistribuidor de los recursos.

- Los individuos con ideología auto-reportada orientada hacia la izquierda, tienen mayor preferencia por la redistribución, en tanto aquellos con ideología orientada hacia la derecha tienen menor preferencia por la redistribución, ya que estos teóricamente no están a favor de la intervención del estado en la economía. 
- Los individuos con mayor religiosidad, tienen menores preferencias por la redistribución, ya que consideran que el estado como asegurador ante eventos desfavorables actúa como sustituto de la religión.

\section{Estrategia empírica}

\subsection{Variables}

La variable de interés para las hipótesis a estudiar es la demanda de redistribución, pero para el período considerado no se cuenta con una variable que permita medir directamente la misma. Alesina y Giuliano (2009) y Gaviria (2007) utilizan como proxy la respuesta a la pregunta sobre si el gobierno debería intervenir más en educación, salud o pensiones, pero esa pregunta no está incluida en la encuesta para el período considerado en el presente trabajo. Gaviria (2007) también utiliza el posicionamiento político como variable dependiente, de manera que para quienes se declaran de izquierda se presume que apoyan la redistribución y quienes se declaran de derecha no la apoyan. Sin embargo, el autor analiza la respuesta a otras preguntas tales como el papel de la economía de mercado, el papel de la empresa privada, el efecto de la inversión, el papel de la libre competencia y el rol del estado, sin encontrar correspondencia entre estas respuestas y el posicionamiento político, por lo que no se recomienda su utilización como proxy de la demanda de redistribución. Dicha variable funcionaría como proxy en el caso de que la definición ideológica de un individuo dependiera únicamente de premisas político económicas y del conocimiento de las mismas, y no de la simpatía o antipatía por los referentes de los partidos, de la influencia de los medios de comunicación u otros factores, por tanto no es utilizada como variable dependiente en el presente trabajo

Así, en base a la cobertura geográfica y la calidad de la variable, y teniendo en cuenta la literatura internacional, en el presente trabajo se utiliza la siguiente pregunta como aproximación a la preferencia por la redistribución: Grado de acuerdo con que la economía de mercado es el único sistema con el que el país puede llegar a ser desarrollado. Las categorías de respuesta incluyen: Muy de acuerdo, De acuerdo, En desacuerdo y Muy en desacuerdo.

Esta variable presenta los problemas usuales de las variables subjetivas tales como la dificultad para hacer comparaciones interpersonales dado que no hay una escala natural para medirla y la posible discrepancia entre lo que el encuestado piensa realmente y lo que declara pensar. Por otro lado, la pregunta deja abierta la posibilidad de que por ejemplo personas que contestan que no apoyan la economía de mercado, en realidad no estén a favor de la redistribución sino que reclamen la presencia del estado en seguridad y defensa nacional o de que consideren 
otros actores redistributivos diferentes al estado, como la iglesia u ONGs a través de la caridad. Además se consideran problemas de endogeneidad que serán retomados más adelante.

Alternativamente, se plantea como ejercicio de robustez un modelo cuya variable dependiente sea la percepción de justicia en la distribución del ingreso del país correspondiente. La misma consiste en una variable categórica que incluye las opciones: Muy injusta, Injusta, Justa y Muy justa. Cabe destacar las limitaciones que conlleva esta variable y que explican la decisión metodológica de no utilizarla en el modelo principal, ya que además de las limitaciones mencionadas para la variable de economía de mercado, se suma tal como argumentan Silva y Figueiredo (2013), el hecho de que es posible percibir injusticia y no demandar redistribución. Tal es el caso de individuos con aversión a un potencial aumento de los impuestos o de individuos que consideran a la desigualdad como una característica inherente a la sociedad humana y que no debe ser modificada.

Para probar la hipótesis POUM, la variable de interés del modelo refiere a la percepción de movilidad. La encuesta cuenta con una pregunta acerca de percepción subjetiva de la situación económica personal futura (doce meses después), cuyas opciones de respuesta son Igual, Mucho peor, Un poco peor, Mucho mejor y Un poco mejor. Esta variable es similar a las utilizadas en los antecedentes presentados.

Las restantes variables explicativas del modelo corresponden a variables sociodemográficas que sirven de control tales como sexo, edad, ideología política, movilidad pasada, estado civil, religiosidad, nivel educativo, ingreso subjetivo ${ }^{2}$, satisfacción con la democracia y percepción de corrupción. De acuerdo con la literatura empírica y teórica revisada, es esperable que las mujeres tengan una mayor demanda por redistribución, que los más jovenes demanden más redistribución, que aquellos con ideología de izquierda demanden más redistribución y que quienes experimentaron movilidad ascendente demanden menos redistribución. Otras variables de control corresponden ciclo económico (logaritmo del PBI per cápita del año y el país) y desigualdad (índice de Gini del año y el país correspondiente) de manera de analizar la influencia del clima económico en las preferencias por la redistribución mediante variables objetivas. Por último, se incluyen efectos fijos por año y país para eliminar sesgos correspondientes a diferencias culturales, eventos transitorios, etc.

Una limitación empírica que presenta la base de datos, corresponde a la ausencia de una variable de ingreso, que permita controlar las preferencias por la redistribución según el nivel de ingreso. Esta variable resulta de gran importancia ya que las preferencias por la redistribu-

\footnotetext{
${ }^{2}$ No se cuenta con información sobre el ingreso, que es de suma relevancia en la determinación de las preferencias por la redistribución ya que depende del mismo el ser beneficiado o perjudicado por la redistribución. Más adelante se explica el tratamiento empírico de este problema.
} 
ción dependen en gran parte del nivel de ingreso, dado que quienes tienen ingresos altos se ven perjudicados por la redistribución y quienes tienen ingresos bajos beneficiados. Por lo tanto, se incluyen en el modelo como variables explicativas el ingreso subjetivo, que sí se encuentra presente en la base, además del nivel educativo del respondente que tiene correlación con el ingreso.

Por último, se presentan modelos que incluyen variables de percepción de la calidad de las instituciones (percepciones de corrupción y satisfacción con la democracia). Así, se constituye un pool de años y países, y en el Anexo se presentan las estimaciones para cada país por separado.

\subsection{Metodología}

La variable de interés para el análisis son las preferencias por la redistribución. Se trata de una variable latente, es decir que no puede observarse directamente en la población. Al ser no observable, la verdadera valoración de las preferencias por la redistribución será aproximada por otra, sí observable que corresponde a la valoración de la economía de mercado y va en aumento en función de la demanda de redistribución que tiene cada individuo. La pregunta acerca de si la economía de mercado es el único sistema con que el país puede llegar al desarrollo puede tomar las siguientes respuestas:

$1=$ Muy de acuerdo

$2=$ De acuerdo

$3=$ En desacuerdo

$4=$ Muy en desacuerdo

Así, la variable considerada toma cuatro valores (Muy de acuerdo, De acuerdo, En desacuerdo, Muy en desacuerdo), con lo que implícitamente se asume que los individuos cuyas preferencias por la redistribución se encuentran por debajo de determinado umbral $\mu_{1}$ contestarán que están muy de acuerdo, aquellos cuyas preferencias estén entre ese valor y un valor $\mu_{2}$ mayor al mismo reportarán que están de acuerdo, aquellos entre $\mu_{2}$ y un $\mu_{3}$ aún mayor declararán que están en desacuerdo y finalmente aquellos con preferencias por encima de $\mu_{3}$ declararán estar muy en desacuerdo ${ }^{3}$. De esta forma, se plantea el siguiente modelo:

$$
Y_{i}^{*}=Z+\epsilon_{i}
$$

donde $Y_{i}^{*}$ son las preferencias por la redistribución, Z es un vector de variables independientes

\footnotetext{
${ }^{3}$ La variable dependiente alternativa, de percepción de justicia en la distribución del ingreso, toma los valores: $1=$ Muy justa, $2=$ Justa, $3=$ Injusta, $4=$ Muy injusta.
} 
y $\epsilon_{i}$ es el término de error. Como $Y_{i}^{*}$ es una variable latente, no observable será aproximada por la variable observable ya mencionada mediante el siguiente modelo:

$$
Y_{i}=\beta_{i} \operatorname{persp}_{i}+\beta_{i} \text { mov }_{i}+\beta_{i} X_{i}+\beta_{i} \text { vpais }_{i}+\alpha_{i}+\epsilon_{i}
$$

donde $Y_{i}$ aproxima las preferencias por la redistribución, siendo la variable categórica de apoyo a la economía de mercado, donde se asume que para aquellos encuestados que consideran a la economía de mercado como el mejor sistema para el desarrollo del país, no demandan redistribución, y aquellos que están en desacuerdo con la economía de mercado, tienen mayores preferencias por la redistribución. Los distintos $\beta_{i}$ corresponden a los coeficientes de la regresión para cada variable independiente, $\operatorname{per} p_{i}$ corresponde a la principal variable de interés, es decir, las perspectivas de movilidad, mov $i$ representa el principal control, es decir la movilidad intergeneracional educativa experimentada por el individuo, $\mathrm{X}$ es la matriz de variables de control (edad, sexo, etc.) antes mencionada, vpais $_{i}$ corresponde a variables macroeconómicas de PBI e Índice de Gini del país del encuestado, $\alpha_{i}$ representa los efectos fijos por año y país y $\epsilon_{i}$ es el término de error.

Las distintas alternativas de variables dependientes consideradas tienen distribuciones discretas por lo que las estimaciones por Mínimos Cuadrados Ordinarios (MCO) serían sesgadas. Por lo tanto, se parte de un modelo probit ordenado que toma en cuenta la ordinalidad de la variable dependiente. Cabe destacar que el efecto fijo por país es común a todos los hogares del país y representa diferencias sistemáticas entre los países no controladas que pueden afectar las preferencias.

De acuerdo con Van Praag y Ferrer-i-Carbonell (2008), se observa que aún en un modelo probit ordenado hay cierta cardinalización de la variable de interés. En ese sentido, proponen un modelo Probit adaptado a Mínimos Cuadrados Ordinarios (POLS), método basado en una transformación de los datos que permite tomar a las variables de elección discreta como continuas. La desventaja es que impone algún grado de cardinalidad en las respuestas lo cual es controvertido pues supone que las preferencias son comparables numéricamente. La principal ventaja de la estimación POLS es que permite la aplicación de métodos más complejos, y que los coeficientes estimados representan los efectos marginales de las variables independientes. Los resultados obtenidos en Van Praag and Ferrer-iCarbonell (2008) sugieren que los resultados de las estimaciones por POLS y por probit ordenado son casi las mismas de acuerdo a un factor de multiplicación. Los resultados obtenidos para una estimación POLS son consistentes con los que se obtienen con un Probit Ordenado.

Las estimaciones POLS intentan evitar los problemas de la asunción de cardinalidad, de 
manera que la transformación consiste primero, en el cálculo de las frecuencias relativas de las diferentes categorías y luego poniendo las frecuencias en una distribución normal estándar para obtener una variable dependiente con una distribución normal estándar, con escala cardinal e insesgada.

Las categorias de respuesta ordenada $\mathrm{k}=1, \ldots, \mathrm{K}$ de $y_{i t}$ se interpretan como valores continuos de la variable latente $y *_{i t}$. Sin embargo, si bien asumir cardinalidad de las respuestas ordenadas puede derivar en estimaciones sesgadas, numerosos estudios han mostrado evidencia de que el sesgo es moderado.

Por lo tanto, siguiendo a estos autores, la regresión será estimada a través del método Probit-Adapted OLS (POLS). El modelo POLS es muy similar a un Probit Ordenado, pero a diferencia de éste requiere de un supuesto adicional, que es la distribución normal del término de error. Así, se considera un modelo lineal con efectos fijos que asume cardinalidad y hace uso de toda la variación en respuestas ordenadas de los individuos, al tiempo que toma en cuenta características no aleatorias de personalidad.

Una de las principales limitaciones que presenta el modelo a estimar es la existencia de problemas de endogeneidad. Al estar evaluando las preferencias por la redistribución, variable subjetiva, ésta puede depender de distintos factores asociados al estado de ánimo del respondente (que depende de cómo se encontraba el día en que fue entrevistado), o a factores inobservables relacionados a la personalidad de la persona. Podría suceder también, que quienes hayan experimentado ciertas trayectorias en cuanto a variación en el nivel de ingresos, o hayan experimentado movilidad social, tengan determinadas preferencias. Esto indica que puede existir endogeneidad como consecuencia de la correlación entre regresores y la variable explicada. Otro factor de endogeneidad podría ser el nivel educativo, donde individuos con mayor nivel educativo incorporen más información a la hora de formar sus preferencias.

A esto se suman posibles errores de medición. Sin embargo, una ventaja de los datos utilizados responde a que la encuesta fue elaborada en el idioma nativo de los respondentes. Además, otras preguntas alternativas que podrían aproximar las preferencias, tal como el grado de acuerdo con el aumento de los impuestos, tampoco soluciona el problema, ya que el individuo puede estar en desacuerdo con cierto diseño impositivo pero aún así demandar redistribución, oferta de servicios públicos, etc.

Por otro lado, podría existir correlación entre los regresores y el término de error ante la presencia de variables relevantes omitidas, como el ingreso. Es decir, en el caso de variables relevantes omitidas, los estimadores que surgen de la regresión podrían ser sesgados e inconsis- 
tentes. Tal es el caso de la aversión al riesgo, por lo que se suponen individuos neutrales al riesgo y lo mismo ocurre con la aversión a la desigualdad. En el caso del ingreso de los individuos se intenta corregir mediante la incorporación del ingreso subjetivo como proxy.

Una herramienta útil para corregir este problema es el método de Variables Instrumentales (VI), para obtener resultados consistentes y eficientes. No es sencillo encontrar un instrumento que cumpla con los requisitos necesarios, pero se puede realizar en una futura investigación. Cabe destacar, sin embargo, que la mayor parte de los antecedentes consultados para el presente trabajo no utiliza VI en sus estimaciones.

\subsection{Fuente de Datos}

El presente trabajo utiliza datos de Latinobarómetro correspondientes al período 2009-2018. Latinobarómetro es un estudio de opinión pública que aplica anualmente alrededor de 20.000 entrevistas en 18 países de América Latina representando a más de 600 millones de habitantes. Los países considerados son Argentina, Bolivia, Brasil, Colombia, Costa Rica, Chile, República Dominicana, Ecuador, El Salvador, Guatemala, Honduras, México, Nicaragua, Panamá, Paraguay, Perú, Uruguay y Venezuela.

Se trata de muestras representativas de la población nacional de cada país, de 1.000 y 1.200 casos, con un margen de error de alrededor del $3 \%$, por país ${ }^{4}$. A continuación se presenta el número de observaciones por año y por país.

\footnotetext{
${ }^{4}$ Para mayor detalle, en latinobarometro.org se presentan las fichas técnicas de la encuesta por año y por país.
} 
Cuadro 1: Observaciones por país por año

\begin{tabular}{lllllllll}
\hline \hline País del estudio/Año & 2009 & 2010 & 2011 & 2013 & 2015 & 2016 & 2017 & 2018 \\
\hline Argentina & 1,200 & 1,200 & 1,200 & 1,200 & 1,200 & 1,200 & 1,200 & 1,200 \\
Bolivia & 1,200 & 1,200 & 1,200 & 1,200 & 1,200 & 1,200 & 1,200 & 1,200 \\
Brasil & 1,204 & 1,204 & 1,204 & 1,204 & 1,250 & 1,204 & 1,200 & 1,204 \\
Chile & 1,200 & 1,200 & 1,200 & 1,200 & 1,200 & 1,200 & 1,200 & 1,200 \\
Colombia & 1,200 & 1,200 & 1,200 & 1,200 & 1,200 & 1,200 & 1,200 & 1,200 \\
Costa Rica & 1,000 & 1,000 & 1,000 & 1,000 & 1,000 & 1,000 & 1,000 & 1,000 \\
Rep. Dominicana & 1,000 & 1,000 & 1,000 & 1,000 & 1,000 & 1,000 & 1,000 & 1,000 \\
Ecuador & 1,200 & 1,200 & 1,200 & 1,200 & 1,200 & 1,200 & 1,200 & 1,200 \\
El Salvador & 1,000 & 1,000 & 1,000 & 1,000 & 1,000 & 1,000 & 1,000 & 1,000 \\
Guatemala & 1,000 & 1,000 & 1,000 & 1,000 & 1,000 & 1,000 & 1,000 & 1,000 \\
Honduras & 1,000 & 1,000 & 1,000 & 1,000 & 1,000 & 1,000 & 1,000 & 1,000 \\
México & 1,200 & 1,200 & 1,200 & 1,200 & 1,200 & 1,200 & 1,200 & 1,200 \\
Nicaragua & 1,000 & 1,000 & 1,000 & 1,000 & 1,000 & 1,000 & 1,000 & 1,000 \\
Panamá & 1,000 & 1,000 & 1,000 & 1,000 & 1,000 & 1,000 & 1,000 & 1,000 \\
Paraguay & 1,200 & 1,200 & 1,200 & 1,200 & 1,200 & 1,200 & 1,200 & 1,200 \\
Perú & 1,200 & 1,200 & 1,200 & 1,200 & 1,200 & 1,200 & 1,200 & 1,200 \\
Uruguay & 1,200 & 1,200 & 1,200 & 1,200 & 1,200 & 1,200 & 1,200 & 1,200 \\
Venezuela & 1,200 & 1,200 & 1,200 & 1,200 & 1,200 & 1,200 & 1,200 & 1,200 \\
\hline Total & 20,204 & 20,204 & 20,204 & 20,204 & 20,250 & 20,204 & 20,200 & 20,204 \\
\hline \hline
\end{tabular}

Fuente: elaboración propia en base a Latinobarómetro.

Se encontró una proporción relevante de datos faltantes en algunas de las variables analizadas, lo que implica un tratamiento especial. Una alternativa es descartar estas observaciones y realizar el análisis para el resto de la muestra. Sin embargo, para no generar un sesgo en las estimaciones, la muestra resultante luego de eliminar estos casos debe ser una muestra aleatoria de la población original, lo cual suele denominarse "missing completely at random (MCAR)" (Cameron y Trivedi, 2005). Para analizar el cumplimiento o no de este supuesto, se comparó la media de las variable mencionadas para todas las personas encuestadas, con la media que surge de la muestra donde se quitan las observaciones sin información, y se observó que no hay cambios significativos. 


\section{Resultados}

En esta sección se presentan los resultados obtenidos. Se divide en tres sub-secciones: primero, un resumen de estadísticas descriptivas acerca de las principales variables utilizadas en el análisis y su variación por año y por país, en segundo lugar los resultados de las estimaciones econométricas y en la última sub-sección un breve análisis de robustez.

\subsection{Estadísticas descriptivas}

En primer lugar se presenta un resumen de las variables sociodemográficas.

Cuadro 2: Variables sociodemográficas y grado de acuerdo con la economía de mercado

\begin{tabular}{lllll}
\hline \hline & Muy de acuerdo & De acuerdo & En desacuerdo & Muy en desacuerdo \\
\hline Media edad & 40.3 & 40.1 & 39.0 & 39.9 \\
\hline \hline Sexo & Muy de acuerdo & De acuerdo & En desacuerdo & Muy en desacuerdo \\
\hline Mujer & 46.9 & 50.4 & 51.0 & 51.1 \\
Hombre & 53.1 & 49.6 & 49.0 & 48.9 \\
\hline \hline Nivel educativo & Muy de acuerdo & De acuerdo & En desacuerdo & Muy en desacuerdo \\
\hline Bajo & 43.3 & 44.0 & 40.7 & 43.5 \\
Medio & 36.6 & 36.9 & 36.6 & 34.0 \\
Alto & 20.2 & 19.1 & 22.7 & 22.5 \\
\hline \hline Estado civil & Muy de acuerdo & De acuerdo & En desacuerdo & Muy en desacuerdo \\
\hline Casado/Unión libre & 56.6 & 56.0 & 54.1 & 55.1 \\
Soltero/Viudo & 43.4 & 44.0 & 46.0 & 44.9 \\
\hline \hline
\end{tabular}

Fuente: elaboración propia en base a Latinobarómetro.

El siguiente cuadro muestra la evolución de las variables de interés para el análisis de la hipótesis POUM por año. En el caso del grado de acuerdo con la economía de mercado, si nos centramos en la evolución por año, la proporción de personas que están en desacuerdo con la economía de mercado ha disminuido con el paso del tiempo, y la de quienes están de acuerdo con la misma ha ido en aumento. Esto implicaría una disminución de las preferencias por la redistribución en el período considerado en América Latina, que a nivel teórico es una posible consecuencia de la reducción de la desigualdad.

En cuanto al grado de justicia en la distribución del ingreso, se observa un aumento con los años de percepción de que la distribución del ingreso es muy injusta, al tiempo que disminuye la proporción de individuos que perciben que es justa. Si se asume que ante la percepción de injusticia los individuos demandan redistribución, este resultado no es consistente con la caída de 
la desigualdad, pero como ya se ha argumentado esto no necesariamente se cumple. Además, esto puede responder a una reacción ante el reciente enlentecimiento de la caída de la desigualdad.

Por su parte, las perspectivas de movilidad muestran una evolución ambigua. Se polarizan las respuestas, ya que a lo largo del tiempo aumentan los porcentajes de quienes responden mucho peor o mucho mejor y disminuyen los casos de respuesta peor o mejor. Por último, la movilidad educativa intergeneracional se mantiene bastante estable en el tiempo, con una leve disminución de los que mantienen el nivel educativo de sus padres en favor de quienes presentan movilidad ascendente.

En síntesis, la evolución de las variables de economía de mercado y de perspectivas de movilidad parece ser consistente con la hipótesis POUM. Ser observa una tendencia creciente de las perspectivas hasta el 2015, coincidentemente con un mayor apoyo a la economía de mercado. 
Cuadro 3: Variables de interés por año

\begin{tabular}{lllllllll}
\hline \hline Economía de mercado & 2009 & 2010 & 2011 & 2013 & 2015 & 2016 & 2017 & 2018 \\
\hline Muy de acuerdo & 13.7 & 18.0 & 15.5 & 16.4 & No disponible & 12.5 & 15.4 & 12.9 \\
De acuerdo & 46.0 & 50.5 & 50.5 & 52.2 & No disponible & 50.8 & 58.5 & 55.1 \\
En desacuerdo & 31.0 & 24.1 & 26.4 & 24.6 & No disponible & 28.9 & 22.5 & 26.2 \\
Muy en desacuerdo & 9.3 & 7.4 & 7.6 & 6.9 & No disponible & 7.8 & 3.6 & 5.8 \\
Total & 100.0 & 100.0 & 100.0 & 100.0 & No disponible & 100.0 & 100.0 & 100.0 \\
\hline \hline Distribución justa & 2009 & 2010 & 2011 & 2013 & 2015 & 2016 & 2017 & 2018 \\
\hline Muy justa & 2.6 & 2.5 & 2.3 & 3.4 & 2.2 & 2.6 & 2.2 & 1.9 \\
Justa & 19.3 & 19.4 & 18.2 & 23.7 & 22.6 & 18.9 & 16.9 & 14.6 \\
Injusta & 53.5 & 53.3 & 55.3 & 47.6 & 49.2 & 49.5 & 52.1 & 52.0 \\
Muy injusta & 24.6 & 24.8 & 24.2 & 25.4 & 25.9 & 28.9 & 28.8 & 31.5 \\
Total & 100.0 & 100.0 & 100.0 & 100.0 & 100.0 & 100.0 & 100.0 & 100.0 \\
\hline \hline Perspectivas de movilidad & 2009 & 2010 & 2011 & 2013 & 2015 & 2016 & 2017 & 2018 \\
\hline Mucho peor & 4.9 & 3.5 & 3.7 & 2.6 & 3.5 & 6.2 & 6.0 & 8.0 \\
Peor & 11.9 & 9.6 & 10.2 & 8.0 & 8.9 & 12.2 & 9.9 & 10.3 \\
Igual & 35.2 & 38.9 & 40.4 & 34.8 & 33.5 & 37.5 & 35.3 & 33.6 \\
Mejor & 37.9 & 38.0 & 35.8 & 40.8 & 40.4 & 33.6 & 36.0 & 34.2 \\
Mucho mejor & 10.1 & 10.0 & 9.8 & 13.8 & 13.7 & 10.5 & 12.7 & 13.9 \\
Total & 100.0 & 100.0 & 100.0 & 100.0 & 100.0 & 100.0 & 100.0 & 100.0 \\
\hline \hline Movilidad educativa & 2009 & 2010 & 2011 & 2013 & 2015 & 2016 & 2017 & 2018 \\
\hline Descendente & 5.4 & 5.5 & 5.5 & 5.6 & 5.7 & 5.3 & 6.4 & 5.5 \\
Igual & 57.2 & 57.8 & 57.5 & 54.3 & 52.6 & 53.2 & 51.2 & 54.2 \\
Ascendente & 37.4 & 36.7 & 37.0 & 40.0 & 41.7 & 41.5 & 42.4 & 40.3 \\
Total & 100.0 & 100.0 & 100.0 & 100.0 & 100.0 & 100.0 & 100.0 & 100.0 \\
\hline \hline
\end{tabular}

Fuente: elaboración propia en base a Latinobarómetro.

El cuadro a continuación presenta la evolución por año de las principales variables de control. En primer lugar, la ideología política presenta diversas variaciones de un año a otro, pero tienden a aumentar los porcentajes de derecha e izquierda y disminuir los de centro y sin ideología. El ingreso subjetivo muestra un aumento de la proporción de casos de ingreso medio y alto, lo cual también es consistente con la hipótesis planteada. En cuanto a la percepción de la corrupción, se observa que cae la proporción de personas con percepción media y aumenta la alta. Por su parte, en lo que respecta al grado de satisfacción con la democracia, se observa una importante caída año a año de las categorías más bien satisfecho y muy satisfecho, y un aumento de las categorías nada satisfecho y no muy satisfecho. Por último, la religiosidad se 
mantuvo relativamente estable.

Cuadro 4: Variables de control por año

\begin{tabular}{lllllllll}
\hline \hline Ideología & 2009 & 2010 & 2011 & 2013 & 2015 & 2016 & 2017 & 2018 \\
\hline Sin ideología & 14.0 & 12.5 & 13.0 & 11.2 & 12.3 & 9.6 & 8.8 & 11.3 \\
Derecha & 24.3 & 25.4 & 22.3 & 26.6 & 28.4 & 25.9 & 28.0 & 24.5 \\
Centro & 42.3 & 44.0 & 46.0 & 39.5 & 37.8 & 40.9 & 41.1 & 40.3 \\
Izquierda & 19.5 & 18.1 & 18.6 & 22.7 & 21.5 & 23.6 & 22.1 & 23.9 \\
Total & 100.0 & 100.0 & 100.0 & 100.0 & 100.0 & 100.0 & 100.0 & 100
\end{tabular}

\begin{tabular}{lllllllll}
\hline \hline Ingreso subjetivo & 2009 & 2010 & 2011 & 2013 & 2015 & 2016 & 2017 & 2018 \\
\hline Muy bajo & 15.4 & 13.5 & 10.0 & 11.7 & 10.8 & 12.4 & 13.2 & 14.6 \\
Bajo & 39.6 & 38.6 & 34.8 & 33.0 & 33.4 & 34.5 & 32.1 & 32.5 \\
Medio & 37.7 & 40.0 & 46.0 & 45.6 & 44.3 & 41.8 & 42.7 & 40.7 \\
Alto & 7.3 & 7.9 & 9.2 & 9.7 & 11.4 & 11.3 & 12.1 & 12.2 \\
Total & 100.0 & 100.0 & 100.0 & 100.0 & 100.0 & 100.0 & 100.0 & 100.0 \\
\hline \hline Percepción de corrupción & 2009 & 2010 & 2011 & 2013 & 2015 & 2016 & 2017 & 2018 \\
\hline Baja & 9.1 & 7.5 & 7.3 & 7.9 & 8.8 & 10.0 & 11.7 & 9.6 \\
Media & 31.7 & 30.4 & 29.8 & 27.9 & 25.8 & 26.0 & 24.5 & 23.8 \\
Alta & 59.2 & 62.1 & 62.9 & 64.2 & 65.4 & 63.9 & 63.9 & 66.5 \\
Total & 100.0 & 100.0 & 100.0 & 100.0 & 100.0 & 100.0 & 100.0 & 100.0 \\
\hline \hline Satisfacción con democracia & 2009 & 2010 & 2011 & 2013 & 2015 & 2016 & 2017 & 2018 \\
\hline Nada satisfecho & 14.3 & 15.3 & 15.3 & 17.3 & 20.0 & 23.4 & 25.9 & 28.5 \\
No muy satisfecho & 39.2 & 38.9 & 44.3 & 42.3 & 39.4 & 41.3 & 42.4 & 45.8 \\
Más bien satisfecho & 33.1 & 35.2 & 32.0 & 27.7 & 30.0 & 25.3 & 22.6 & 18.6 \\
Muy satisfecho & 13.4 & 10.6 & 8.4 & 12.7 & 10.6 & 9.9 & 9.1 & 7.1 \\
Total & 100.0 & 100.0 & 100.0 & 100.0 & 100.0 & 100.0 & 100.0 & 100.0 \\
\hline \hline Religiosidad & 2009 & 2010 & 2011 & 2013 & 2015 & 2016 & 2017 & 2018 \\
\hline Sin religión & 11.6 & 12.4 & 14.1 & 12.5 & 13.1 & 18.6 & 19.3 & 18.4 \\
No Practicante & 10.7 & 11.4 & 10.5 & 9.8 & 9.2 & 9.9 & 8.6 & 10.1 \\
No muy practicante & 33.6 & 32.9 & 34.2 & 31.9 & 31.8 & 28.7 & 29.2 & 30.9 \\
Practicante & 32.0 & 31.2 & 30.2 & 34.2 & 34.3 & 31.1 & 32.8 & 31.7 \\
Muy practicante & 12.0 & 12.1 & 11.1 & 11.6 & 11.5 & 11.8 & 10.2 & 9.0 \\
Total & 100.0 & 100.0 & 100.0 & 100.0 & 100.0 & 100.0 & 100.0 & 100.0 \\
\hline \hline
\end{tabular}

Fuente: elaboración propia en base a Latinobarómetro.

A continuación se presentan gráficos descriptivos acerca de las principales variables utiliza- 
das en el análisis por país. La figura 1 muestra los porcentajes por país del grado de acuerdo con la economía de mercado, e indirectamente, las preferencias por la redistribución.

Figura 1: Grado de acuerdo con la economía de mercado

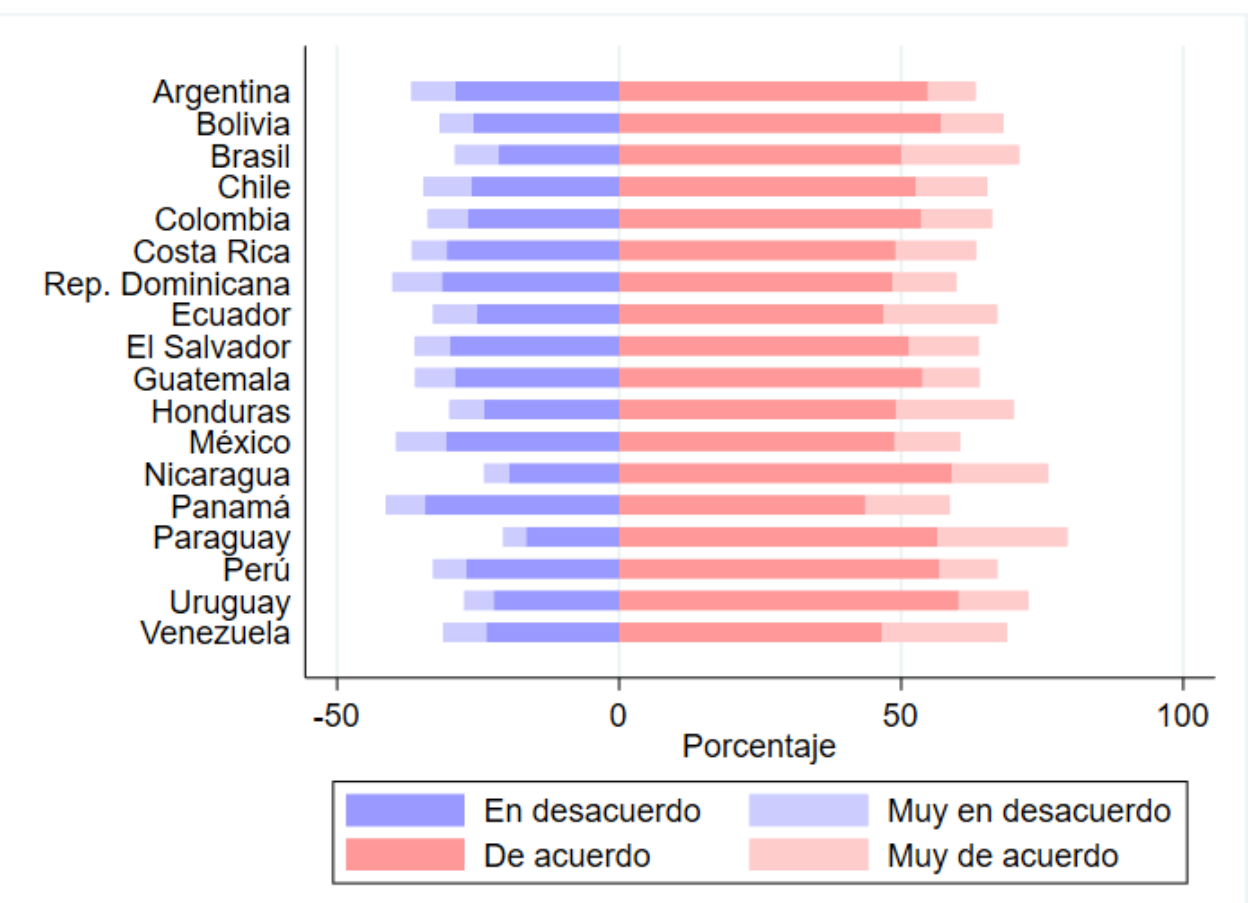

Fuente: elaboración propia en base a Latinobarómetro.

En todos los países se observa un mayor grado de acuerdo que de desacuerdo con la economía de mercado, y por tanto de desacuerdo con la redistribución por parte del estado, destacándose en ese sentido Nicaragua y Paraguay. En sentido contrario, los países que presentan mayor porcentaje de desacuerdo con la economía de mercado son Argentina, República Dominicana, México y Panamá.

La figura a continuación muestra los porcentajes por país de percepciones de justicia en la distribución del ingreso. Como ya se mencionó, esta variable ha sido utilizada en trabajos previos como medida indirecta de las preferencias por la redistribución, bajo el supuesto de que si se percibe que la distribución del ingreso es injusta, se demandará más redistribución, y viceversa. 
Figura 2: Percepción de justicia en la distribución del ingreso

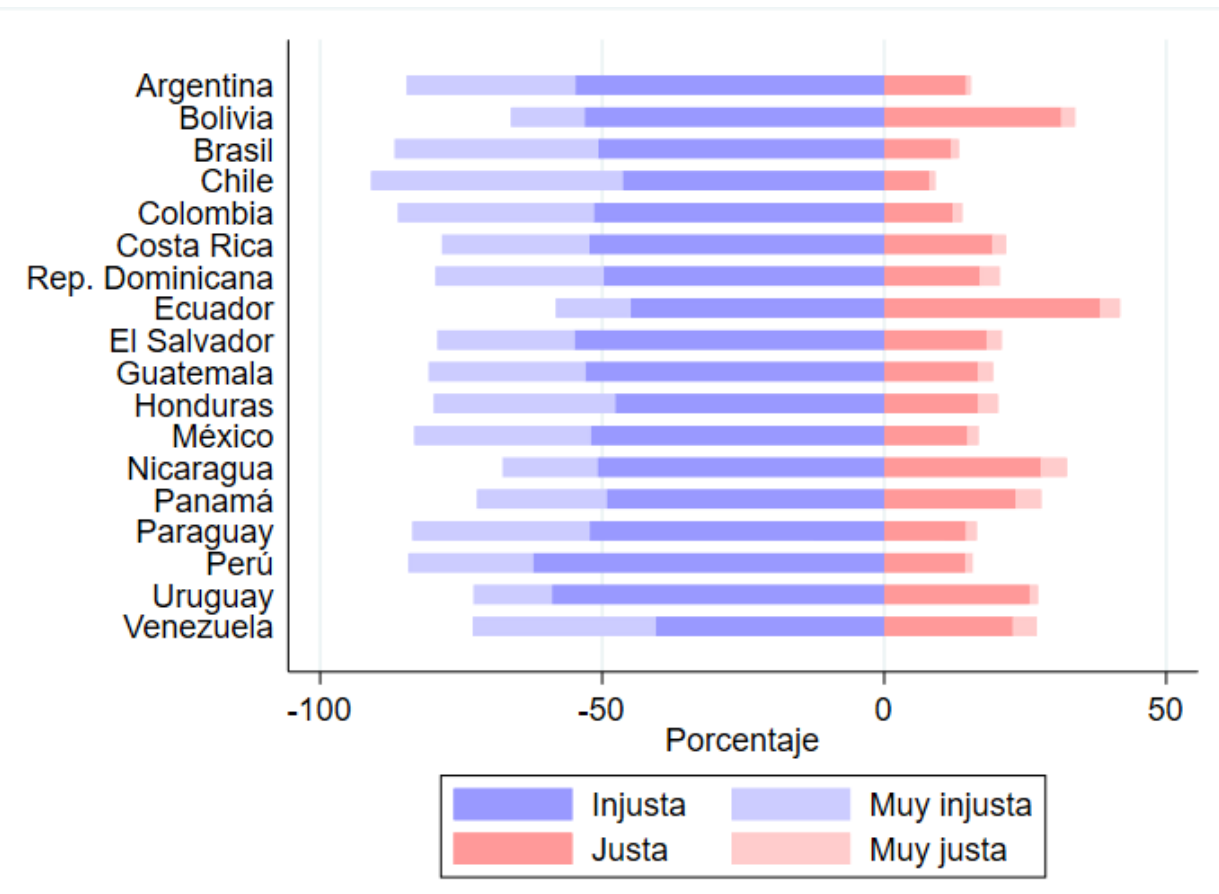

Fuente: elaboración propia en base a Latinobarómetro.

En todos los países se puede apreciar una amplia diferencia en favor de las percepciones de una injusta o muy injusta distribución del ingreso. Los países que muestran mayor percepción de justicia son Ecuador en primer lugar seguido de Bolivia. Por su parte, Chile es el que presenta mayor percepción de injusticia en la distribución del ingreso.

La siguiente figura muestra los porcentajes de las perspectivas de movilidad por país, que es la principal variable de interés en el análisis de la hipótesis POUM. 
Figura 3: Perspectivas de movilidad

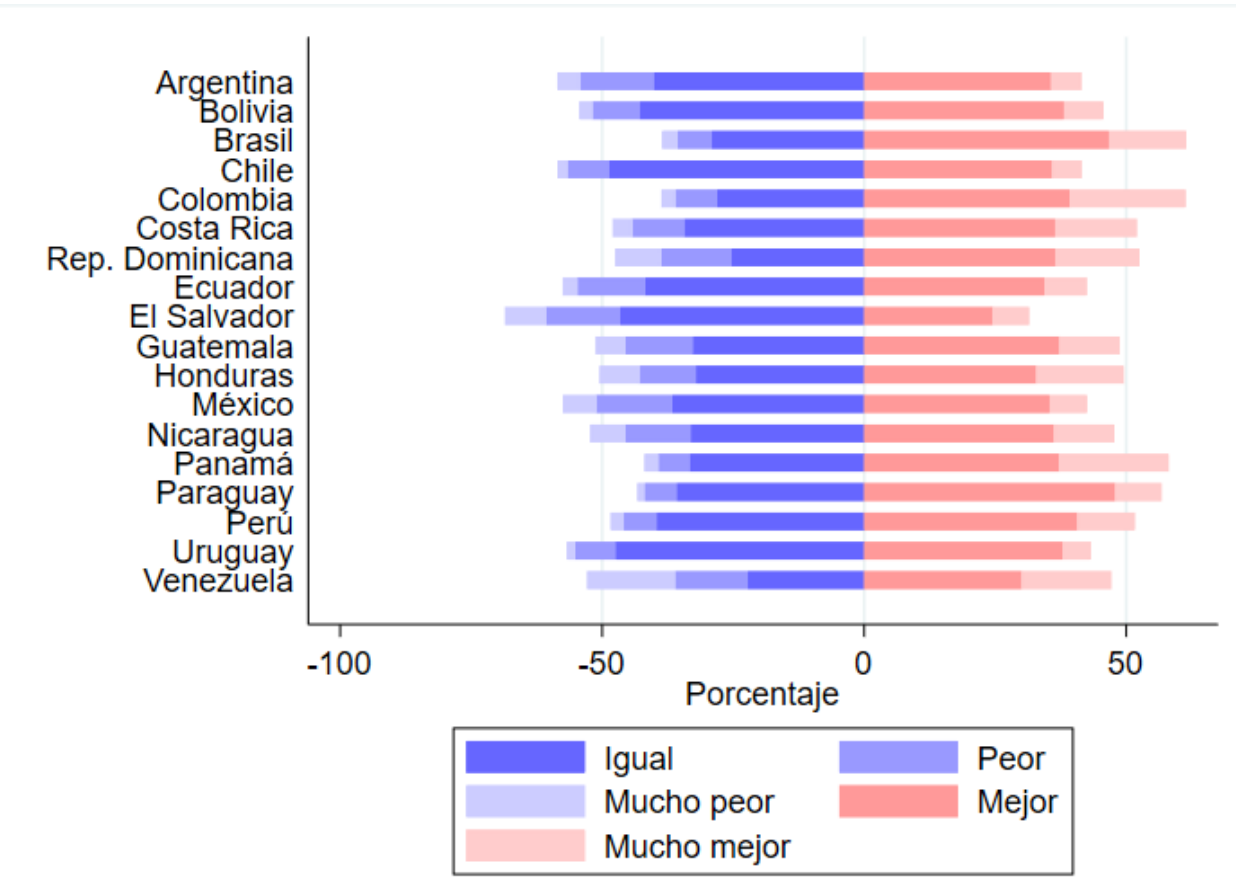

Fuente: elaboración propia en base a Latinobarómetro.

A nivel general, se observa que los porcentajes de personas que creen que su situación económica futura será mejor o mucho mejor que la actual son elevados. Si bien en la mayoría de los países hay un amplio porcentaje de individuos que creen que permanecerán igual, en casi todos los casos el porcentaje de quienes creen que estarán mejor o mucho mejor es mayor. Cabe destacar que esto no se cumple en el caso de El Salvador, Chile, y Uruguay. En el caso de Venezuela, se observa que si bien el porcentaje de personas que creen que estarán igual en el futuro es relativamente bajo, el de quienes creen que estarán peor o mucho peor es elevado. Esto no implica que los individuos del país de que se trate tengan una personalidad más o menos optimista, sino que las respuestas dependen del contexto del país.

A continuación se presentan los datos correspondientes a la movilidad educativa intergeneracional por país. Se trata de la movilidad en términos absolutos, es decir, el movimiento total con respecto a sus padres en términos de nivel educativo, sin tener en cuenta la movilidad relativa al nivel educativo del resto de la sociedad, que ha ido en aumento a lo largo del tiempo. 
Figura 4: Movilidad educativa intergeneracional

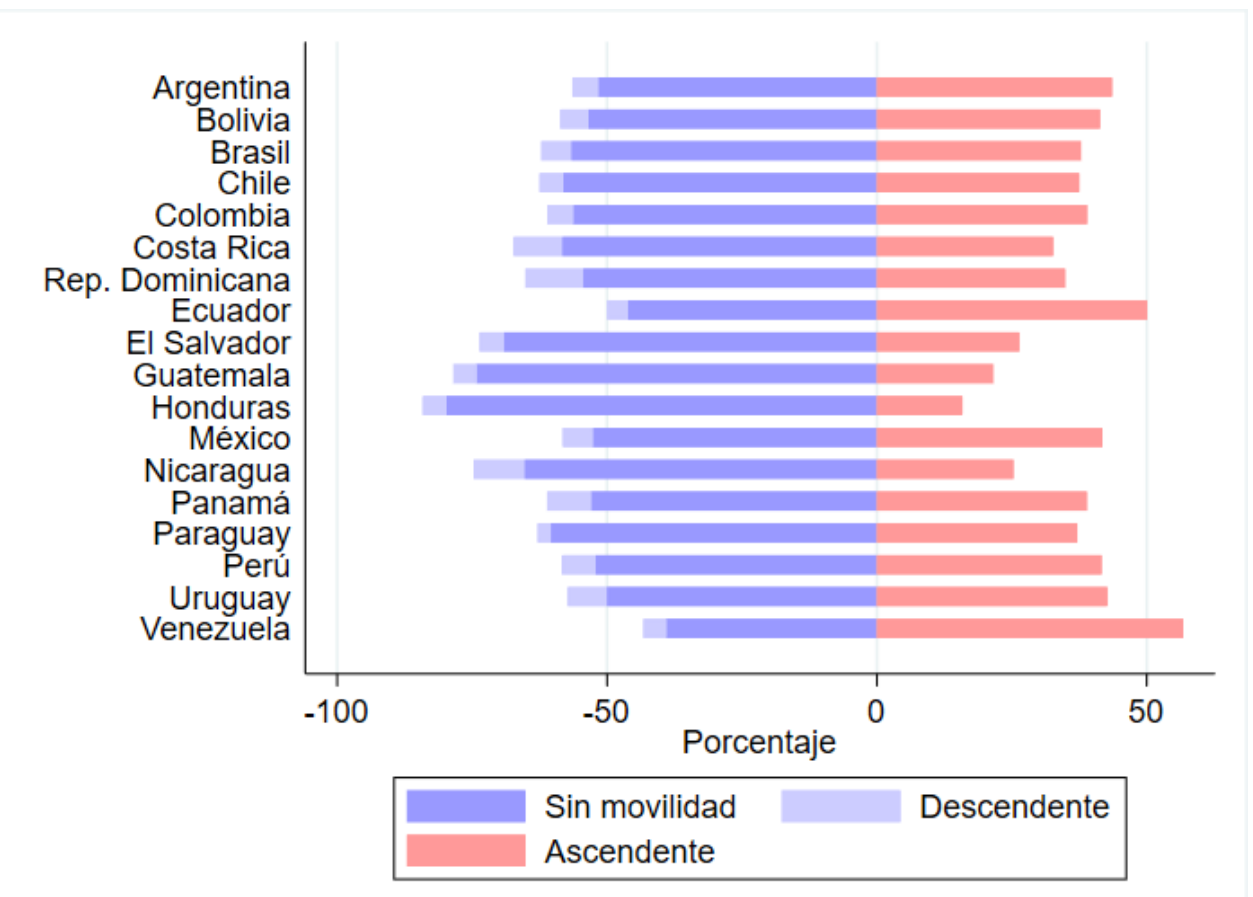

Fuente: elaboración propia en base a Latinobarómetro.

De acuerdo con el gráfico anterior, se observa un alto porcentaje de movilidad educativa ascendente, y una proporción baja de individuos que experimentaron movilidad descendente. Esto es un movimiento natural por el crecimiento promedio de los años de educación, lo cual no necesariamente se cumple en lo que respecta a la movilidad educativa. De todas formas, en la mayoría de los casos se constata que el nivel educativo se ha mantenido con respecto a la generación anterior. Venezuela y Ecuador se destacan como los países con mayor movilidad ascendente, y Honduras como aquel con mayor persistencia en el nivel educativo.

La figura 5 muestra la proporción de individuos por país que declaran tener ideología política de derecha, centro, izquierda y sin ideología. 
Figura 5: Ideología política

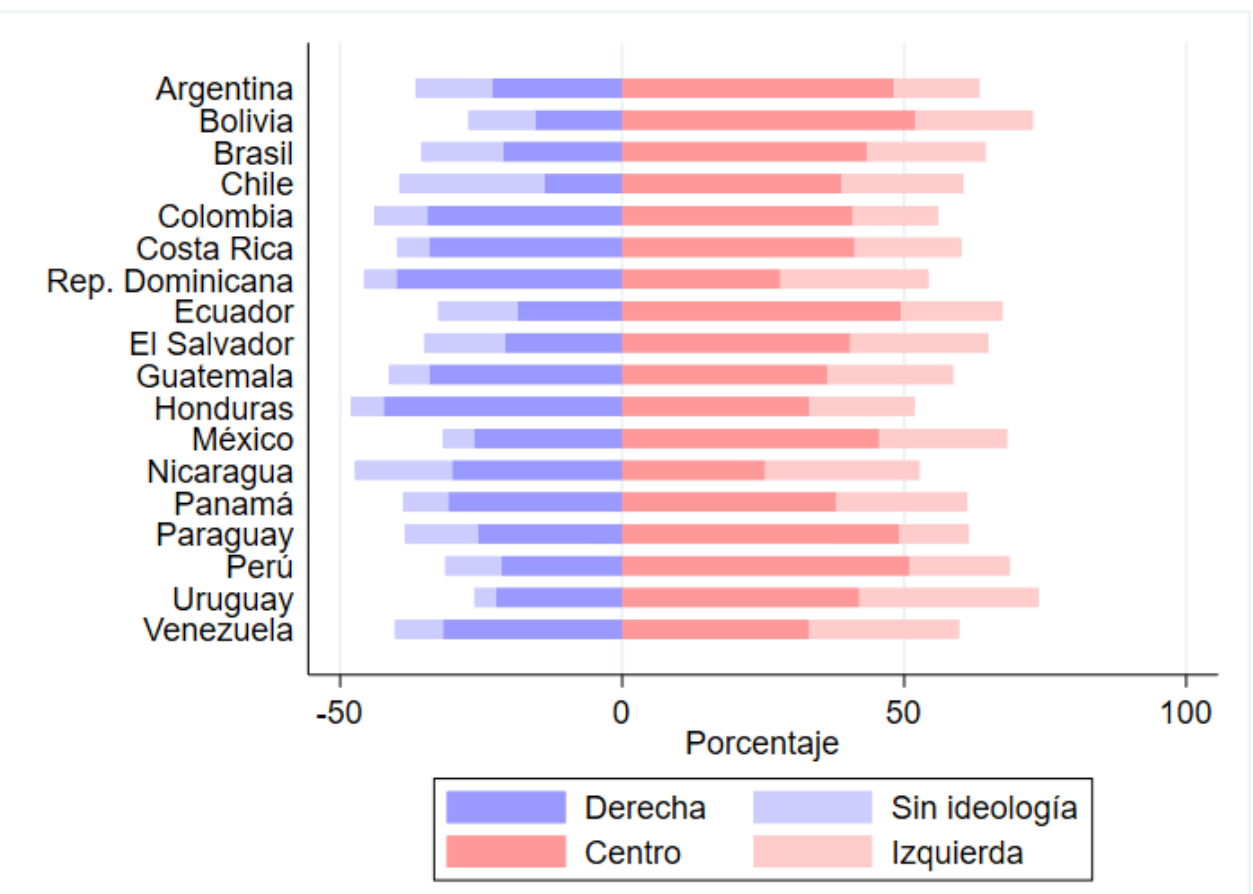

Fuente: elaboración propia en base a Latinobarómetro.

En la mayoría de los países se observa una predominancia de la ideología de centro. En algunos casos, como Bolivia, Chile y Uruguay, un mayor porcentaje de la población se declara de izquierda que de derecha, en el resto, los porcentajes de izquierda y derecha son similares o la derecha es considerablemente mayor que la izquierda. Cabe destacar que en el caso de Chile hay un alto porcentaje de individuos que se declara sin ideología.

La siguiente figura indica la percepción de la corrupción por países. 
Figura 6: Percepción corrupción

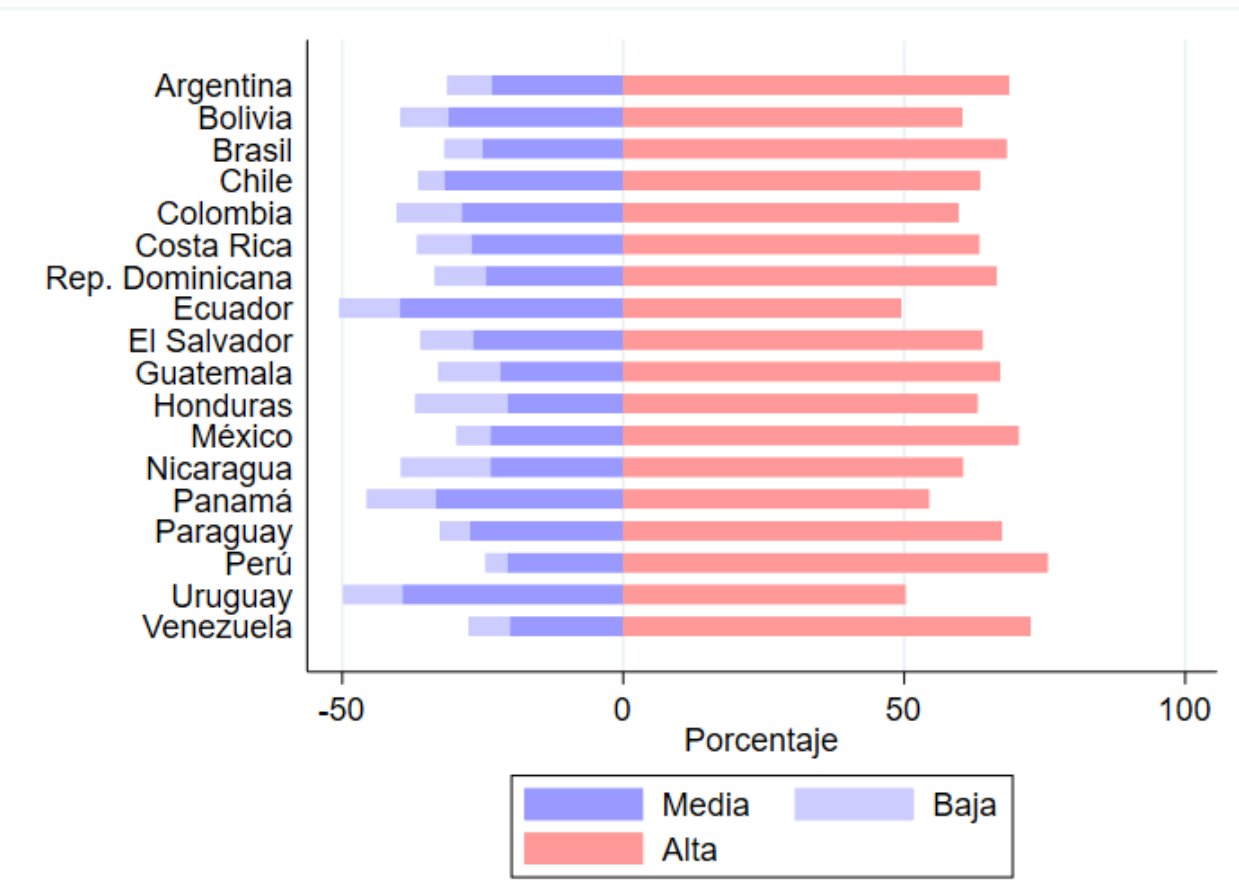

Fuente: elaboración propia en base a Latinobarómetro.

En todos los casos predomina una alta percepción de la corrupción, siendo México, Perú y Venezuela aquellos donde la percepción de la corrupción es mayor. Por su parte, Ecuador y Uruguay se muestran como aquellos con percepciones de corrupción más bajas.

La siguiente figura presenta el grado de satisfacción con la democracia por país. A excepción del caso de Uruguay, en todos los casos la mayoría está más insatisfecha que satisfecha con el funcionamiento de la democracia en su país, siendo esta tendencia más pronunciada en México y Perú. 
Figura 7: Grado de satisfacción con la democracia

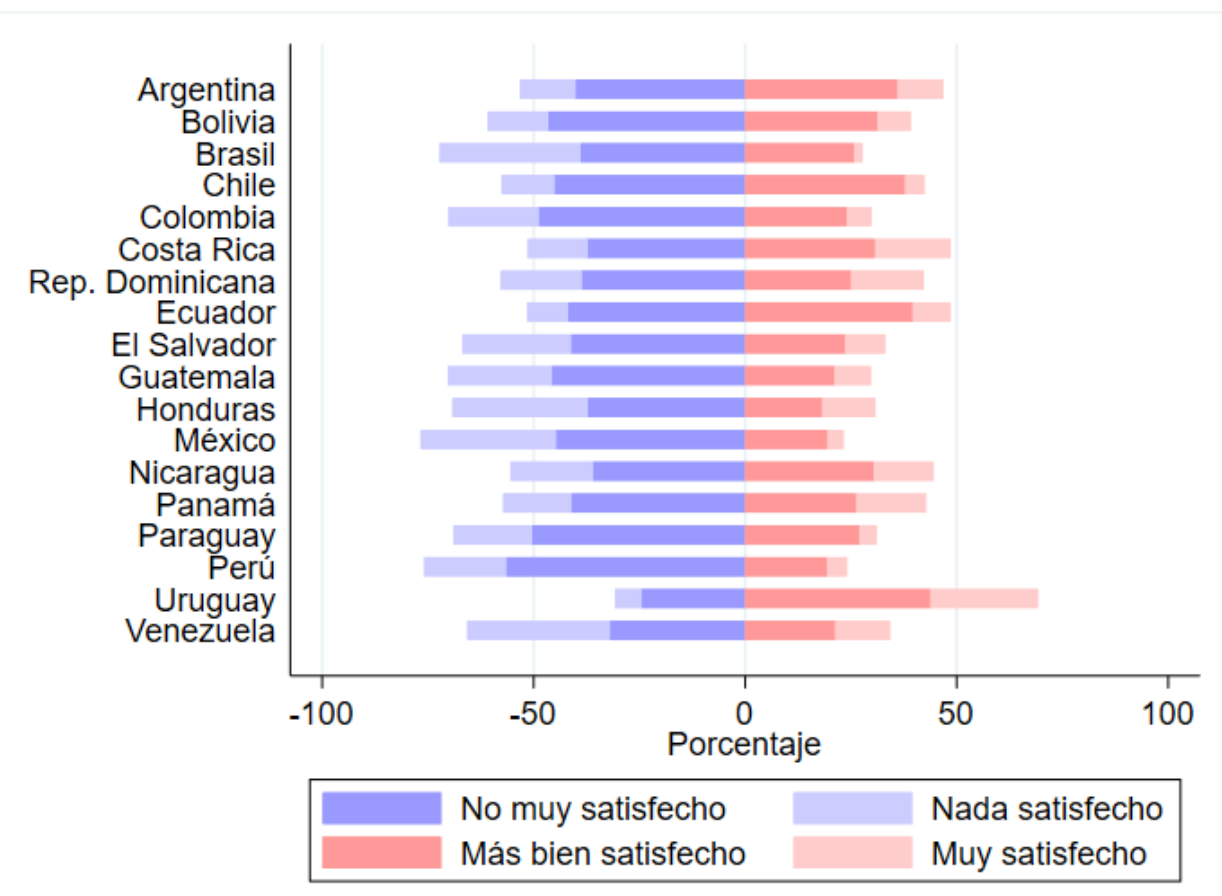

Fuente: elaboración propia en base a Latinobarómetro.

En el caso del ingreso subjetivo, la figura a continuación muestra a nivel general, que la mayor parte de la población presenta ingreso medio e ingreso bajo y que la proporción con ingreso bajo es mayor que la de ingreso alto. Argentina, Brasil, Costa Rica y Uruguay son los que presentan mayores niveles de ingreso subjetivo, en tanto que República Dominicana, Honduras, Nicaragua y Venezuela son los que presentan menores ingresos. 
Figura 8: Ingreso subjetivo

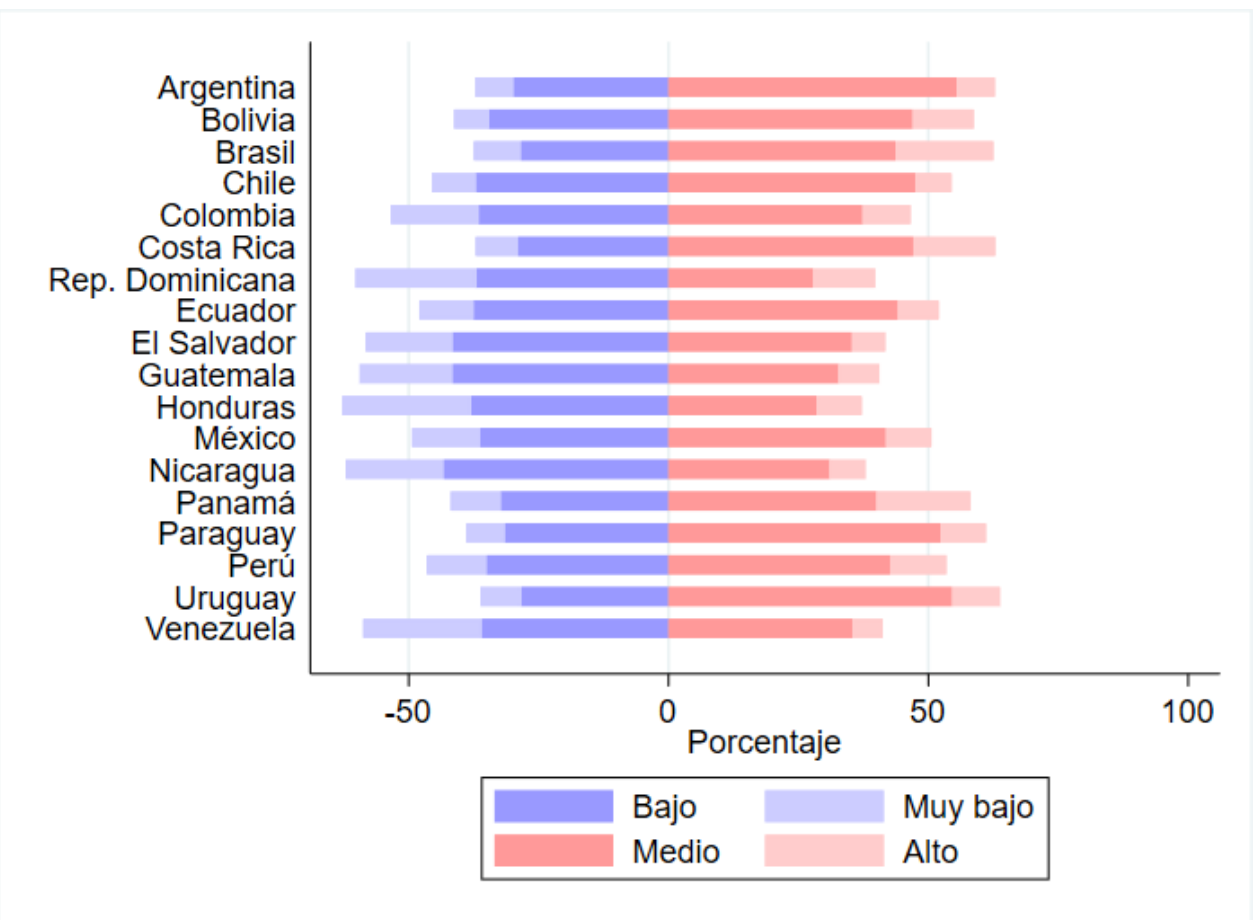

Fuente: elaboración propia en base a Latinobarómetro.

Por último, el siguiente gráfico muestra que a excepción de Uruguay que se destaca por su bajo nivel de religiosidad, el resto presenta altos niveles de la misma. Le siguen a Uruguay Chile y Argentina. 
Figura 9: Religiosidad

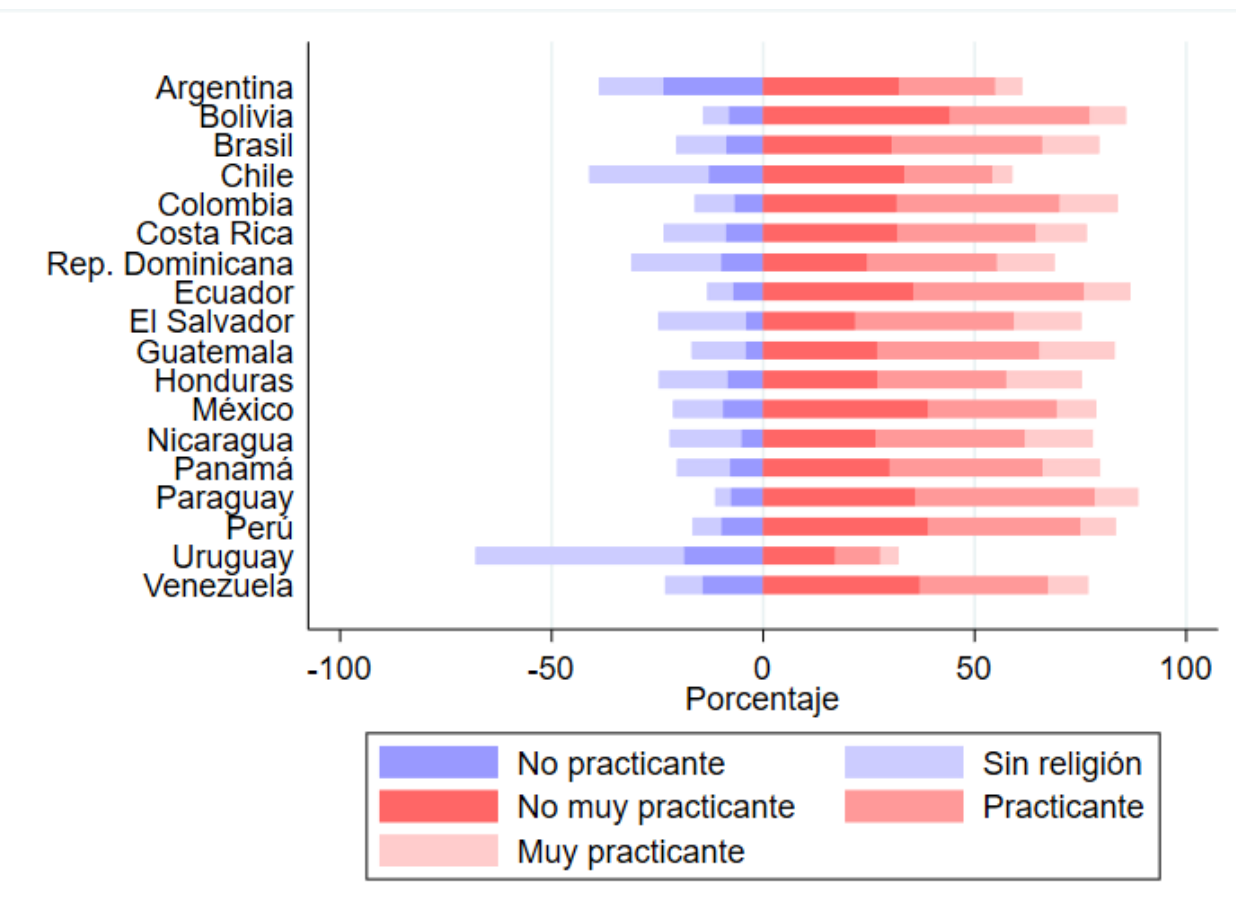

Fuente: elaboración propia en base a Latinobarómetro.

\subsection{Estimaciones econométricas}

El siguiente cuadro muestra los resultados las estimaciones del modelo POLS presentado en la sección anterior. Se presentan cuatro modelos, utilizando como variable dependiente el grado de acuerdo con la economía de mercado $^{5}$ y la percepción de justicia en la distribución del ingreso $^{6}$. En ambos casos se presenta un modelo incluyendo variables de calidad de las instituciones (percepciones de corrupción y satisfacción con la democracia) y otro sin incluirlas. Todos los casos incluyen dummies por país y por año. ${ }^{7}$

\footnotetext{
${ }^{5}$ Para la lectura de los resultados se debe tener en cuenta que por el orden de las categorías de la variable, mientras mayor es el valor de la misma, menor es el apoyo a la economía de mercado, y mayores las preferencias por la redistribución.

${ }^{6}$ Se lee igual que la variable de economía de mercado. Por el orden de las categorías, mientras mayor es el valor de la variable, mayor es la injusticia percibida, y mayores las preferencias por la redistribución

${ }^{7} \mathrm{En}$ el caso de las variables con más de dos categorías, se omite una de ellas. Las dummies omitidas son en orden: perspectivas de movilidad muy bajas, movilidad educativa intergeneracional descendente, nivel educativo bajo, sin religión, sin ideología, ingreso subjetivo muy bajo, percepción de corrupción baja y nada satisfecho con la democracia.
} 
Estimaciones Probit-Adaptadas MCO (POLS)

\begin{tabular}{|c|c|c|c|c|}
\hline & $(1)$ & $(2)$ & (3) & (4) \\
\hline VARIABLES & Economía de mercado & Economía de mercado & Distribución justa & Distribución justa \\
\hline \multirow[t]{2}{*}{ Perspectivas de movilidad bajas } & 0.0111 & 0.0213 & $-0.218^{* * *}$ & $-0.150^{* * *}$ \\
\hline & $(0.0191)$ & $(0.0195)$ & $(0.0150)$ & $(0.0149)$ \\
\hline \multirow[t]{2}{*}{ Perspectivas de movilidad medias } & $-0.0417^{* *}$ & -0.0195 & $-0.415^{* * *}$ & $-0.275^{* * *}$ \\
\hline & $(0.0173)$ & $(0.0177)$ & $(0.0135)$ & $(0.0135)$ \\
\hline \multirow[t]{2}{*}{ Perspectivas de movilidad altas } & $-0.0862^{* * *}$ & $-0.0497^{* * *}$ & $-0.565^{* * *}$ & $-0.366^{* * *}$ \\
\hline & $(0.0172)$ & $(0.0178)$ & $(0.0135)$ & $(0.0137)$ \\
\hline \multirow[t]{2}{*}{ Perspectivas de movilidad muy altas } & $-0.149 * * *$ & $-0.0999 * * *$ & $-0.709^{* * *}$ & $-0.466^{* * *}$ \\
\hline & $(0.0190)$ & $(0.0196)$ & $(0.0155)$ & $(0.0155)$ \\
\hline \multirow[t]{2}{*}{ Movilidad educativa intergeneracional igual } & 0.0200 & 0.0202 & $-0.0557^{* * *}$ & $-0.0458^{* * *}$ \\
\hline & $(0.0145)$ & $(0.0148)$ & $(0.0125)$ & $(0.0120)$ \\
\hline \multirow[t]{2}{*}{ Movilidad educativa intergeneracional ascendente } & 0.00910 & 0.00940 & $-0.0791^{* * *}$ & $-0.0670^{* * *}$ \\
\hline & $(0.0153)$ & $(0.0155)$ & $(0.0135)$ & $(0.0131)$ \\
\hline \multirow[t]{2}{*}{ Edad } & $-0.00141^{* * *}$ & $-0.00135^{* * *}$ & $0.000722^{* * *}$ & $0.00111^{* * *}$ \\
\hline & $(0.000222)$ & $(0.000226)$ & $(0.000205)$ & $(0.000202)$ \\
\hline \multirow[t]{2}{*}{ Hombre } & $-0.0513^{* * *}$ & $-0.0497^{* * *}$ & $-0.0189 * * *$ & -0.00787 \\
\hline & $(0.00631)$ & $(0.00641)$ & $(0.00573)$ & $(0.00558)$ \\
\hline \multirow[t]{2}{*}{ Nivel educativo medio } & 0.00743 & 0.00470 & $0.0575^{* * *}$ & $0.0429^{* * *}$ \\
\hline & $(0.0101)$ & $(0.0102)$ & $(0.00889)$ & $(0.00870)$ \\
\hline \multirow[t]{2}{*}{ Nivel educativo superior } & $0.0635^{* * *}$ & $0.0566^{* * *}$ & $0.167^{* * *}$ & $0.142^{* * *}$ \\
\hline & $(0.0118)$ & $(0.0119)$ & $(0.0107)$ & $(0.0104)$ \\
\hline \multirow[t]{2}{*}{ Compromiso religioso - no practicante } & $-0.0840^{* * *}$ & $-0.0858 * * *$ & 0.0167 & 0.0163 \\
\hline & $(0.0131)$ & $(0.0133)$ & $(0.0115)$ & $(0.0114)$ \\
\hline \multirow[t]{2}{*}{ Compromiso religioso - no muy practicante } & $-0.0952^{* * *}$ & $-0.0968^{* * *}$ & $-0.0421^{* * *}$ & $-0.0339 * * *$ \\
\hline & $(0.0104)$ & $(0.0106)$ & $(0.00927)$ & $(0.00913)$ \\
\hline \multirow[t]{2}{*}{ Compromiso religioso - practicante } & $-0.0831^{* * *}$ & $-0.0823^{* * *}$ & $-0.0738^{* * *}$ & $-0.0552^{* * *}$ \\
\hline & $(0.0105)$ & $(0.0106)$ & $(0.00988)$ & $(0.00966)$ \\
\hline \multirow[t]{2}{*}{ Compromiso religioso - muy practicante } & $-0.134^{* * *}$ & $-0.130 * * *$ & $-0.0574^{* * *}$ & $-0.0377^{* * *}$ \\
\hline & $(0.0135)$ & $(0.0137)$ & $(0.0120)$ & $(0.0118)$ \\
\hline Casado/unión & $-0.0162^{* *}$ & $-0.0170^{* * *}$ & $0.0276^{* * *}$ & $0.0257^{* * *}$ \\
\hline & $(0.00649)$ & $(0.00659)$ & $(0.00579)$ & $(0.00567)$ \\
\hline Ideología - derecha & $-0.165^{* * *}$ & $-0.150^{* * *}$ & $-0.176^{* * *}$ & $-0.110^{* * *}$ \\
\hline & $(0.0129)$ & $(0.0133)$ & $(0.0116)$ & $(0.0117)$ \\
\hline Ideología - centro & $-0.0663^{* * *}$ & $-0.0582^{* * *}$ & $-0.125^{* * *}$ & $-0.0825^{* * *}$ \\
\hline & $(0.0123)$ & $(0.0126)$ & $(0.0110)$ & $(0.0111)$ \\
\hline Ideología - izquierda & -0.00393 & 0.0148 & $-0.200^{* * *}$ & $-0.127 * * *$ \\
\hline & $(0.0134)$ & $(0.0137)$ & $(0.0120)$ & $(0.0120)$ \\
\hline Ingreso subjetivo - bajo & $0.0269^{* *}$ & $0.0280^{* *}$ & $-0.144^{* * *}$ & $-0.118^{* * *}$ \\
\hline & $(0.0112)$ & $(0.0114)$ & $(0.00960)$ & $(0.00968)$ \\
\hline Ingreso subjetivo - medio & $0.0238^{* *}$ & $0.0339 * * *$ & $-0.273^{* * *}$ & $-0.214^{* * *}$ \\
\hline & $(0.0113)$ & $(0.0115)$ & $(0.00981)$ & $(0.00982)$ \\
\hline Ingreso subjetivo - alto & 0.00737 & 0.0232 & $-0.354 * * *$ & $-0.275^{* * *}$ \\
\hline & $(0.0141)$ & $(0.0143)$ & $(0.0124)$ & $(0.0123)$ \\
\hline Gini & $0.00857^{* * *}$ & $0.0102^{* * *}$ & -0.00243 & $0.00507^{* *}$ \\
\hline & $(0.00262)$ & $(0.00268)$ & $(0.00219)$ & $(0.00216)$ \\
\hline Log. PBI per cápita & $0.132^{* * *}$ & $0.144^{* * *}$ & $-0.122^{* * *}$ & $-0.116^{* * *}$ \\
\hline & $(0.0360)$ & $(0.0368)$ & $(0.0318)$ & $(0.0307)$ \\
\hline Percepción de corrupción - media & & $0.0361^{* * *}$ & & $0.0454^{* * *}$ \\
\hline & & $(0.0123)$ & & $(0.0108)$ \\
\hline Percepción de corrupción - alta & & $0.0560^{* * *}$ & & $0.244^{* * *}$ \\
\hline & & $(0.0116)$ & & $(0.0103)$ \\
\hline Satisfacción con democracia - no muy satisfecho & & $-0.0254^{* * *}$ & & $-0.243^{* * *}$ \\
\hline & & $(0.00913)$ & & $(0.00749)$ \\
\hline Satisfacción con democracia - más bien satisfecho & & $-0.0917 * * *$ & & $-0.536^{* * *}$ \\
\hline & & $(0.0102)$ & & $(0.00886)$ \\
\hline Satisfacción con democracia - muy satisfecho & & $-0.151^{* * *}$ & & $-0.708^{* * *}$ \\
\hline & & $(0.0135)$ & & $(0.0118)$ \\
\hline Constant & $-1.130 * * *$ & $-1.330^{* * *}$ & $2.178^{* * *}$ & $1.756^{* * *}$ \\
\hline & $(0.382)$ & $(0.390)$ & $(0.349)$ & $(0.338)$ \\
\hline Dummies año & Sí & Sí & Sí & Sí \\
\hline Dummies país & Sí & Sí & Sí & Sí \\
\hline & 33 & & & \\
\hline Observaciones & 93,497 & 90,268 & 113,829 & 108,983 \\
\hline R-cuadrado & 0.035 & 0.037 & 0.116 & 0.191 \\
\hline
\end{tabular}


El primer resultado a destacar en el primer modelo, es que las variables asociadas a perspectivas de movilidad resultan significativas, salvo el caso de perspectivas bajas, de signo negativo y de mayor magnitud en valor absoluto a medida que aumentan las perspectivas. Este resultado es consistente con la hipótesis POUM, es decir, como de acuerdo con la construcción de la variable de economía de mercado, a medida que aumenta su valor aumenta el desacuerdo con la misma, se observa que a medida que aumentan las perspectivas de movilidad, disminuye el grado de desacuerdo con la economía de mercado, y de esta forma, disminuyen las preferencias por la redistribución. Por su parte, la movilidad educativa intergeneracional resulta no significativa, lo que puede deberse a que en el presente análisis se considera la movilidad en términos absolutos y no relativos.

Asimismo, la edad resulta significativa y de signo negativo, es decir que a medida que aumenta la edad, disminuyen las preferencias por la redistribución, lo cual es coherente con la noción de la teoría del ciclo de vida de que el ingreso es mayor a medida que aumenta la edad. El sexo también es significativo, donde el ser hombre incide negativamente en las preferencias por la redistribución, lo cual coincide con la literatura previa que muestra que las mujeres demandan más redistribución. El nivel educativo medio no es significativo pero si el nivel educativo superior, y su signo es positivo, es decir que incide positivamente en las preferencias por la redistribución, a pesar de que el mayor nivel educativo se asocia también con mayores ingresos. De todas formas, este resultado también se cumple si no se incluye en el modelo la variable de ingreso subjetivo. Podemos decir que este resultado es consistente con la hipótesis POUM o con modelos de preferencias en base al interés individual.

Otra variable incluida en el análisis es el grado de compromiso religioso. Todas las categorías resultan significativas, de significativo, y de mayor magnitud en valor absoluto a medida que aumenta el grado de compromiso religioso. Es decir, a mayor compromiso religioso, menor preferencia por la redistribución. Este resultado coincide con trabajos realizados para otros países que muestran que la religión es un factor importante en la formación de las preferencias, y que la religión y las políticas redistributivas son factores sustitutos en la provisión de seguridad ante los eventos de la vida, por eso a mayor religiosidad, mayor oposición a la redistribución, a pesar de que en términos generales los más pobres suelen ser los más religiosos. La literatura encuentra evidencia de que es relevante a qué religión se pertenece (católico, protestante, etc.), lo cual no fue incluido en el modelo debido a que ese dato no se encuentra disponible para todo el período, pero dados estos resultados, sería conveniente profundizar en ello. Cabe destacar que en América Latina hay un alto componente de religiosidad. Por su parte, el estar casado o en unión libre también resulta significativa y de signo negativo, es decir que incide negativamente en las preferencias por la redistribución, lo cual puede tener relación con el mayor nivel de ingreso de los casados. 
Otra de las variables explicativas de las preferencias por la redistribución incluidas en el modelo es la ideología política. Si bien el caso de ser de izquierda no es significativo, los coeficientes asociados a estas variables son coherentes con la idea de que mientras más hacia la derecha se ubiquen, mayor es su grado de acuerdo con la economía de mercado y menores las preferencias por la redistribución. Ser de derecha y ser de centro inciden negativamente en las preferencias por la redistribución, donde ser de derecha es la de mayor efecto negativo. También se incluyó la variable de ingreso subjetivo, y se constata que quienes perciben que su ingreso es bajo y medio demandan redistribución.

Por último, se incluyen variables macroeconómicas según el país y el año de la encuesta, como ser el índice de Gini y el PBI per cápita. Ambas son significativas y de signo positivo, es decir, a mayor desigualdad mayor demanda de redistribución, lo cual es un resultado intuitivo. También, a mayor PBI per cápita más demanda de redistribución, lo cual puede deberse a mayor nivel de ingreso mayor es el monto a repartir y menor el impacto negativo en caso de salir perdiendo con la redistribución.

Si nos centramos en el segundo modelo, que es igual al anterior pero incluye las variables de percepción de la corrupción y satisfacción con la democracia, vemos que la mayoría de los resultados antes comentados se mantienen, solo varían levemente algunos coeficientes. En cuanto a las variables acerca de la calidad de las instituciones incluidas, se obtienen resultados ambiguos. En primer lugar, la percepción de la corrupción resulta significativa y de signo positivo, siendo mayor el coeficiente mientras más corrupción se percibe. Este resultado, coincide con lo obtenido por Oviedo y Ramos (2017), donde el efecto negativo de la corrupción sobre el ingreso relativo domina a la desconfianza en el gobierno. ${ }^{8}$ Por su parte, la satisfacción con la democracia tiene el efecto opuesto, a mayor satisfacción con la democracia, menor es la demanda de redistribución.

Alternativamente, se plantean dos modelos iguales a los anteriores pero con las percepciones de justicia como variable dependiente. En un primer resultado a destacar, podemos observar que las variables asociadas a percepción de movilidad son significativas, de signo negativo, y que el coeficiente asociado a las mismas es mayor en valor absoluto a medida que aumentan las percepciones de movilidad. Esto es consistente con la hipótesis POUM, ya que ante mayores perspectivas de mejora, mayor percepción de que la distribución del ingreso es justa y por lo tanto menor preferencia por la redistribución. Esto coincide con los modelos anteriores, e implica un cambio con respecto a estudios anteriores de la hipótesis POUM que mostraban que esta se cumplía en Europa y Estados Unidos pero no se cumplía en América Latina.

\footnotetext{
${ }^{8}$ Este resultado se mantiene si se incluyen en el modelo variables de interacción de corrupción y perspectivas.
} 
En cuanto a la movilidad intergeneracional educativa, podemos observar que en este caso sí tiene un efecto significativo. Su signo es negativo, y aumenta en valor absoluto en el caso de movilidad ascendente, de manera que el haber experimentado movilidad ascendente, aumenta la percepción de justicia en la distribución del ingreso. La edad presenta signo positivo, a diferencia de los modelos anteriores, de manera que a mayor edad mayor percepción de injusticia en la distribución del ingreso. Por su parte, ser hombre tiene signo negativo, por lo que perciben mayor justicia que las mujeres en la distribución del ingreso. Por su parte, el nivel educativo presenta signo positivo y mayor en el caso de educación superior, por lo que, a pesar de que la educación se asocia a mayor ingreso, esto está reflejando otros efectos de la educación en la percepción de justicia en la distribución del ingreso.

Con respecto al compromiso religioso, se observa un resultado similar a los modelos anteriores, el compromiso religioso incide positivamente en la percepción de justicia en la distribución del ingreso. La variable casado es significativa y de signo positivo, lo cual difiere de los modelos anteriores, ya que en este caso el ser casado incide negativamente en la percepción de justicia, lo que podría aumentar la demanda de redistribución. Las variables correspondientes a la ideología, también muestran un comportamiento diferente a los modelos anteriores. Son significativas y de signo negativo pero no hay una relación entre ser de izquierda, derecha o centro y la percepción de justicia. En el caso del ingreso subjetivo, se obtienen los resultados esperados, a mayor ingreso, mayor percepción de justicia en la distribución del ingreso, y menor demanda de reditribución. Por último, el índice de Gini no resulta significativo, y el logaritmo del PBI per cápita presenta signo negativo, por lo que a mayor PBI per cápita mayor percepción de justicia en la distribución del ingreso.

El último modelo es igual a este pero incorporando las variables de calidad de las instituciones, tales como la percepción de la corrupción y la satisfacción con la democracia. Los resultados de las variables mencionadas en el modelo anterior en general se mantienen al incluir estas variables, salvo por ejemplo el índice de Gini que pasa a ser significativo y de signo positivo, es decir, un aumento en el Gini aumenta la percepción de injusticia en la distribución del ingreso lo cual es coincidente con lo esperado. Los resultados sobre percepción de la corrupción y satisfacción con la democracia están en la misma línea del modelo con grado de acuerdo con la economía de mercado como variable dependiente. Mientras mayor sea la percepción de la corrupción, mayor es la percepción de injusticia en la distribución. En sentido contrario, a mayor satisfacción con la democracia, mayor percepción de justicia en la distribución del ingreso.

A modo de síntesis, con el análisis de los modelos POLS podemos ver que las perspectivas de movilidad se correlacionan positivamente tanto en el grado de acuerdo con la economía de 
mercado como en la percepción de justicia en la distribución del ingreso, controlando o no por variables de calidad de las instituciones, y por lo tanto, implican menor demanda de redistribución. Este resultado es consistente con la hipótesis POUM.

En el anexo se presentan estos resultados para cada país por separado y no para América Latina en su conjunto. Se observa que para algunos países se cumple la hipótesis POUM y para otros no. Además, otros de los resultados aquí mencionados tales como aquellos acerca de la calidad de las instituciones o la religiosidad, requieren un mayor análisis. A continuación se presentan a modo de resumen, dos gráficos de los coeficientes estimados de las perspectivas ascendentes, ordenando los países según PIB per cápita a 2018, la figura 10 para las estimaciones con la variable dependiente de apoyo a la economía de mercado y la figura 11 con percepciones de justicia como variable dependiente.

Figura 10: Coeficientes estimados de perspectivas ascendentes según PIB per cápita por país (2018) - Apoyo a la economía de mercado

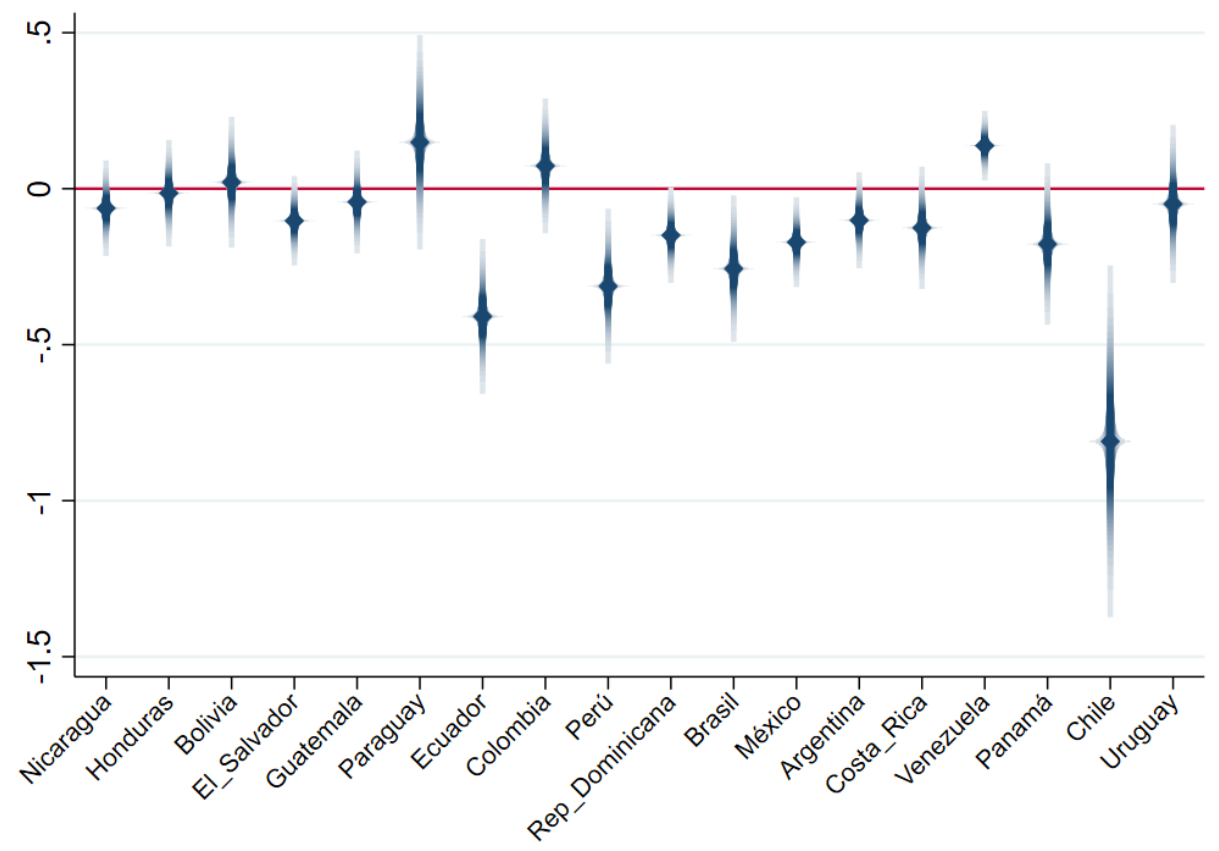

Fuente: elaboración propia en base a Latinobarómetro. 
Figura 11: Coeficientes estimados de perspectivas ascendentes según PIB per cápita por país (2018) - Percepción de justicia

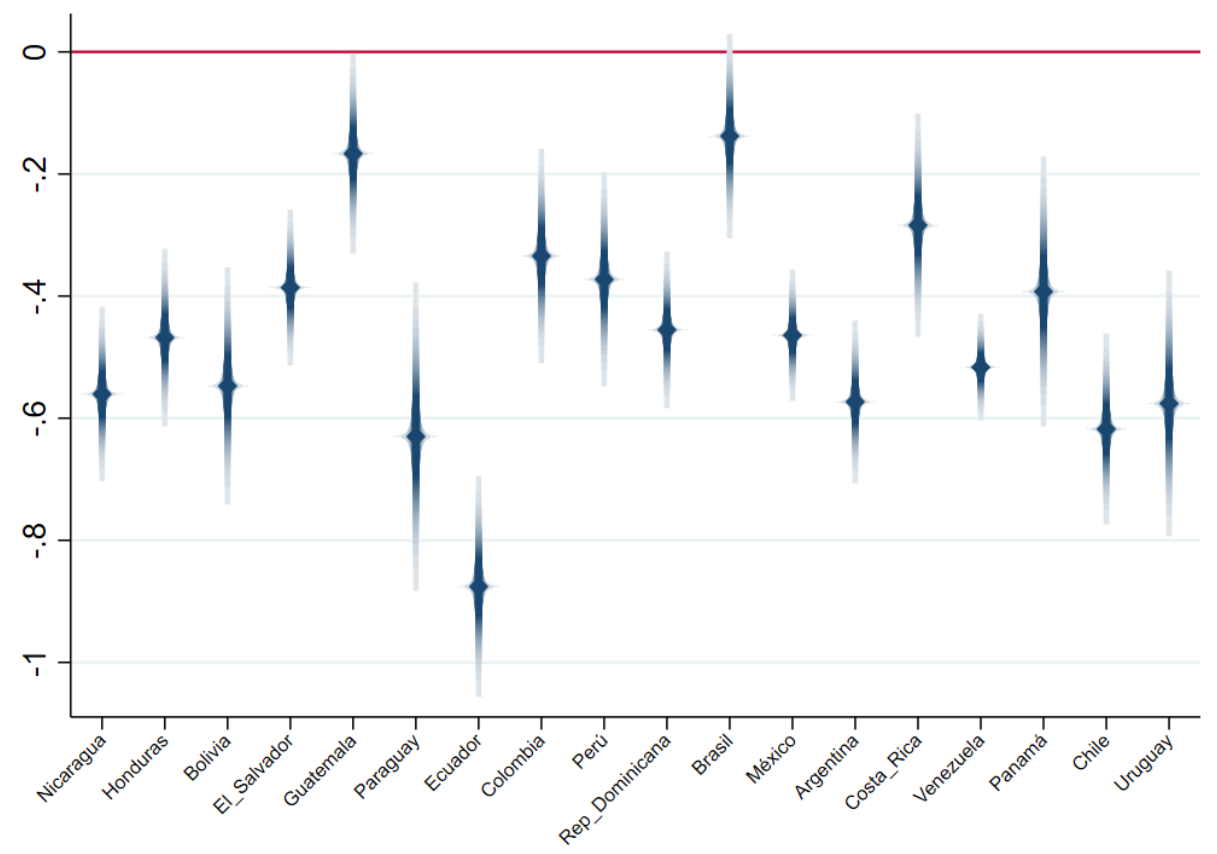

Fuente: elaboración propia en base a Latinobarómetro.

Podemos observar que para el caso de la figura 10, existe cierta tendencia en cuanto al cumplimiento de la hipótesis POUM y el PIB per cápita del país. En el caso de los primeros países, es decir, los de menor PIB, los coeficientes representados se encuentran más en torno al cero o por encima, en cambio de Perú en adelante, es decir la mitad de mayores ingresos, salvo el caso de Venezuela (cuyo dato de PIB no está actualizado sino que se incluye el último disponible según el Banco Mundial) todos los coeficientes presentan signo negativo, lo que implica cumplimiento de la hipótesis POUM. Esto podría estar indicando que la hipótesis POUM se cumple a partir de cierto umbral de ingresos, y que por debajo de dicho umbral, por más que las perspectivas de movilidad sean ascendentes, el ingreso es tan bajo que igual se demanda redistribución. Por su parte, al analizar la figura 11, se encuentra que en el caso de las percepciones de justicia no hay una tendencia clara respecto al nivel de ingreso per cápita.

\subsection{Robustez}

Dadas las limitaciones empíricas mencionadas en la sección anterior, se realizaron pruebas de robustez de manera de validar los resultados obtenidos. El siguiente cuadro muestra una de ellas, que consiste en realizar las estimaciones eliminando todas las variables subjetivas. 
Perspectivas de movilidad bajas

Perspectivas de movilidad medias

Perspectivas de movilidad altas

Perspectivas de movilidad muy altas

Movilidad educativa intergeneracional igual

Movilidad educativa intergeneracional ascendente

Hombre

Nivel educativo medio

Nivel educativo superior

Casado/unión

Gini

Log. PBI per cápita

Constante

Dummies año

Dummies país

Observations

R-squared

$$
\begin{gathered}
0.0203 \\
(0.0179) \\
-0.0395^{* *} \\
(0.0161)
\end{gathered}
$$

$-0.0927^{* * *}$

(0.0160)

$-0.154^{* * *}$

(0.0177)

0.0112

(0.0142)

0.000382

$$
\text { (0.0150) }
$$

$-0.00182^{* * *}$

(0.000207)

$-0.0419 * * *$

(0.00594)

0.00802

(0.00949)

$0.0601^{* * *}$

(0.0111)

$-0.0165^{* * *}$

(0.00614)

$0.00899 * * *$

(0.00246)

$0.164^{* * *}$

(0.0345)

$-1.573^{* * *}$

(0.365)

Sí

Sí

$$
104,573
$$

0.028
$-0.245^{* * *}$

0.0977

(0.0139)

(0.0624)

$-0.469 * * *$

$0.151^{* *}$

(0.0124)

(0.0592)

$-0.635^{* * *}$

(0.0125)

$-0.799^{* * *}$

(0.0145)

$-0.0392^{* * *}$

(0.0120)

$0.195 * * *$

(0.0594)

$0.240^{* * *}$

(0.0631)

$-0.0328$

(0.0415)

$-0.0465^{* * *}$

$-0.0635$

(0.0130)

(0.0419)

$0.000491^{* * *}$

$-0.000399$

(0.000188)

(0.000530)

$-0.0265 * * *$

(0.00529)

$0.0754^{* * *}$

(0.0153)

0.0137

$0.0962 * * *$

(0.00845)

(0.0248)

$0.0844^{* * *}$

$0.151^{* * *}$

(0.0100)

(0.0294)

$0.0245 * * *$

0.00726

(0.00545)

(0.0158)

$-0.00277$

$-0.112^{* * *}$

(0.00206)

(0.0189)

$-0.194^{* * *}$

$2.356^{* * *}$

(0.0304)

(0.356)

2.609 ***

$-18.53^{* * *}$

(0.334)

(3.137)

Sí

No

Sí

Sí

Robust standard errors in parentheses

$$
* * * \mathrm{p}<0.01, * * \mathrm{p}<0.05,{ }^{*} \mathrm{p}<0.1
$$

Como podemos observar, el coeficiente asociado a las variables de perspectivas de movilidad es negativo y aumenta en valor absoluto a medida que aumentan las perspectivas. Esto es consistente con la hipótesis POUM.

Otra prueba de robustez realizada aprovecha que el cuestionario correspondiente al año 2011 
cuenta con una pregunta acerca de si los impuestos que se pagan son: muy altos, altos, correctos, bajos o muy bajos ${ }^{9}$. En principio, se podría suponer que quienes creen que los impuestos son muy altos no están a favor de la redistribución y quienes creen que son bajos si lo están. Sin embargo, bajo este supuesto, la evidencia no respalda la hipótesis POUM. Esto no afecta la robustez del análisis, ya que no hay una relación lineal entre esta pregunta como variable dependiente y las verdaderas preferencias por la redistribución. Por ejemplo, el respondente puede creer que los impuestos que él paga son altos, pero que no son redistributivos y que los ricos deberían pagar más y así redistribuir.

Por último, en el anexo se presentan los resultados a nivel país. En varios casos, no se obtiene evidencia estadísticamente significativa del cumplimiento de la hipótesis, lo que da cuenta de las heterogeneidades entre países. Sin embargo, en la mayor parte de los casos la hipótesis se cumple.

No se observa una relación exacta entre crecimiento económico y evidencia favorable a la hipótesis POUM en el país o desigualdad y evidencia favrable a la hipótesis. Esto da cuenta de diferencias culturales entre países en torno a las preferencias por la redistribución.

\section{Conclusiones}

Los resultados presentados tanto para grado de acuerdo con la economía de mercado como para percepción de justicia en la distribución del ingreso ponen de manifiesto la importancia de las perspectivas de movilidad en la formación de las preferencias por la redistribución. Estudios previos mostraban que este fenómeno no se cumplía para América Latina, pero sí para Estados Unidos y Europa. El presente trabajo, realizado para el período 2009-2018, muestra evidencia consistente con la hipótesis POUM, ya que se observa una correlación negativa entre perspectivas de movilidad y preferencias por la redistribución controlando por múltiples factores. Además, la evolución temporal de ambas variables también es consistente con la hipótesis. Como primera conclusión, esto puede indicar un mayor peso del interés personal que del altruismo en las preferencias por la redistribución.

En líneas generales América Latina ha tenido un fuerte crecimiento económico en la década pasada acompañado por una caída de la desigualdad, por lo cual, dichos indicadores se asemejan un poco más a los correspondientes a Estados Unidos y Europa, para los cuales sí se constata la hipótesis POUM. De esta forma, una posible explicación para este cambio es que el nivel de ingreso y de desigualdad del país influyen en el cumplimiento de la hipótesis POUM, es decir, que a partir de cierto umbral de desarrollo y movilidad social empiezan a pesar las perspectivas de movilidad en las preferencias por redistribución. Conocer los mecanismos que operan detrás

\footnotetext{
${ }^{9}$ Nuevamente ocurre que a medida que aumenta el valor de la variable, más bajos se cree que son los impuestos, y a priori más distribución se demanda
} 
de las preferencias por la redistribución es particularmente importante en el contexto latinoamericano, que se caracteriza por una alta desigualdad.

Los resultados también muestran una baja incidencia de la movilidad educativa intergeneracional en las preferencias por la redistribución, sin embargo este efecto puede deberse a su consideración en términos absolutos y no relativos, y por la inmovilidad que suele observarse en los extremos de acuerdo a estudios previos para algunos de los países analizados. Alternativamente, puede ocurrir que la movilidad experimentada percibida difiera de la efectivamente experimentada y esto altere la relación entre movilidad intergeneracional y preferencias. Cabe destacar la importancia de las percepciones sobre corrupción y funcionamiento de la democracia en las variables estudiadas, lo cual es particularmente importante en el caso de América Latina, ya que ha sido una problemática característica de la región y la diferencia en cierto punto de los casos de Europa y Estados Unidos. Por último, se observa una incidencia importante de la religiosidad en la formación de las preferencias por la redistribución, lo que también tiene un peso particular en América Latina en comparación con otras regiones menos religiosas.

Sin embargo, dadas las limitaciones en cuanto a la disponibilidad de datos y la metodología para interpretar causalidad, quedan abiertas algunas preguntas para futuras investigaciones. Una de ellas consiste en considerar en el análisis sesgos comportamentales y aversión al riesgo, que puede modificar los resultados obtenidos. Además, hay evidencia de la importancia del ingreso relativo, es decir de la posición en relación a los demás en términos comparativos, lo cual puede tener influencia en las perspectivas de movilidad y en la formación de las preferencias por la redistribución.

Teniendo en cuenta la evolución reciente de la desigualdad en América Latina, y en particular el mantenimiento o incluso aumento de la proporción de ingresos que se apropian los percentiles más altos de ingresos, sería interesante incorporar al análisis la influencia de los medios de comunicación y los grupos de poder económico en la formación de las perspectivas de movilidad y otras percepciones subjetivas que influyen en las preferencias por redistribución. La influencia de los medios de comunicación podría explicar la alternancia entre gobiernos redistributivos y no redistributivos. Los datos con los que cuenta la base de datos utilizada acerca de este tema son insuficientes para incorporarlos al análisis, pero pueden desarrollarse otras fuentes de información o explorarse otras existentes. Por último, para futuras investigaciones es importante incorporar metodologías que permitan un análisis causal y obtener resultados concluyentes. Para ello, si bien Latinobarómetro es una excelente fuente de información con múltiples ventajas, sería necesaria una mejora de los datos disponibles, ya sea incorporando otras preguntas o experimentos. 


\section{Referencias}

Alesina, A. Angeletos, G. 2005. Corruption, Inequality and Fairness. Journal of Monetary Economics 52: 1227-44.

Alesina, A. Angeletos, G. 2005. Fairness and Redistribution: US vs. Europe. American Economic Review 95, 913-35

Alesina, A. Giuliano, P. 2009. Preferences for Redistribution, No 14825, NBER Working Papers, National Bureau of Economic Research, Inc

Alesina, A. La Ferrara, E. 2002. Who Trusts Others?, Journal of Public Economics, Journal of Public Economics 85, 207-34

Alesina, A., Stantcheva, S. Teso, E. 2018. Intergenerational Mobility and Support for Redistribution. American Economic Review [also NBER Working Paper 23027] 108 (2): 521-554.

Benabou, R. Ok, E. 2001. Social Mobility and the Demand for Redistribution: The Poum Hypothesis, The Quarterly Journal of Economics, Oxford University Press, vol. 116(2), 447-487

Burdín G., De Rosa M., Vigorito A. y Vilá J. 2019. Was falling inequality in all Latin American countries a data-driven illusion? Income distribution and mobility patterns in Uruguay 2009-2016. Serie Documentos de Trabajo, DT 30/2019. Instituto de Economía, Facultad de Ciencias Económicas y Administración, Universidad de la República, Uruguay.

Cameron, A. Trivedi, P. 2005. Microeconometrics: Methods and Applications. Cambridge University Press, New York.

Cecchini, S. Madariaga, A. 2011. Conditional cash transfer programmes: the recent experience in Latin America and the Caribbean, Naciones Unidas Comisión Económica para América Latina y el Caribe (CEPAL)

Checchi, D. Filippin, A. 2004. An Experimental Study of the POUM Hypothesis, en Frank Cowell (ed.) Inequality, Welfare and Income Distribution: Experimental Approaches (Research on Economic Inequality, Volume 11) Emerald Group Publishing Limited, 115-136

Cojocaru, A. 2014. Prospects of upward mobility and preferences for redistribution: Evidence from the Life in Transition Survey, European Journal of Political Economy, 34, (C), 300-314

Conconi, A., Cruces, G., Olivieri, S. Sanchez, R. 2007. E pur si muove? Movilidad, Pobreza y Desigualdad en América Latina, CEDLAS, Working Papers, CEDLAS, Universidad Nacional de La Plata

Corneo, G. Gruner, H. 2002. Individual preferences for political redistribution, Journal of Public Economics, 83, (1), 83-107

Cruces, G., Gasparini, L. Tornarolli, L. 2016. Chronicle of a deceleration foretold: income inequality in Latin America in the 2010s. Revista de Economía Mundial 43, 25-46 (ISSN 15760162)

Dalton, R.J. 2006. Citizen politics: Public opinion and political parties in advanced industrial democracies. Washington, DC: Congressional Quarterly Press. 
Daude, C. Melguizo, A. 2010. Taxation and More Representation?: On Fiscal Policy, Social Mobility and Democracy in Latin America, OECD Development Centre Working Papers, No. 294, OECD Publishing, Paris

Daude, C. Robano, V. 2015. On intergenerational (im)mobility in Latin America. Latin American Economic Review, volumen 24, número 1

Engelhardt, C. Wagener, A. 2014. Biased Perceptions of Income Inequality and Redistribution, Hannover Economic Papers (HEP), Leibniz Universität Hannover, Wirtschaftswissenschaftliche Fakultät

Ferreira, F., Messina, J., Rigolini, J., López-Calva, L., Lugo, M. Vakis, R.. 2013. La movilidad económica y el crecimiento de la clase media en América Latina. Washington, DC: Banco Mundial.

Gaviria, A. 2007. Movilidad Social y Preferencias por Redistribución en América Latina, Documentos CEDE 003261, Universidad De Los Andes-CEDE.

Goda, T. Sánchez, A. 2018. Corruption and the 'Paradox of Redistribution'. Social Indicators Research: An International and Interdisciplinary Journal for Quality-of-Life Measurement, Springer, vol. 140(2), pages 675-693, November.

Hauk, E., Oviedo, M., and Ramos, X. 2017. Perception of Corruption and Public Support for. Redistribution in Latin America. IZA Discussion Paper No. 10854.

Hirschman, A. Rothschild, M. 1973. The Changing Tolerance for Income Inequality in the Course of Economic Development With A Mathematical Appendix, The Quarterly Journal of Economics, 87, (4), 544-566

Jantti, M. Jenkins, S. 2015. Income Mobility, en AB Atkinson and F. Bourguignon (eds), Handbook of Income Distribution, Volume 2A, North-Holland Elsevier, 2015, Chapter 10, $807-935$

Kahneman, D., Siovic, P. Tversky, A. 1982. Judgment under uncertainty: Heuristics and biases, Cambridge University Press, Nueva York.

Lee, S. 2016. Hopeless Future and the Desire for Welfare Expansion: Testing the Prospect of Upward Mobility Hypothesis in South Korea, The Social Science Journal

Lee, W. , Roemer, J. 2005. Values and politics in the U.S.: An equilibrium analysis of the 2004 election (Working Paper 2005-08). University of Massachusetts, Amherst, Department of Economics.

Melo, E., Porras, H. Sarango, J. 2016. Percepción de justicia en la distribución del ingreso con el socialismo del siglo XXI. Revista de análisis estadístico Analitika, Vol. 11.

Meltzer, A. Richard, S. 1981. A Rational Theory of the Size of Government, Journal of Political Economy, 89, (5), 914-27

Newell, A., Simon, H. A. (1972). Human problem solving. Prentice-Hall.

Pfarr, C. 2012. Meltzer-Richard and Social Mobility Hypothesis: Revisiting the IncomeRedistribution Nexus Using German Choice Data, MPRA Paper 43325, University Library of 
Munich, Germany

Piketty, T. 1995. Social Mobility and Redistributive Politics, The Quarterly Journal of Economics, Volume 110, Issue 3, 551-584

Rainer, H. Siedler, T. 2008. Subjective income and employment expectations and preferences for redistribution, Economics Letters, 99, (3), 449-453

Ravallion, M. Lokshin, M. 2000. Who wants to redistribute?: The tunnel effect in 1990s Russia, Journal of Public Economics, 76, (1), 87-104

Roemer, J. Trannoy, A. 2016. Equality of Opportunity: Theory and Measurement. Journal of Economic Literature, 54 (4): 1288-1332.

Scheve, K. Stasavage, D. 2006. Religion and Preferences for Social Insurance. Quarterly Journal of Political Science: Vol. 1: No. 3, pp 255-286.

Silva, C. Figueiredo, E. 2013. Social mobility and the demand for income redistribution in Latin America, Revista CEPAL, Naciones Unidas Comisión Económica para América Latina y el Caribe (CEPAL), Agosto.

Solimano, Andrés. 2016. Is inequality really declining in Latin America? Evidence on income, wealth and the social structure. Revista de Economía Mundial. 2016, (43), 69-91. 


\section{Anexo}

Aquí se presenta el modelo econométrico para probar el cumplimiento de la hipótesis POUM para cada país considerado individualmente. Como podemos observar, el resultado obtenido para América Latina en su conjunto no necesariamente se cumple a nivel de países. De los 18 países considerados, se observa que las perspectivas de movilidad inciden negativamente en las preferencias por la redistribución salvo en el caso de Venezuela, para la cual existe evidencia estadísticamente significativa de que las perspectivas de movilidad operan en sentido contrario al postulado por la hipótesis. En los casos de Bolivia, Colombia, Guatemala, Honduras, Paraguay y Uruguay, las variables asociadas a las perspectivas de movilidad no resultan significativas. Sin embargo, en todos los casos sí se observa el resultado esperado en el modelo alternativo que toma como variable dependiente la percepción de justicia en la distribución del ingreso. 
Estimaciones Probit-Adaptadas MCO (POLS) - Argentina

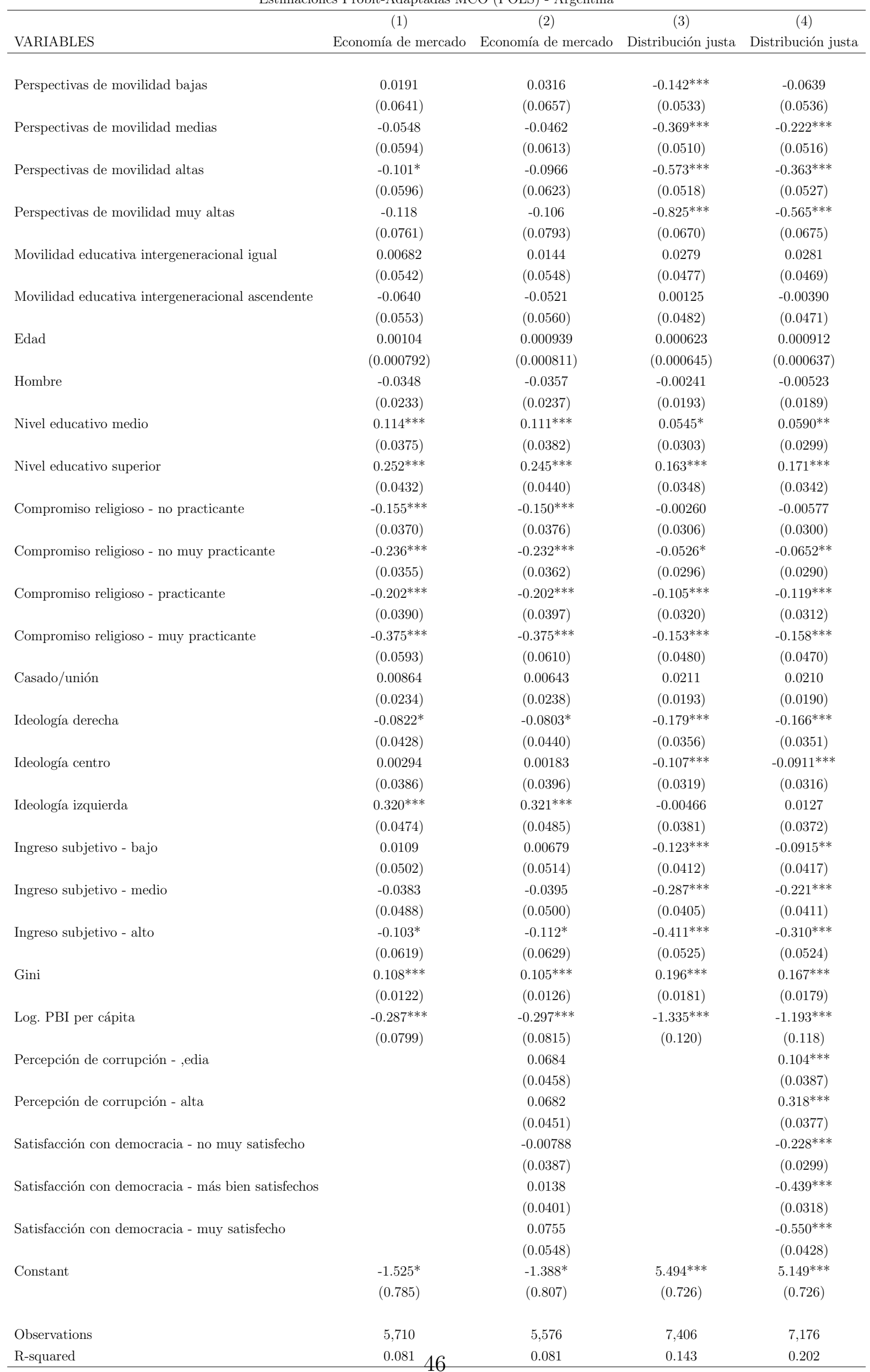


Estimaciones Probit-Adaptadas MCO (POLS) - Bolivia

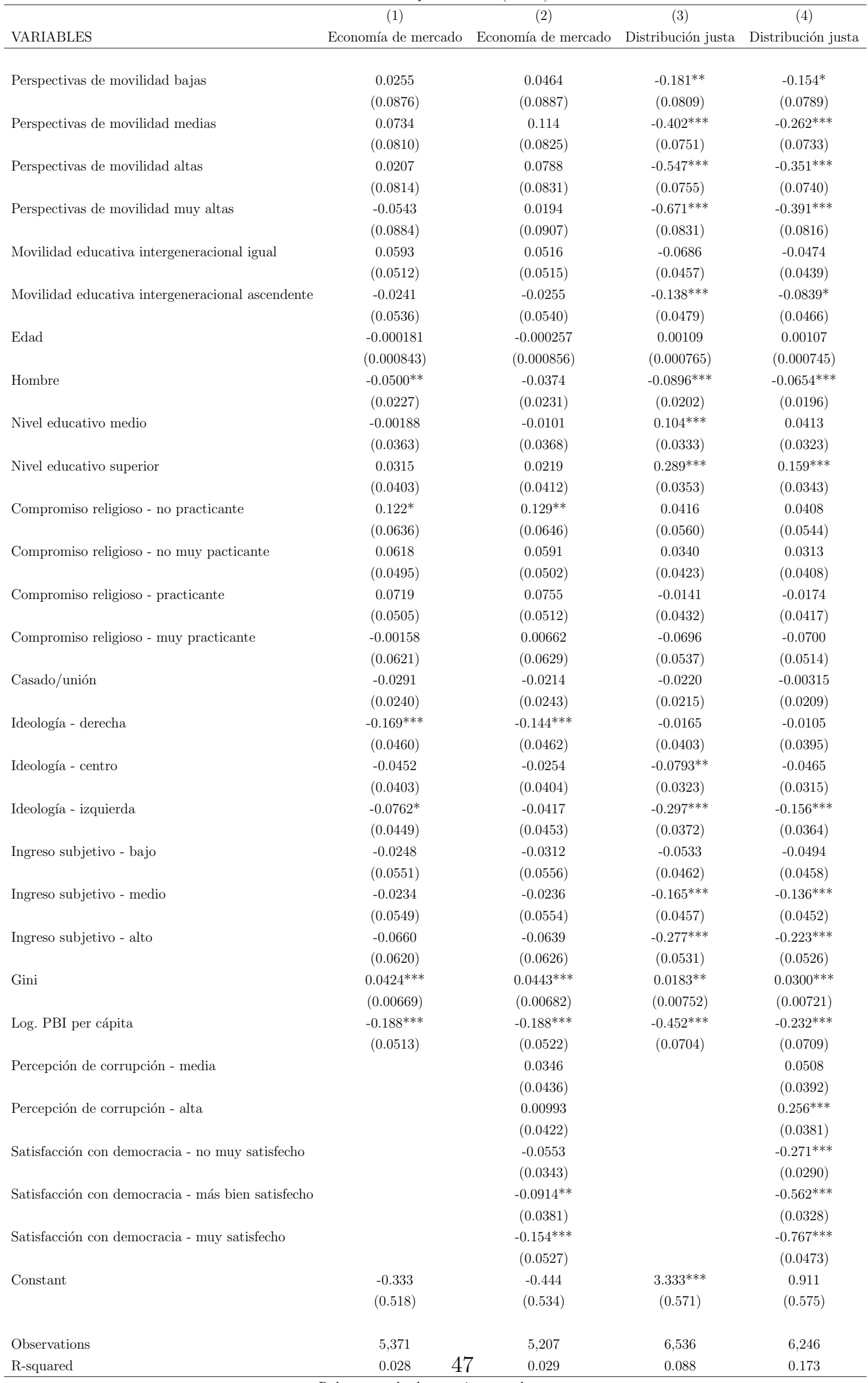


Estimaciones Probit-Adaptadas MCO (POLS) - Brasil

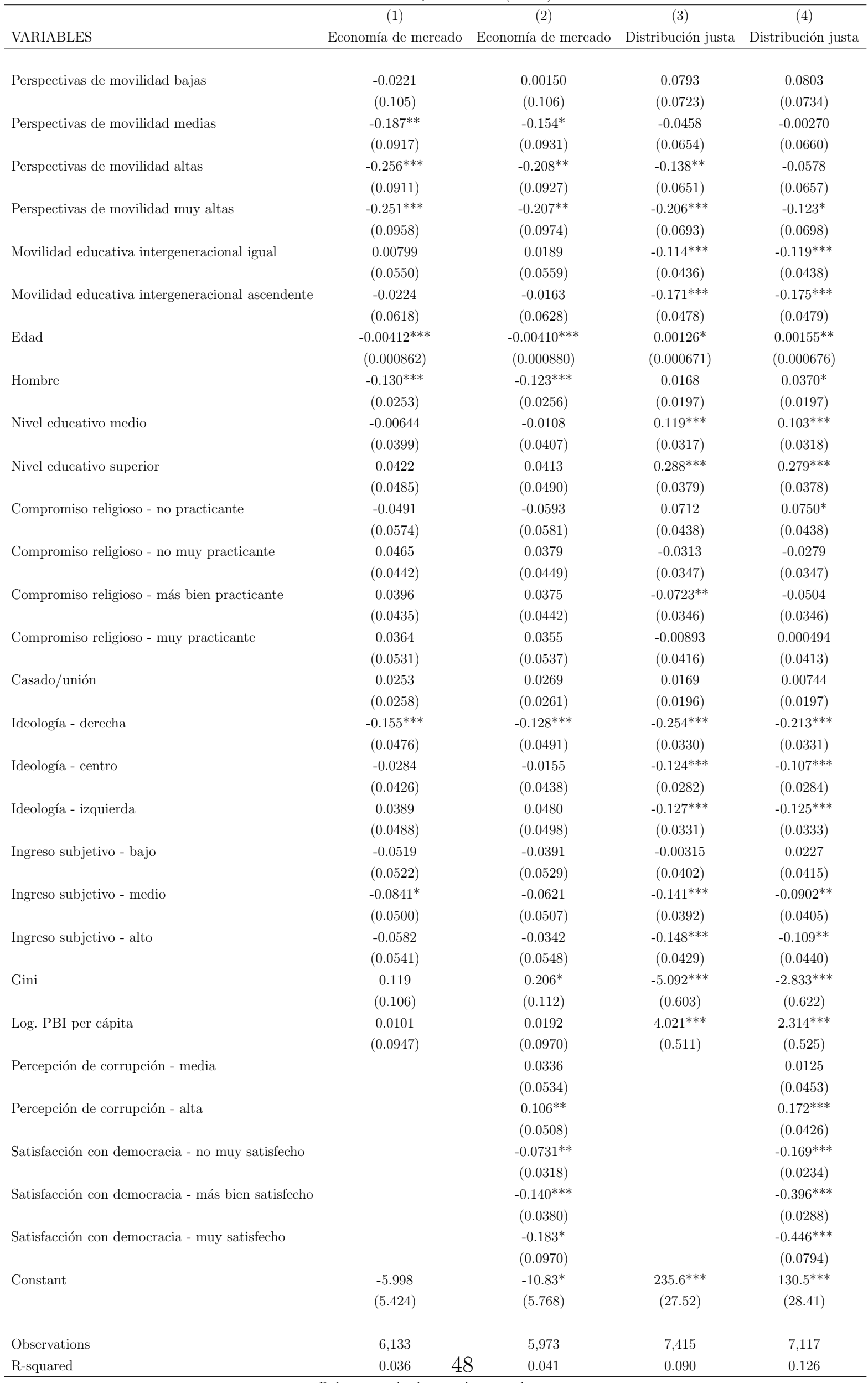


Estimaciones Probit-Adaptadas MCO (POLS) - Chile

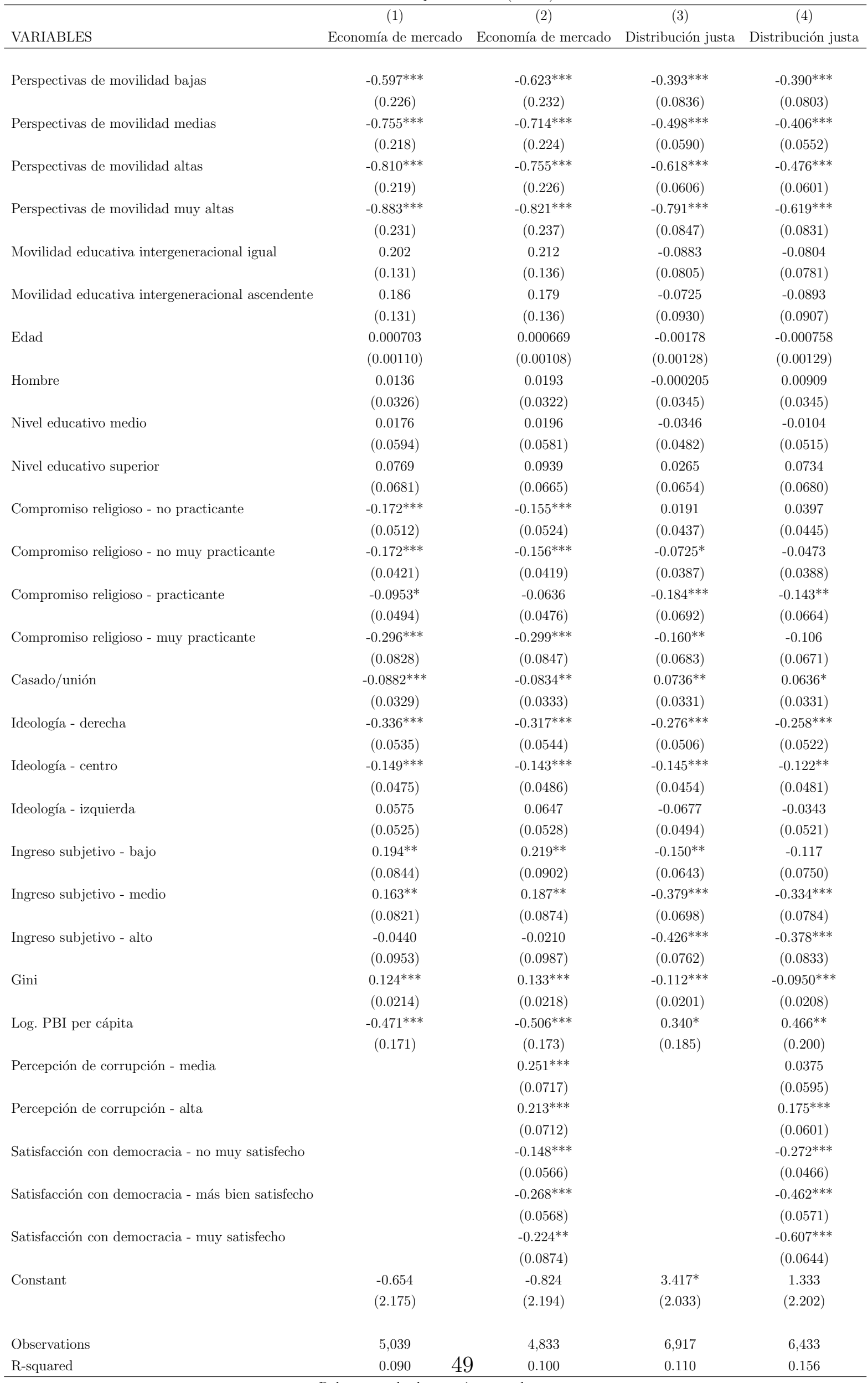


Estimaciones Probit-Adaptadas MCO (POLS) - Colombia

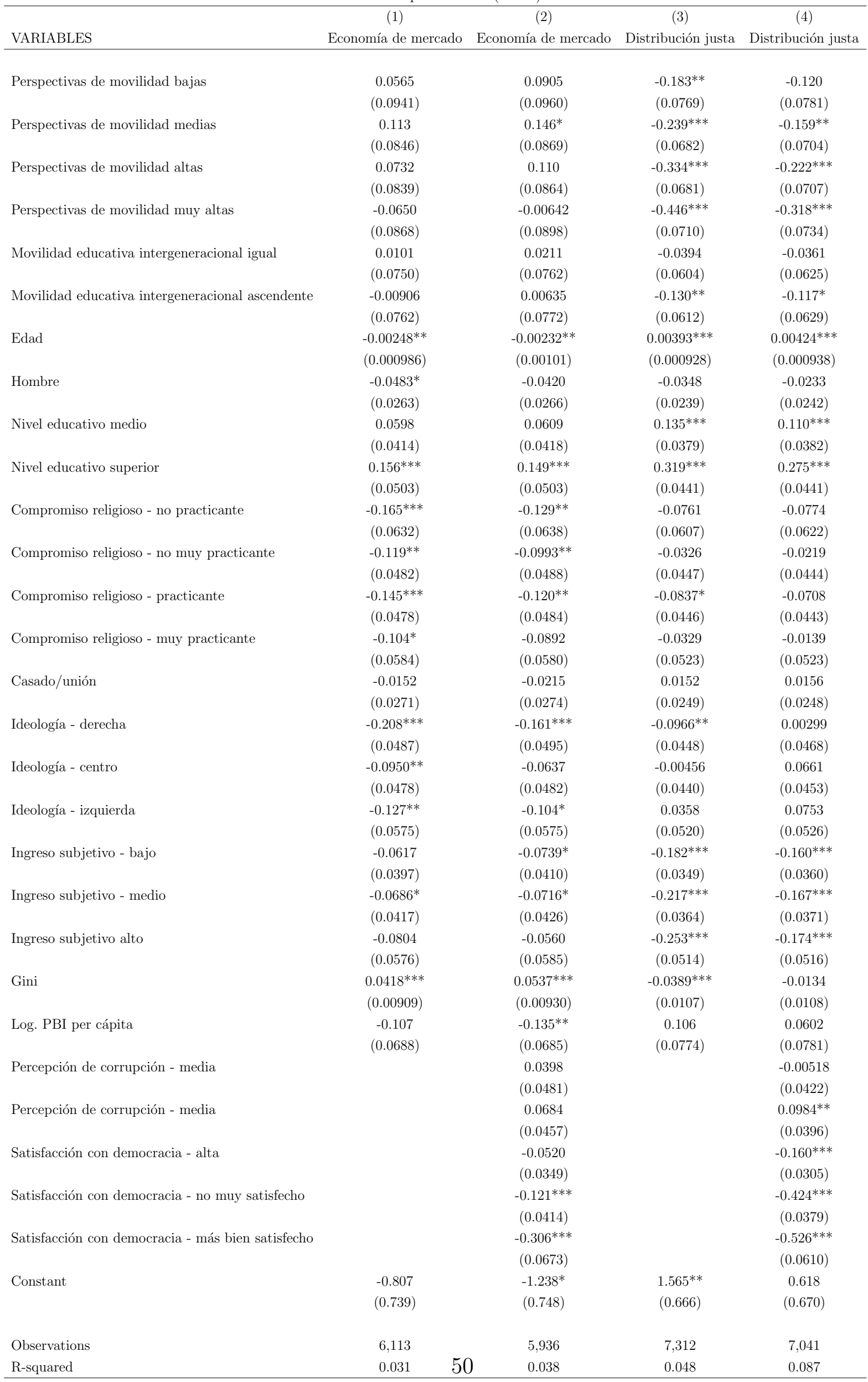


Estimaciones Probit-Adaptadas MCO (POLS) - Costa Rica

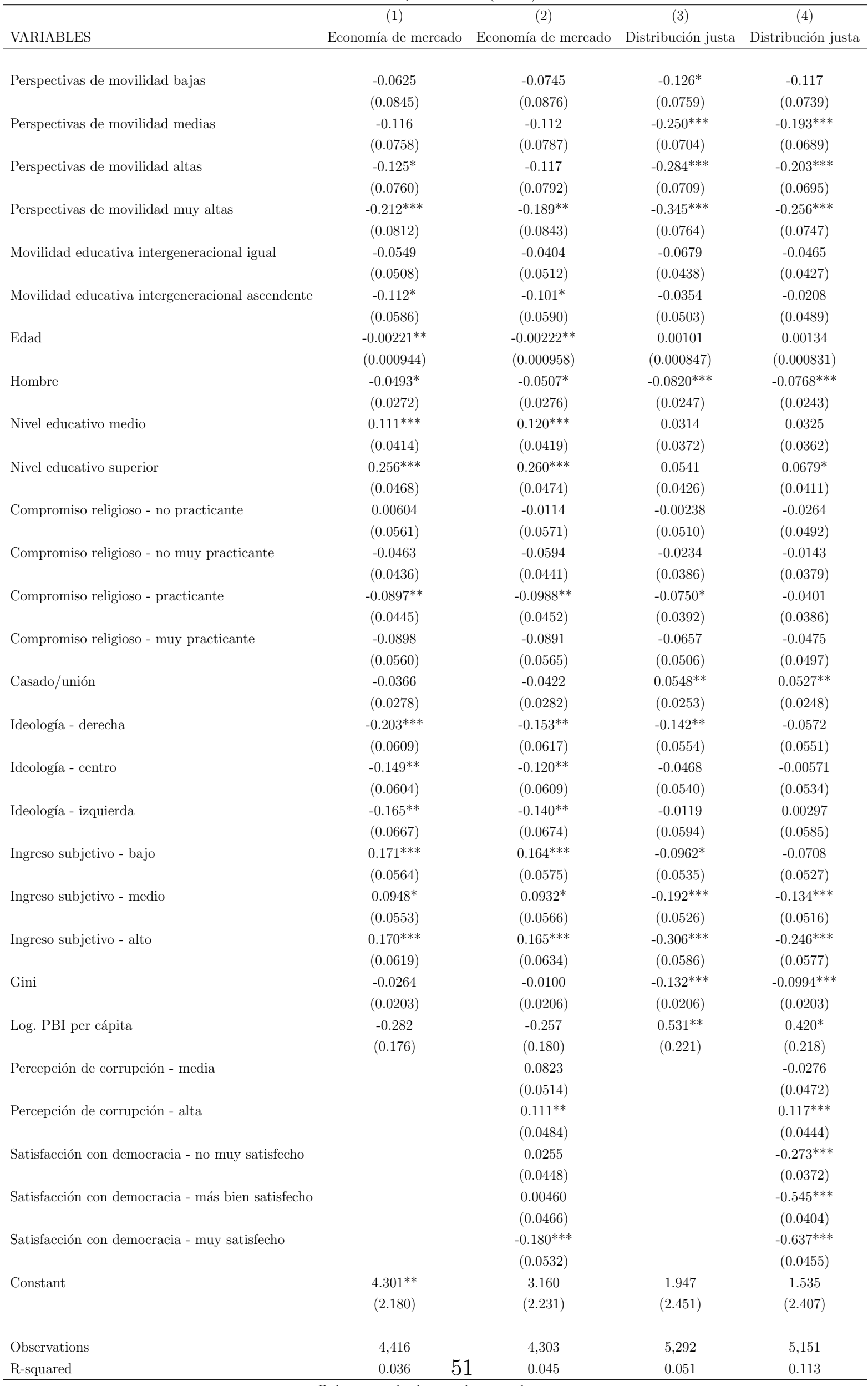


Estimaciones Probit-Adaptadas MCO (POLS) - Rep. Dominicana

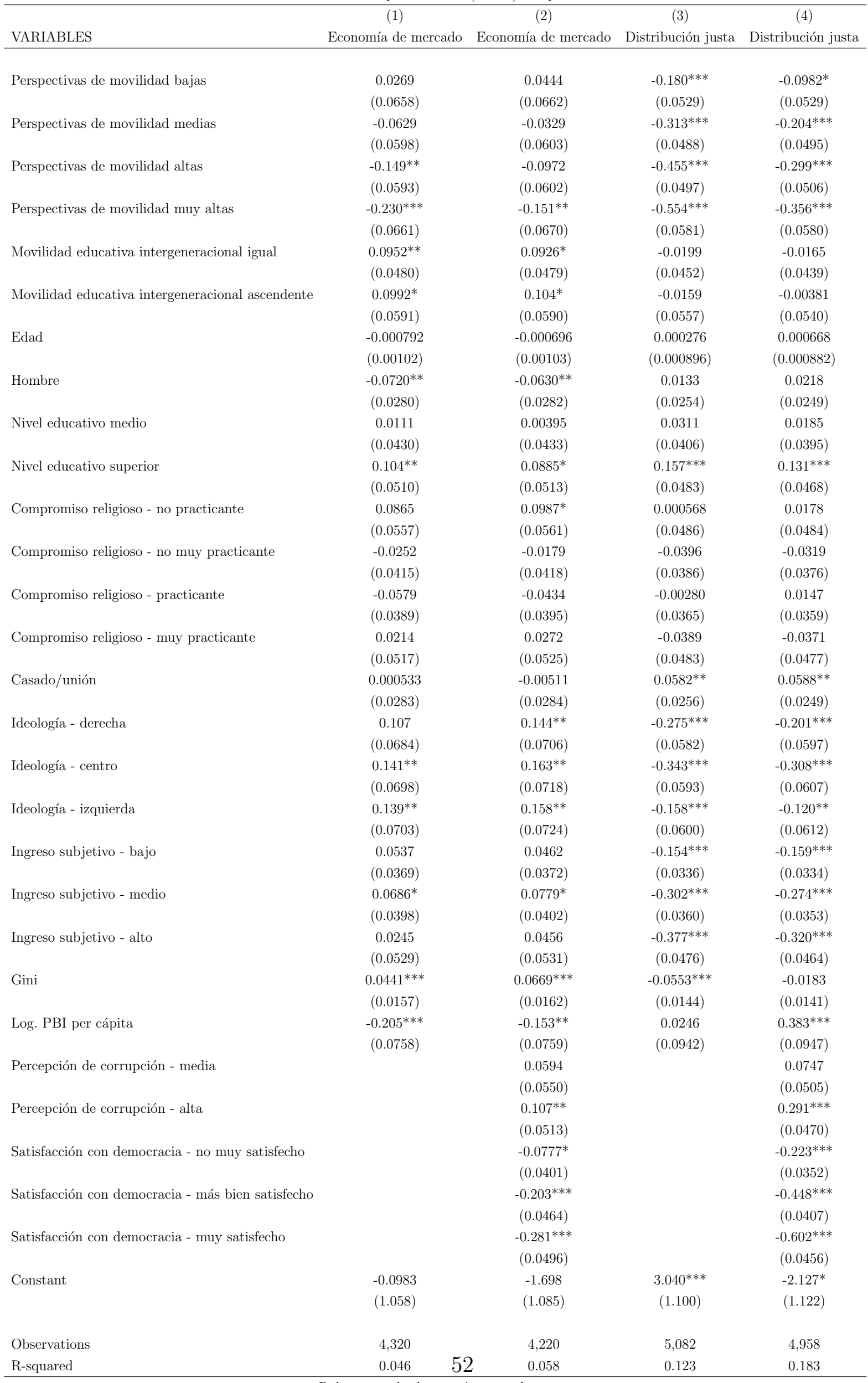


Estimaciones Probit-Adaptadas MCO (POLS) - Ecuador

\begin{tabular}{|c|c|c|c|c|}
\hline & $(1)$ & $(2)$ & $(3)$ & $(4)$ \\
\hline VARIABLES & Economía de mercado & Economía de mercado & Distribución justa & Distribución justa \\
\hline \multirow[t]{2}{*}{ Perspectivas de movilidad bajas } & $-0.180^{*}$ & -0.161 & $-0.303^{* * *}$ & $-0.189^{* *}$ \\
\hline & $(0.1000)$ & $(0.101)$ & $(0.0720)$ & $(0.0739)$ \\
\hline \multirow[t]{2}{*}{ Perspectivas de movilidad medias } & $-0.304^{* * *}$ & $-0.266^{* * *}$ & $-0.664^{* * *}$ & $-0.466^{* * *}$ \\
\hline & $(0.0955)$ & $(0.0972)$ & $(0.0692)$ & $(0.0718)$ \\
\hline \multirow[t]{2}{*}{ Perspectivas de movilidad altas } & $-0.409^{* * *}$ & $-0.368^{* * *}$ & $-0.876^{* * *}$ & $-0.598^{* * *}$ \\
\hline & $(0.0963)$ & $(0.0985)$ & $(0.0701)$ & $(0.0731)$ \\
\hline \multirow[t]{2}{*}{ Perspectivas de movilidad muy altas } & $-0.520^{* * *}$ & $-0.472^{* * *}$ & $-1.072^{* * *}$ & $-0.739^{* * *}$ \\
\hline & $(0.105)$ & $(0.107)$ & $(0.0773)$ & $(0.0796)$ \\
\hline \multirow[t]{2}{*}{ Movilidad educativa intergeneracional igual } & $0.123^{*}$ & $0.122^{*}$ & $-0.0947^{*}$ & -0.0830 \\
\hline & $(0.0680)$ & $(0.0691)$ & $(0.0543)$ & $(0.0506)$ \\
\hline \multirow[t]{2}{*}{ Movilidad educativa intergeneracional ascendente } & $0.217^{* * *}$ & $0.215^{* * *}$ & $-0.113^{* *}$ & $-0.0969^{*}$ \\
\hline & $(0.0716)$ & $(0.0725)$ & $(0.0559)$ & $(0.0518)$ \\
\hline \multirow[t]{2}{*}{ Edad } & -0.00118 & -0.00130 & 0.000183 & $5.90 \mathrm{e}-05$ \\
\hline & $(0.000900)$ & $(0.000910)$ & $(0.000688)$ & $(0.000664)$ \\
\hline \multirow[t]{2}{*}{ Hombre } & -0.0280 & -0.0282 & -0.0204 & -0.0177 \\
\hline & $(0.0252)$ & $(0.0253)$ & $(0.0197)$ & $(0.0190)$ \\
\hline \multirow[t]{2}{*}{ Nivel educativo medio } & $-0.175^{* * *}$ & $-0.187^{* * *}$ & -0.0264 & -0.0348 \\
\hline & $(0.0415)$ & $(0.0418)$ & $(0.0323)$ & $(0.0314)$ \\
\hline \multirow[t]{2}{*}{ Nivel educativo superior } & $-0.201^{* * *}$ & $-0.213^{* * *}$ & 0.0508 & 0.0351 \\
\hline & $(0.0466)$ & $(0.0468)$ & $(0.0359)$ & $(0.0346)$ \\
\hline \multirow[t]{2}{*}{ Compromiso religioso - no practicante } & $-0.197^{* * *}$ & $-0.238^{* * *}$ & -0.0394 & -0.0687 \\
\hline & $(0.0694)$ & $(0.0700)$ & $(0.0553)$ & $(0.0534)$ \\
\hline \multirow[t]{2}{*}{ Compromiso religioso - no muy practicante } & -0.0749 & -0.0887 & $-0.0788^{*}$ & -0.0642 \\
\hline & $(0.0568)$ & $(0.0573)$ & $(0.0440)$ & $(0.0427)$ \\
\hline \multirow[t]{2}{*}{ Compromiso religioso - practicante } & $-0.127^{* *}$ & $-0.146^{* *}$ & $-0.128^{* * *}$ & $-0.103^{* *}$ \\
\hline & $(0.0566)$ & $(0.0571)$ & $(0.0440)$ & $(0.0427)$ \\
\hline \multirow[t]{2}{*}{ Compromiso religioso - muy practicante } & -0.0698 & -0.0848 & $-0.130 * *$ & $-0.127^{* *}$ \\
\hline & $(0.0679)$ & $(0.0684)$ & $(0.0519)$ & $(0.0501)$ \\
\hline \multirow[t]{2}{*}{ Casado/unión } & -0.0374 & -0.0366 & -0.0131 & -0.000197 \\
\hline & $(0.0263)$ & $(0.0265)$ & $(0.0204)$ & $(0.0197)$ \\
\hline \multirow[t]{2}{*}{ Ideología - derecha } & -0.0132 & -0.0163 & $-0.129^{* * *}$ & $-0.0937^{* *}$ \\
\hline & $(0.0486)$ & $(0.0494)$ & $(0.0372)$ & $(0.0366)$ \\
\hline Ideología - centro & $0.144^{* * *}$ & $0.140^{* * *}$ & $-0.117^{* * *}$ & $-0.0940 * * *$ \\
\hline & $(0.0420)$ & $(0.0428)$ & $(0.0312)$ & $(0.0306)$ \\
\hline Ideología - izquierda & $0.155^{* * *}$ & $0.159^{* * *}$ & $-0.172^{* * *}$ & $-0.111^{* * *}$ \\
\hline & $(0.0511)$ & $(0.0518)$ & $(0.0367)$ & $(0.0357)$ \\
\hline Ingreso subjetivo - bajo & 0.0299 & 0.0223 & $-0.185^{* * *}$ & $-0.163^{* * *}$ \\
\hline & $(0.0477)$ & $(0.0485)$ & $(0.0404)$ & $(0.0392)$ \\
\hline Ingreso subjetivo - medio & 0.0273 & 0.0213 & $-0.260^{* * *}$ & $-0.193^{* * *}$ \\
\hline & $(0.0477)$ & $(0.0485)$ & $(0.0406)$ & $(0.0394)$ \\
\hline Ingreso subjetivo - alto & 0.00146 & 0.0124 & $-0.351 * * *$ & $-0.260^{* * *}$ \\
\hline & $(0.0631)$ & $(0.0640)$ & $(0.0525)$ & $(0.0505)$ \\
\hline Gini & $0.158^{* * *}$ & $0.154^{* * *}$ & $0.0558^{* * *}$ & $0.0361^{* * *}$ \\
\hline & $(0.0117)$ & $(0.0119)$ & $(0.0108)$ & $(0.0104)$ \\
\hline Log. PBI per cápita & $-0.664^{* * *}$ & $-0.623^{* * *}$ & $-0.675^{* * *}$ & $-0.411^{* * *}$ \\
\hline & $(0.0857)$ & $(0.0866)$ & $(0.0755)$ & $(0.0744)$ \\
\hline Percepción de corrupción - media & & 0.00626 & & $0.0691^{* *}$ \\
\hline & & $(0.0452)$ & & $(0.0322)$ \\
\hline Percepción de corrupción - alta & & 0.00306 & & $0.318^{* * *}$ \\
\hline & & $(0.0450)$ & & $(0.0329)$ \\
\hline Satisfacción con democracia - no muy satisfecho & & -0.0465 & & $-0.263^{* * *}$ \\
\hline & & $(0.0507)$ & & $(0.0382)$ \\
\hline Satisfacción con democracia - más bien satisfecho & & $-0.0883^{*}$ & & $-0.564^{* * *}$ \\
\hline & & $(0.0518)$ & & $(0.0400)$ \\
\hline Satisfacción con democracia - muy satisfecho & & $-0.177^{* * *}$ & & $-0.687^{* * *}$ \\
\hline & & $(0.0650)$ & & $(0.0503)$ \\
\hline Constant & -0.913 & -1.040 & $4.394^{* * *}$ & $2.788^{* * *}$ \\
\hline & $(0.859)$ & $(0.868)$ & $(0.712)$ & $(0.708)$ \\
\hline Observations & 5,986 & 5,857 & 7,133 & 6,934 \\
\hline R-squared & 0.073 & 0.074 & 0.144 & 0.221 \\
\hline
\end{tabular}


Estimaciones Probit-Adaptadas MCO (POLS) - El Salvador

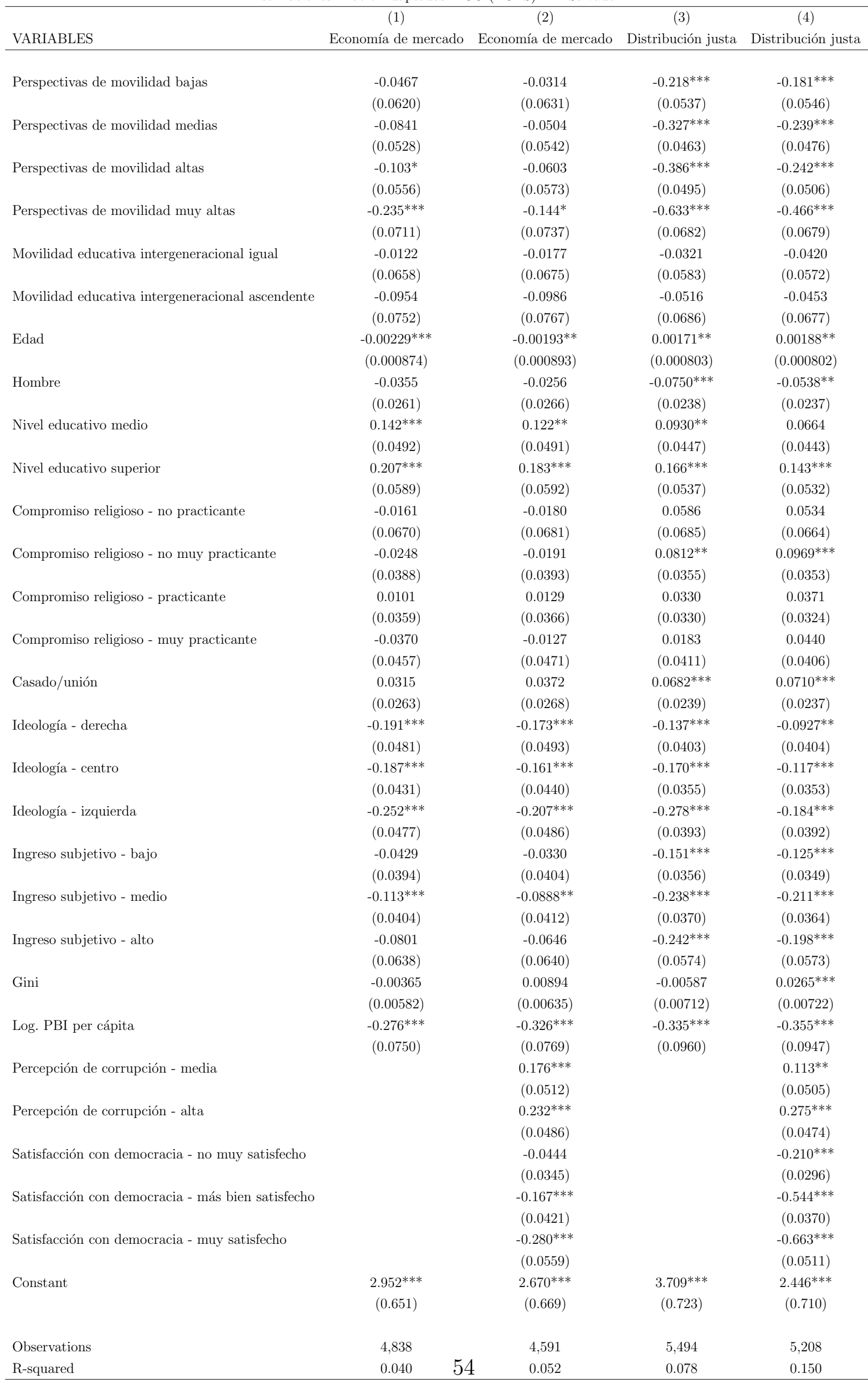


Estimaciones Probit-Adaptadas MCO (POLS) - Guatemala

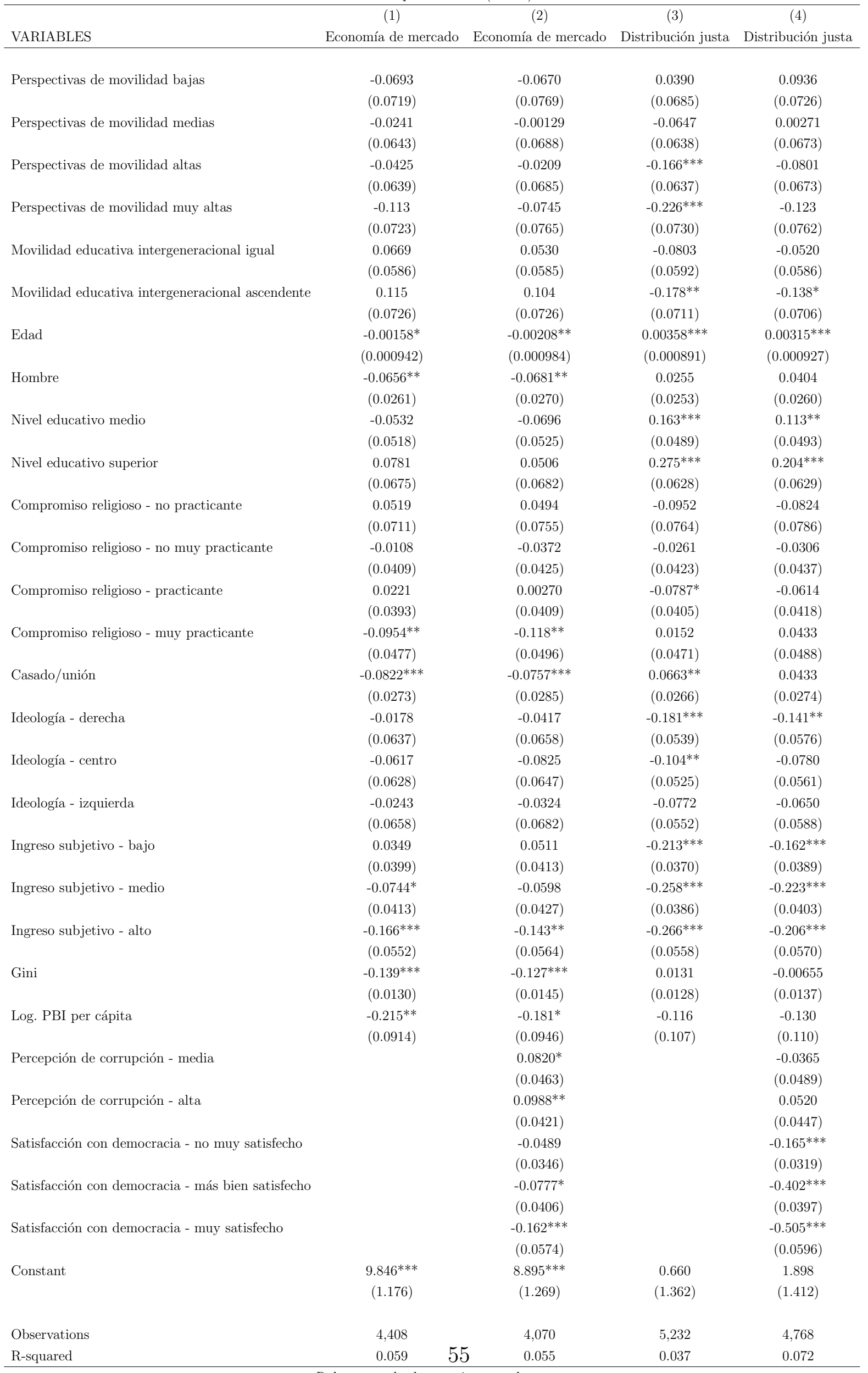


Estimaciones Probit-Adaptadas MCO (POLS) - Honduras

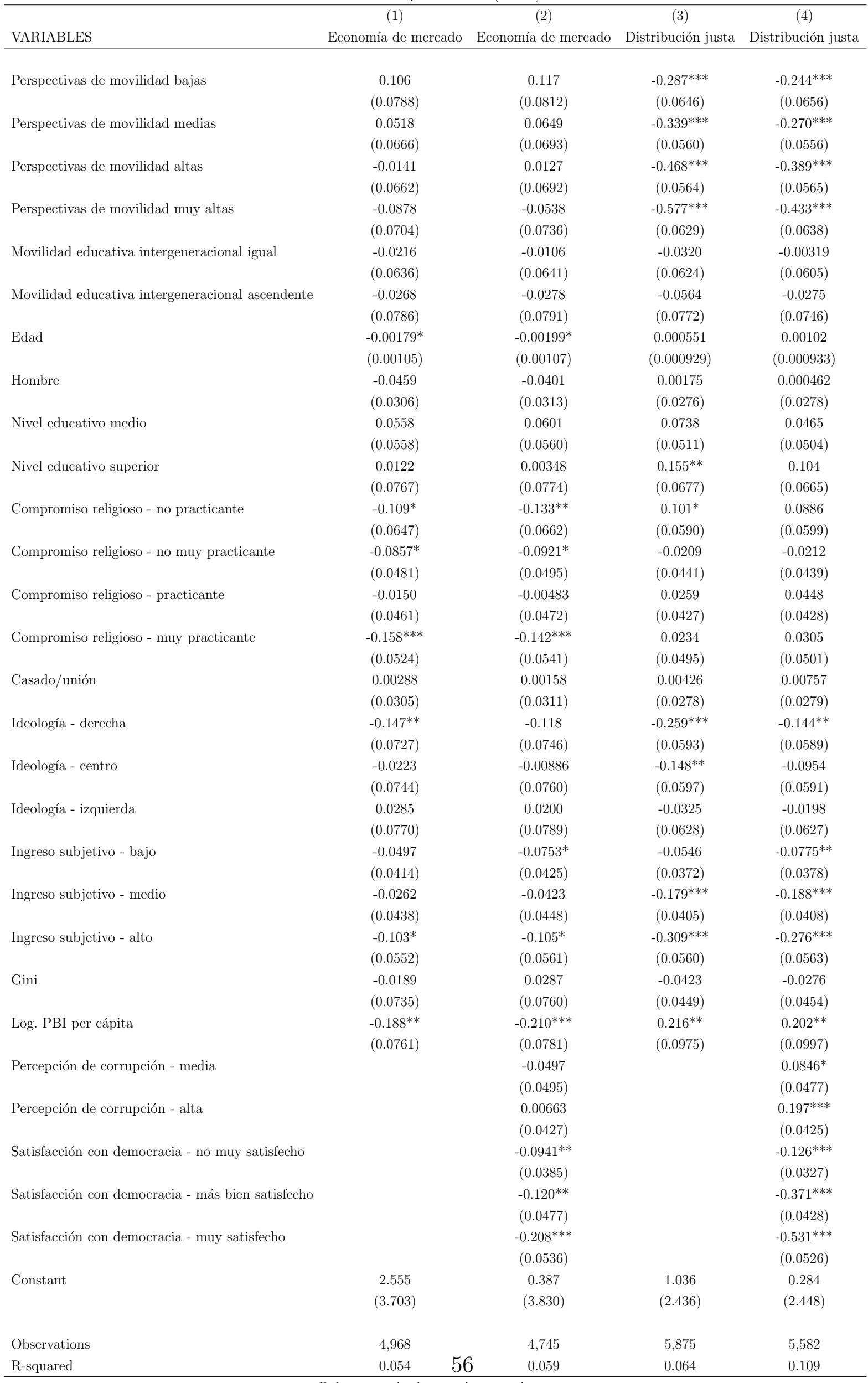


Estimaciones Probit-Adaptadas MCO (POLS) - México

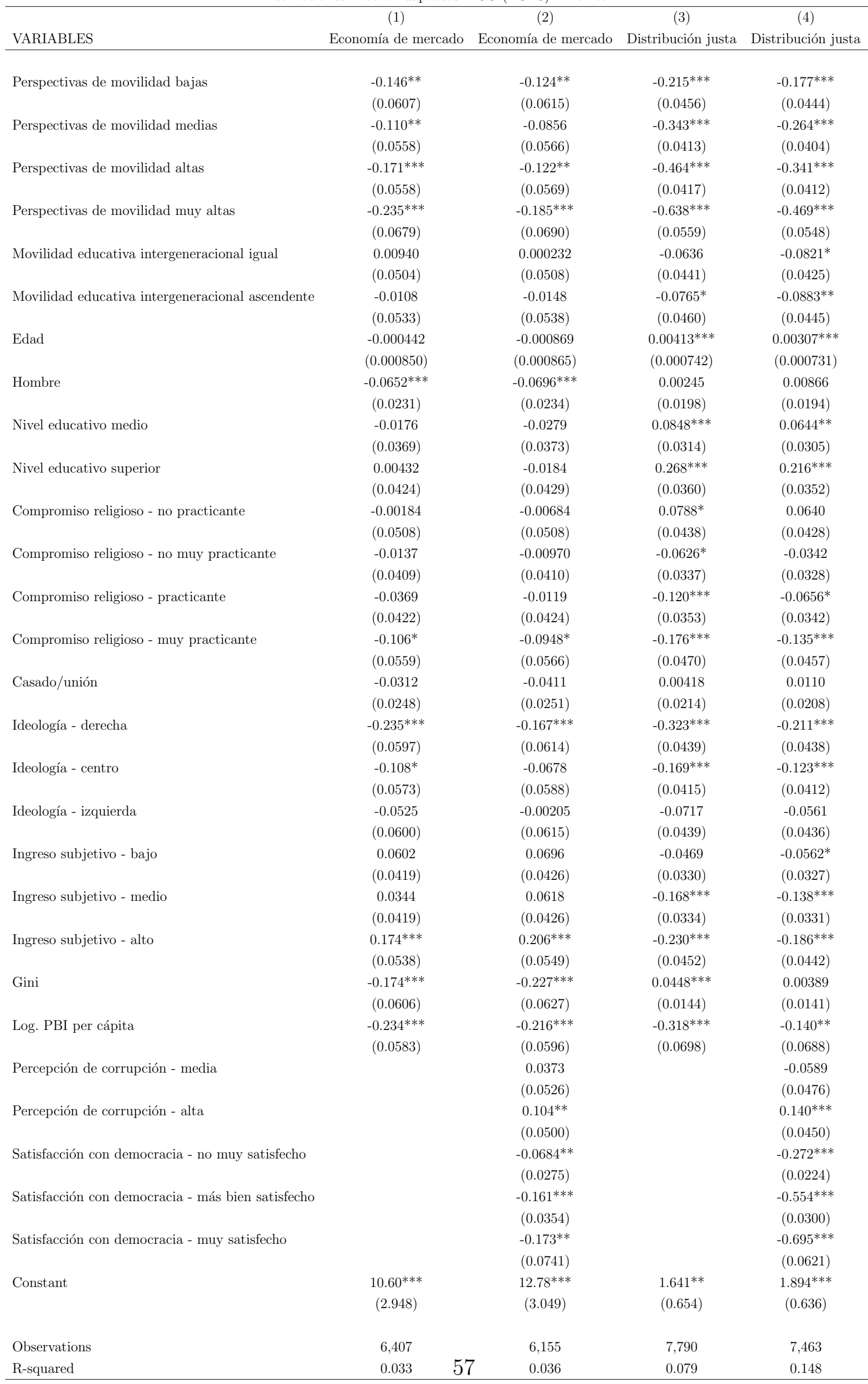


Estimaciones Probit-Adaptadas MCO (POLS) - Nicaragua

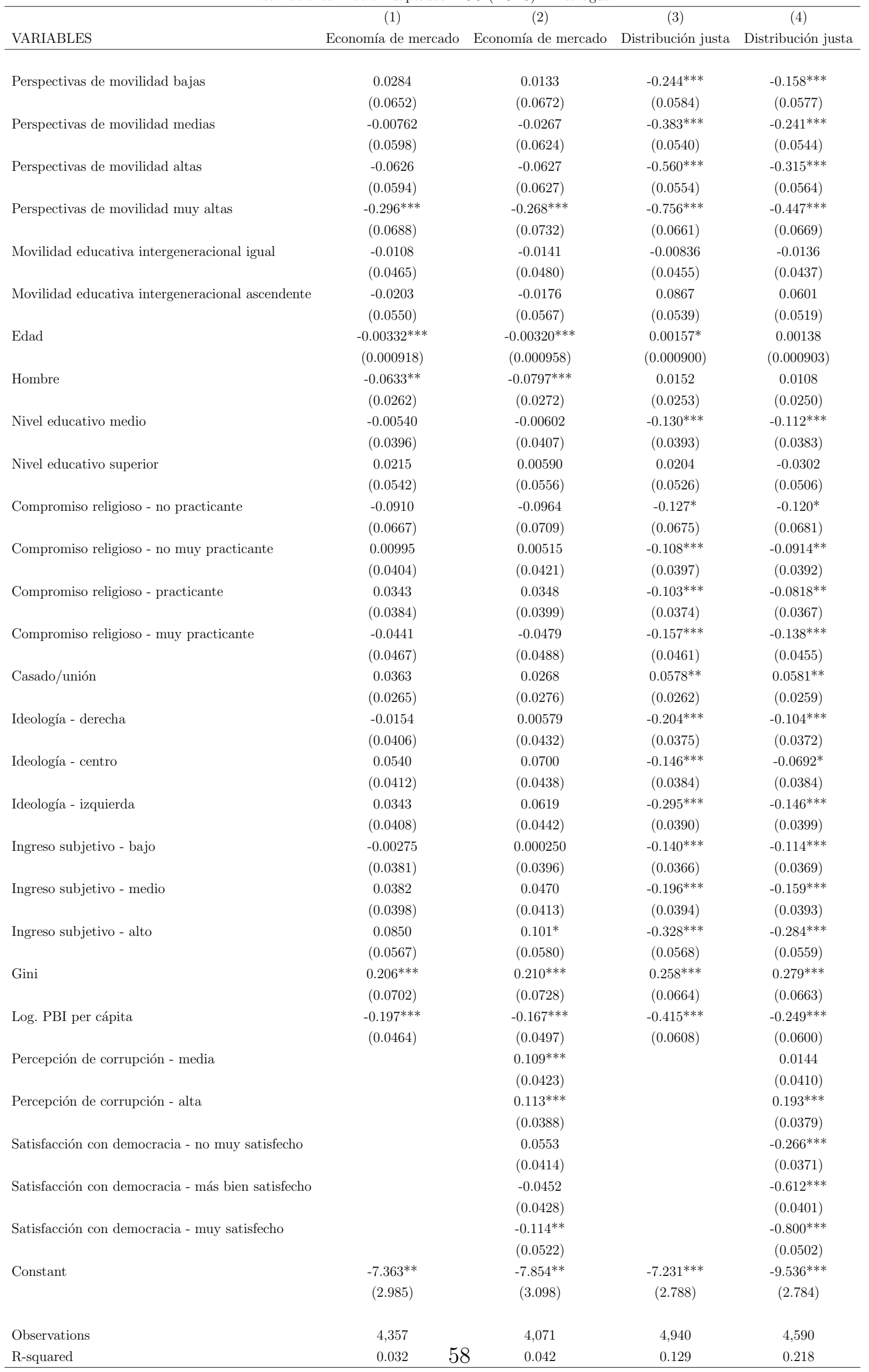


Estimaciones Probit-Adaptadas MCO (POLS) - Panamá

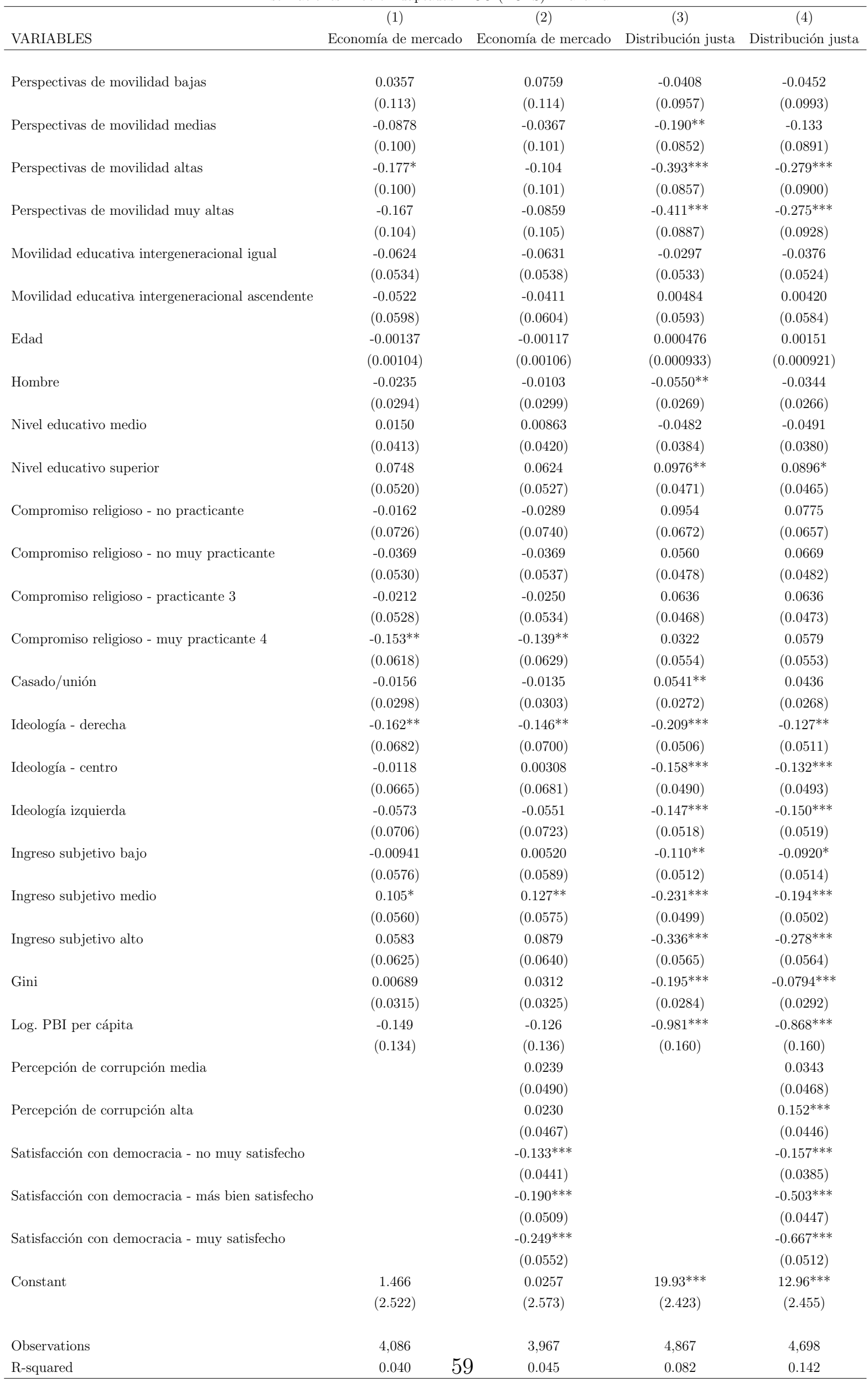


Estimaciones Probit-Adaptadas MCO (POLS) - Paraguay

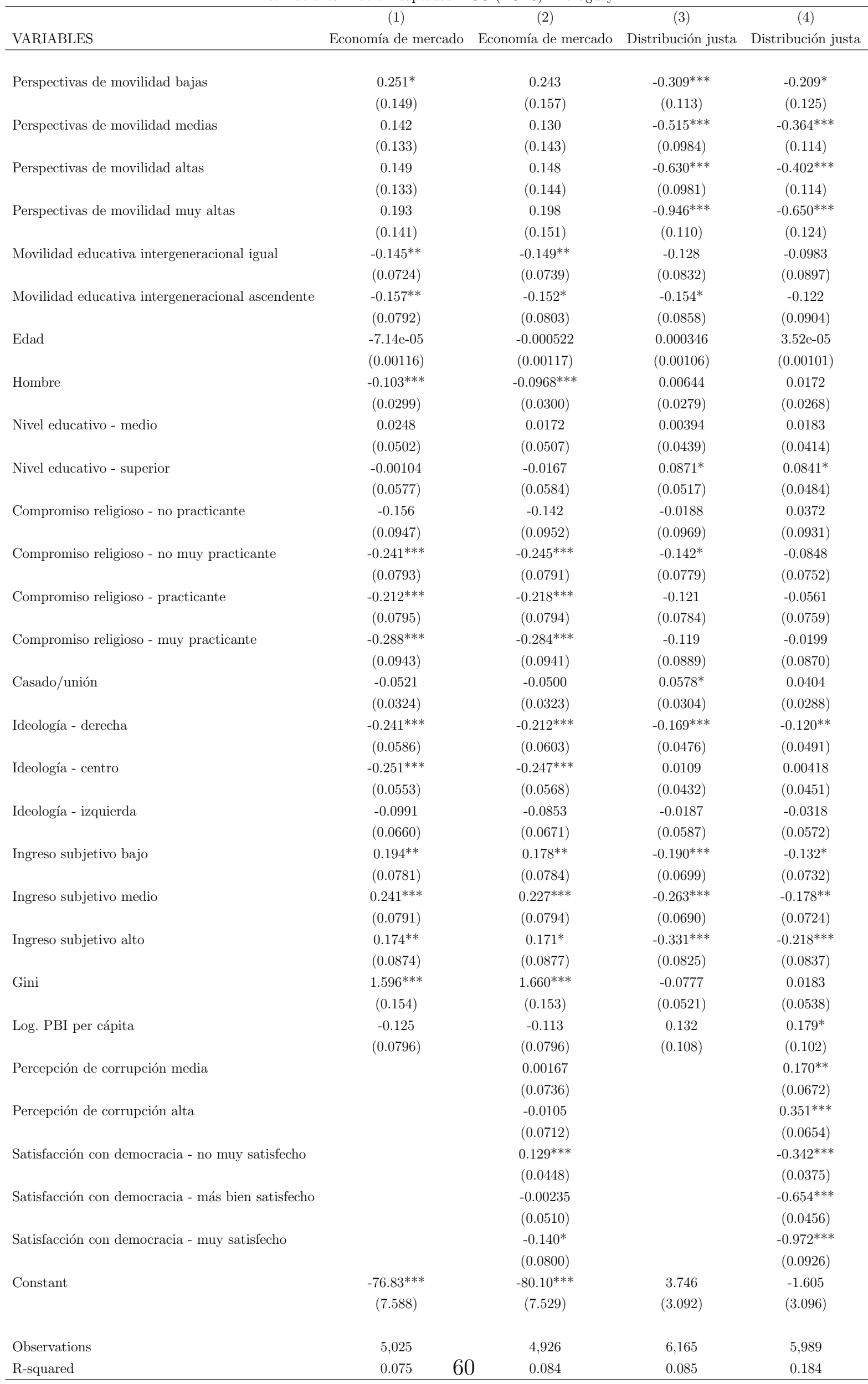


Estimaciones Probit-Adaptadas MCO (POLS) - Perú

\begin{tabular}{|c|c|c|c|c|}
\hline & (1) & $(2)$ & (3) & (4) \\
\hline VARIABLES & Economía de mercado & Economía de mercado & Distribución justa & Distribución justa \\
\hline \multirow[t]{2}{*}{ Perspectivas de movilidad bajas } & $-0.196^{*}$ & $-0.180^{*}$ & $-0.224^{* * *}$ & $-0.164^{* *}$ \\
\hline & $(0.104)$ & $(0.107)$ & $(0.0772)$ & $(0.0807)$ \\
\hline \multirow[t]{2}{*}{ Perspectivas de movilidad medias } & $-0.248^{* * *}$ & $-0.219^{* *}$ & $-0.296 * * *$ & $-0.202^{* * *}$ \\
\hline & $(0.0958)$ & $(0.0986)$ & $(0.0676)$ & $(0.0716)$ \\
\hline \multirow[t]{2}{*}{ Perspectivas de movilidad altas } & $-0.313^{* * *}$ & $-0.271^{* * *}$ & $-0.373^{* * *}$ & $-0.255^{* * *}$ \\
\hline & $(0.0964)$ & $(0.0992)$ & $(0.0681)$ & $(0.0722)$ \\
\hline \multirow[t]{2}{*}{ Perspectivas de movilidad muy altas } & $-0.397^{* * *}$ & $-0.347^{* * *}$ & $-0.456^{* * *}$ & $-0.317^{* * *}$ \\
\hline & $(0.101)$ & $(0.104)$ & $(0.0732)$ & $(0.0767)$ \\
\hline \multirow[t]{2}{*}{ Movilidad educativa intergeneracional igual } & 0.0511 & 0.0390 & 0.00414 & 0.00655 \\
\hline & $(0.0460)$ & $(0.0460)$ & $(0.0442)$ & $(0.0442)$ \\
\hline \multirow[t]{2}{*}{ Movilidad educativa intergeneracional ascendente 2} & $0.104^{* *}$ & $0.0878^{*}$ & -0.0304 & -0.0182 \\
\hline & $(0.0483)$ & $(0.0483)$ & $(0.0467)$ & $(0.0466)$ \\
\hline \multirow[t]{2}{*}{ Edad } & $-0.00159^{*}$ & $-0.00145^{*}$ & $0.00405^{* * *}$ & $0.00382^{* * *}$ \\
\hline & $(0.000834)$ & $(0.000846)$ & $(0.000720)$ & $(0.000719)$ \\
\hline \multirow[t]{2}{*}{ Hombre } & -0.00848 & -0.00904 & $-0.0345^{*}$ & -0.0247 \\
\hline & $(0.0225)$ & $(0.0227)$ & $(0.0194)$ & $(0.0193)$ \\
\hline \multirow[t]{2}{*}{ Nivel educativo - medio } & $-0.0726^{* *}$ & $-0.0793^{* *}$ & $0.108^{* * *}$ & $0.0959 * * *$ \\
\hline & $(0.0354)$ & $(0.0359)$ & $(0.0311)$ & $(0.0310)$ \\
\hline \multirow[t]{2}{*}{ Nivel educativo - superior } & $-0.0956^{* *}$ & $-0.0992^{* * *}$ & $0.131^{* * *}$ & $0.109^{* * *}$ \\
\hline & $(0.0375)$ & $(0.0381)$ & $(0.0331)$ & $(0.0329)$ \\
\hline \multirow[t]{2}{*}{ Compromiso religioso - no practicante } & $-0.198^{* * *}$ & $-0.190 * * *$ & 0.0174 & 0.0228 \\
\hline & $(0.0579)$ & $(0.0580)$ & $(0.0483)$ & $(0.0477)$ \\
\hline \multirow[t]{2}{*}{ Compromiso religioso - no muy practicante } & $-0.181^{* * *}$ & $-0.171^{* * *}$ & $-0.0776^{*}$ & -0.0584 \\
\hline & $(0.0484)$ & $(0.0485)$ & $(0.0405)$ & $(0.0400)$ \\
\hline \multirow[t]{2}{*}{ Compromiso religioso - practicante } & $-0.176^{* * *}$ & $-0.159 * * *$ & $-0.137^{* * *}$ & $-0.115^{* * *}$ \\
\hline & $(0.0489)$ & $(0.0490)$ & $(0.0410)$ & $(0.0405)$ \\
\hline \multirow[t]{2}{*}{ Compromiso religioso - muy practicante } & $-0.197^{* * *}$ & $-0.197 * * *$ & -0.0659 & -0.0340 \\
\hline & $(0.0621)$ & $(0.0625)$ & $(0.0539)$ & $(0.0530)$ \\
\hline \multirow[t]{2}{*}{ Casado/unión } & -0.00563 & -0.00618 & 0.0158 & 0.00638 \\
\hline & $(0.0240)$ & $(0.0242)$ & $(0.0203)$ & $(0.0203)$ \\
\hline \multirow[t]{2}{*}{ Ideología - derecha } & $-0.131 * * *$ & $-0.119^{* *}$ & $-0.176^{* * *}$ & $-0.118^{* * *}$ \\
\hline & $(0.0477)$ & $(0.0487)$ & $(0.0374)$ & $(0.0381)$ \\
\hline Ideología - centro & 0.0115 & 0.0107 & $-0.135^{* * *}$ & $-0.0987^{* * *}$ \\
\hline & $(0.0438)$ & $(0.0446)$ & $(0.0330)$ & $(0.0336)$ \\
\hline Ideología izquierda & 0.0118 & 0.00866 & $-0.134^{* * *}$ & $-0.0962^{* *}$ \\
\hline & $(0.0490)$ & $(0.0500)$ & $(0.0386)$ & $(0.0391)$ \\
\hline Ingreso subjetivo bajo & -0.0445 & -0.0445 & $-0.147^{* * *}$ & $-0.124^{* * *}$ \\
\hline & $(0.0477)$ & $(0.0485)$ & $(0.0371)$ & $(0.0377)$ \\
\hline Ingreso subjetivo medio & -0.0657 & -0.0640 & $-0.225^{* * *}$ & $-0.185^{* * *}$ \\
\hline & $(0.0479)$ & $(0.0487)$ & $(0.0379)$ & $(0.0383)$ \\
\hline Ingreso subjetivo alto & -0.0597 & -0.0520 & $-0.327^{* * *}$ & $-0.269^{* * *}$ \\
\hline & $(0.0560)$ & $(0.0569)$ & $(0.0463)$ & $(0.0463)$ \\
\hline Gini & $0.0754^{* * *}$ & $0.0847^{* * *}$ & -0.0117 & 0.00429 \\
\hline & $(0.00993)$ & $(0.0101)$ & $(0.00911)$ & $(0.00922)$ \\
\hline Log. PBI per cápita & -0.0785 & -0.0687 & $-0.308^{* * *}$ & $-0.205^{* * *}$ \\
\hline & $(0.0640)$ & $(0.0646)$ & $(0.0682)$ & $(0.0681)$ \\
\hline Percepción de corrupción media & & $-0.147^{* *}$ & & $-0.134^{* *}$ \\
\hline & & $(0.0653)$ & & $(0.0596)$ \\
\hline Percepción de corrupción alta & & $-0.129 * *$ & & $0.0937^{*}$ \\
\hline & & $(0.0621)$ & & $(0.0566)$ \\
\hline Satisfacción con democracia - no muy satisfecho & & $-0.0931^{* * *}$ & & $-0.145^{* * *}$ \\
\hline & & $(0.0312)$ & & $(0.0263)$ \\
\hline Satisfacción con democracia - más bien satisfecho & & $-0.203^{* * *}$ & & $-0.319^{* * *}$ \\
\hline & & $(0.0389)$ & & $(0.0331)$ \\
\hline Satisfacción con democracia - muy satisfecho & & $-0.204^{* * *}$ & & $-0.483^{* * *}$ \\
\hline & & $(0.0627)$ & & $(0.0565)$ \\
\hline Constant & $-2.061 * * *$ & $-2.386 * * *$ & $3.900^{* * *}$ & $2.184^{* * *}$ \\
\hline & $(0.745)$ & $(0.756)$ & $(0.698)$ & $(0.706)$ \\
\hline Observations & 5,389 & 5,262 & 6,654 & 6,437 \\
\hline R-squared & 0.036 & 0.043 & 0.049 & 0.086 \\
\hline
\end{tabular}


Estimaciones Probit-Adaptadas MCO (POLS) - Uruguay

\begin{tabular}{|c|c|c|c|c|}
\hline & (1) & $(2)$ & $(3)$ & $(4)$ \\
\hline VARIABLES & Economía de mercado & Economía de mercado & Distribución justa & Distribución justa \\
\hline \multirow[t]{2}{*}{ Perspectivas de movilidad bajas } & -0.0136 & -0.00408 & $-0.159^{*}$ & -0.120 \\
\hline & $(0.104)$ & $(0.103)$ & $(0.0877)$ & $(0.0901)$ \\
\hline \multirow[t]{2}{*}{ Perspectivas de movilidad medias } & -0.0515 & -0.0355 & $-0.443^{* * *}$ & $-0.296^{* * *}$ \\
\hline & $(0.0972)$ & $(0.0977)$ & $(0.0835)$ & $(0.0869)$ \\
\hline \multirow[t]{2}{*}{ Perspectivas de movilidad altas } & -0.0490 & -0.0233 & $-0.576^{* * *}$ & $-0.407^{* * *}$ \\
\hline & $(0.0983)$ & $(0.0989)$ & $(0.0844)$ & $(0.0878)$ \\
\hline \multirow[t]{2}{*}{ Perspectivas de movilidad muy altas } & -0.118 & -0.0925 & $-0.654^{* * *}$ & $-0.498^{* * *}$ \\
\hline & $(0.111)$ & $(0.112)$ & $(0.0943)$ & $(0.0972)$ \\
\hline \multirow[t]{2}{*}{ Movilidad educativa intergeneracional igual } & -0.0354 & -0.0505 & -0.0157 & -0.0301 \\
\hline & $(0.0461)$ & $(0.0480)$ & $(0.0367)$ & $(0.0372)$ \\
\hline \multirow[t]{2}{*}{ Movilidad educativa intergeneracional ascendente } & $-0.104^{* *}$ & $-0.127 * *$ & -0.0368 & -0.0543 \\
\hline & $(0.0492)$ & $(0.0510)$ & $(0.0391)$ & $(0.0393)$ \\
\hline \multirow[t]{2}{*}{ Edad } & $-0.00134^{*}$ & -0.00120 & -0.000233 & 0.000585 \\
\hline & $(0.000715)$ & $(0.000734)$ & $(0.000579)$ & $(0.000588)$ \\
\hline \multirow[t]{2}{*}{ Hombre } & $-0.0781^{* * *}$ & $-0.0721 * * *$ & $-0.0692^{* * *}$ & $-0.0585^{* * *}$ \\
\hline & $(0.0228)$ & $(0.0233)$ & $(0.0184)$ & $(0.0185)$ \\
\hline \multirow[t]{2}{*}{ Nivel educativo medio } & $0.0720^{* *}$ & $0.0862^{* *}$ & $0.0803^{* * *}$ & $0.0924^{* * *}$ \\
\hline & $(0.0337)$ & $(0.0344)$ & $(0.0274)$ & $(0.0275)$ \\
\hline \multirow[t]{2}{*}{ Nivel educativo superior } & $0.225^{* * *}$ & $0.244^{* * *}$ & $0.0901^{* * *}$ & $0.135^{* * *}$ \\
\hline & $(0.0426)$ & $(0.0436)$ & $(0.0339)$ & $(0.0338)$ \\
\hline \multirow[t]{2}{*}{ Compromiso religioso - no practicante } & $-0.0925^{* * *}$ & $-0.0945^{* * *}$ & $-0.0526^{* *}$ & $-0.0561^{* *}$ \\
\hline & $(0.0322)$ & $(0.0328)$ & $(0.0257)$ & $(0.0257)$ \\
\hline \multirow[t]{2}{*}{ Compromiso religioso - no muy practicante } & $-0.149^{* * *}$ & $-0.148^{* * *}$ & $-0.0961 * * *$ & $-0.0865 * * *$ \\
\hline & $(0.0315)$ & $(0.0320)$ & $(0.0245)$ & $(0.0249)$ \\
\hline \multirow[t]{2}{*}{ Compromiso religioso - practicante } & $-0.0890^{* *}$ & $-0.0997^{* * *}$ & -0.0417 & -0.0467 \\
\hline & $(0.0364)$ & $(0.0373)$ & $(0.0323)$ & $(0.0323)$ \\
\hline \multirow[t]{2}{*}{ Compromiso religioso - muy practicante } & $-0.158^{* *}$ & $-0.152^{* *}$ & 0.0717 & 0.0763 \\
\hline & $(0.0648)$ & $(0.0660)$ & $(0.0487)$ & $(0.0502)$ \\
\hline \multirow[t]{2}{*}{ Casado/unión } & 0.0194 & 0.0151 & -0.0281 & $-0.0368^{* *}$ \\
\hline & $(0.0227)$ & $(0.0233)$ & $(0.0182)$ & $(0.0183)$ \\
\hline \multirow[t]{2}{*}{ Ideología - derecha } & $-0.217^{* * *}$ & $-0.221^{* * *}$ & -0.0285 & -0.0391 \\
\hline & $(0.0708)$ & $(0.0753)$ & $(0.0510)$ & $(0.0542)$ \\
\hline Ideología - centro & $-0.187^{* * *}$ & $-0.175^{* *}$ & -0.0715 & -0.0319 \\
\hline & $(0.0685)$ & $(0.0731)$ & $(0.0489)$ & $(0.0524)$ \\
\hline Ideología - izquierda & -0.0423 & -0.0207 & $-0.221^{* * *}$ & $-0.0945^{*}$ \\
\hline & $(0.0700)$ & $(0.0751)$ & $(0.0501)$ & $(0.0541)$ \\
\hline Ingreso subjetivo bajo & 0.0357 & 0.0487 & $-0.215^{* * *}$ & $-0.176^{* * *}$ \\
\hline & $(0.0514)$ & $(0.0517)$ & $(0.0422)$ & $(0.0425)$ \\
\hline Ingreso subjetivo medio & 0.0361 & 0.0727 & $-0.403^{* * *}$ & $-0.320^{* * *}$ \\
\hline & $(0.0496)$ & $(0.0500)$ & $(0.0409)$ & $(0.0411)$ \\
\hline Ingreso subjetivo alto & 0.0658 & $0.104^{*}$ & $-0.533^{* * *}$ & $-0.425^{* * *}$ \\
\hline & $(0.0615)$ & $(0.0620)$ & $(0.0499)$ & $(0.0500)$ \\
\hline Gini & $0.0212^{* *}$ & $0.0297^{* * *}$ & $-0.0591 * * *$ & $-0.0340 * * *$ \\
\hline & $(0.00950)$ & $(0.00973)$ & $(0.00862)$ & $(0.00870)$ \\
\hline Log. PBI per cápita & -0.173 & -0.0910 & $-1.505^{* * *}$ & $-1.117^{* * *}$ \\
\hline & $(0.217)$ & $(0.223)$ & $(0.252)$ & $(0.252)$ \\
\hline Percepción de corrupción media & & $-0.0877^{* *}$ & & $0.100^{* * *}$ \\
\hline & & $(0.0434)$ & & $(0.0337)$ \\
\hline Percepción de corrupción alta & & $-0.0771^{*}$ & & $0.280^{* * *}$ \\
\hline & & $(0.0442)$ & & $(0.0348)$ \\
\hline Satisfacción con democracia - no muy satisfecho & & 0.00595 & & $-0.168^{* * *}$ \\
\hline & & $(0.0522)$ & & $(0.0426)$ \\
\hline Satisfacción con democracia - más bien satisfecho & & $-0.0997^{*}$ & & $-0.373^{* * *}$ \\
\hline & & $(0.0522)$ & & $(0.0425)$ \\
\hline Satisfacción con democracia - muy satisfecho & & $-0.141^{* *}$ & & $-0.477^{* * *}$ \\
\hline & & $(0.0579)$ & & $(0.0471)$ \\
\hline Constant & 1.094 & 0.0273 & $17.89^{* * *}$ & $12.88^{* * *}$ \\
\hline & $(2.402)$ & $(2.464)$ & $(2.734)$ & $(2.739)$ \\
\hline Observations & 5,365 & 5,115 & 6,970 & 6,559 \\
\hline R-squared & 0.040 & 0.047 & 0.110 & 0.156 \\
\hline
\end{tabular}


Estimaciones Probit-Adaptadas MCO (POLS) - Venezuela

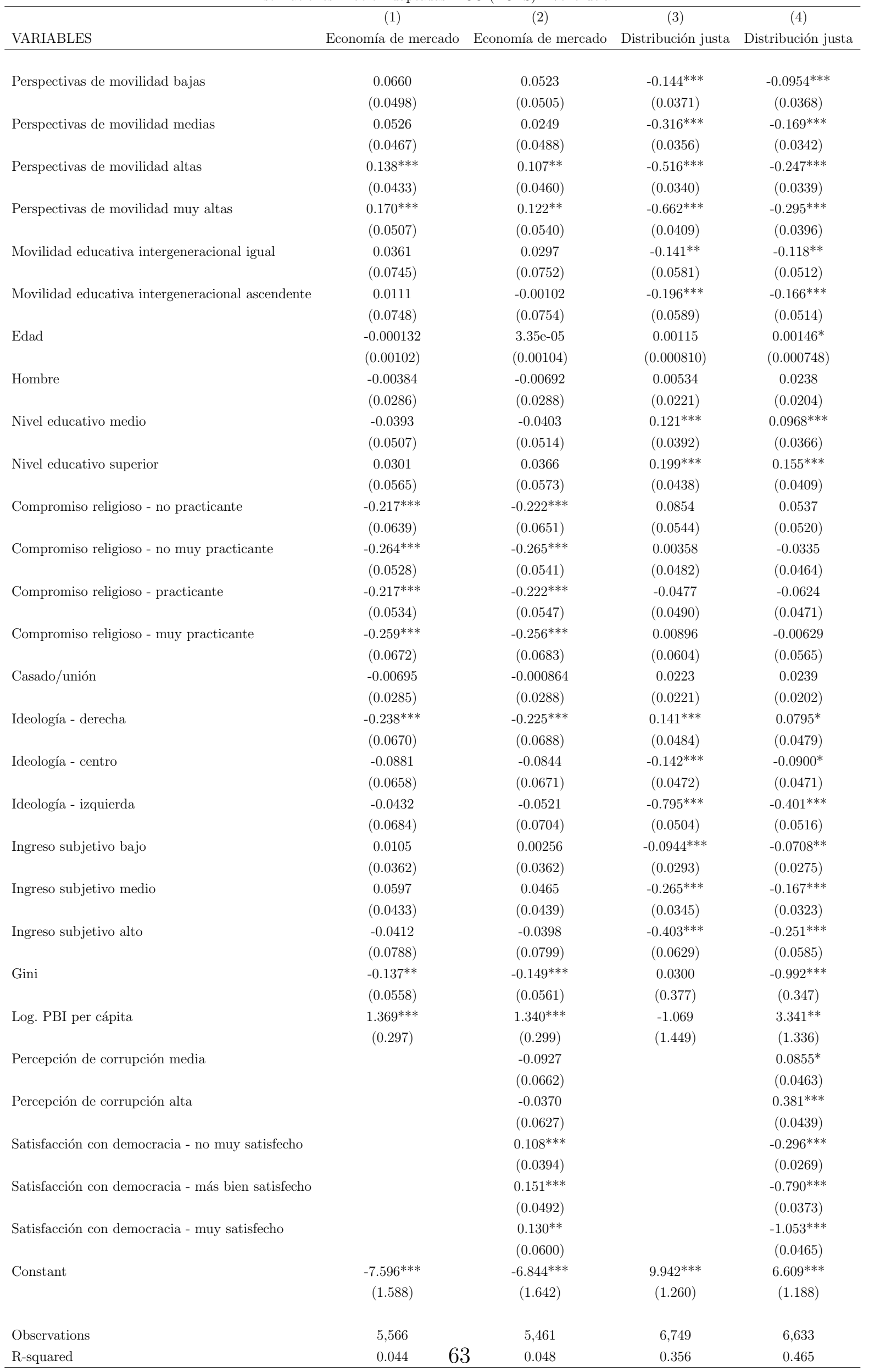

